\title{
An Evaluation of Various Carbonaceous and Synthetic Adsorbents for the Treatment of Sulfolane
}

\author{
by \\ LeMy Dinh
}

A thesis submitted to the Faculty of Graduate and Postdoctoral Affairs in partial fulfillment of the requirements for the degree of

\author{
Master of Applied Science \\ in \\ Environmental Engineering \\ Ottawa-Carleton Institute for Environmental Engineering \\ Carleton University \\ Ottawa, Ontario \\ (C) 2019, LeMy Dinh
}




\section{Abstract}

Sulfolane (2,3,4,5-tetrahydrothiophene-1,1-dioxide) is an industrial solvent used in a variety of applications including in synthetic chemistry, electric and electrical circuit processing, and in the oil and gas industry. The most popular application of sulfolane is for the extraction of aromatic hydrocarbons and sweetening of natural gas in which sulfolane is mixed with alkanolamines (such as diisopropanolamine) as well as other organic substances. Improper handling, storage, and disposal of pure sulfolane solvent and sulfolane-containing wastes have created contaminated sites where the concentration of sulfolane can be hundreds of $\mathrm{mg} / \mathrm{L}$. Sulfolane is miscible with water, non-volatile, does not adsorb to mineral surfaces to an appreciable extent, and does not biodegrade quickly under conditions where nutrients and oxygen are limited. As such, once sulfolane is released into the subsurface it will travel long distances and create large contamination plumes that can be difficult to contain and mitigate. Sulfolane in groundwater systems and private wells have been detected in Canada, the US, Australia, and other countries. While sulfolane's toxicity and the risk that it can pose to human health are not thoroughly understood, residences whose drinking water wells containing detectable levels of sulfolane $(0.01 \mathrm{mg} / \mathrm{L}$ $-1 \mathrm{mg} / \mathrm{L}$ ) have been put under water advisories. Therefore, there is an urgent need to develop treatment technologies capable of cleaning up sulfolane-contaminated sites and removing sulfolane from drinking water to protect water resources and human health.

The overall objective of this research was to investigate the adsorption of sulfolane on a wide variety of natural and synthetic adsorbents, including sand, iron oxide, aluminum oxide, eight types of granular activated carbons (GAC), Ambersorb 560, Optipore L493, silica gel, zeolite, and silica gel. The removal of sulfolane by these materials were 
investigated by employing synthetic solutions and authentic groundwater samples spiked with $1-500 \mathrm{mg} / \mathrm{L}$ of sulfolane. In some experiments, the solution also consisted of either diisopropanolamine or benzene (i.e., co-contaminants). A pre-screening test indicated that GACs, Ambersorb 560, and Optipore L493 possessed the highest sulfolane adsorption capacity. These materials were tested further in a series of experiments that aimed to examine the kinetics of sulfolane adsorption, adsorption isotherm, and effects of cocontaminants and other water chemistry conditions on the adsorption. It was observed that while the adsorption capacity of GACs and Ambersorb 560 were comparable, the adsorption equilibrium was established much faster on GACs (less than 24 hours) than on Ambersorb 560 (over 10 days). It was also observed that sulfolane adsorption was influenced by major divalent cations in groundwater (e.g., calcium, and magnesium) and dissolved organic carbon. Additionally, it was observed that diisopropanol amine and benzene inhibited sulfolane adsorption, although the degree of inhibition varied among adsorbents. Overall, the research suggests that the treatment of sulfolane by adsorption is a feasible approach for the treatment of contaminated groundwater by pump and treat (i.e., ex situ treatment). Although the research focused particularly on treating sulfolanecontaminated source zones where the concentration of sulfolane and other co-contaminants can range from a few $\mathrm{mg} / \mathrm{L}$ to up to a few hundred $\mathrm{mg} / \mathrm{L}$, the knowledge generated can be relevant to the treatment of water systems with low contamination levels (i.e., less than 1 $\mathrm{mg} / \mathrm{L})$.

Another objective of this research was to develop a simple, robust, and sensitive method for the analysis of sulfolane in aqueous solution based on prepping samples by isotopic dilution and liquid-liquid extraction, followed by analysis by Gas-Chromatography Mass 
Spectrometry (GC/MS). Deuterium-labelled sulfolane ( $\mathrm{d}_{8}$-sulfolane) was used as an internal standard and was spiked into aqueous samples. Subsequently, the samples were extracted by toluene, and the toluene extract was injected into GC/MS. The concentration of sulfolane in the sample was calculated from the ratio between the GC/MS responses from sulfolane and $\mathrm{d}_{8}$-sulfolane. The GC/MS analysis method was optimized by testing various extraction conditions and GC/MS operating parameters. The method developed herein is highly reproducible and has a detection limit (MDL) of $30 \mu \mathrm{g} / \mathrm{L}$, and a quantitation limit (MQL) of $70 \mu \mathrm{g} / \mathrm{L}$. The method can be readily employed to detect the presence of sulfolane in drinking water wells. 


\section{Table of Contents}

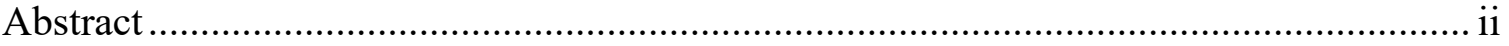

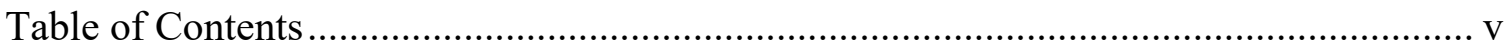

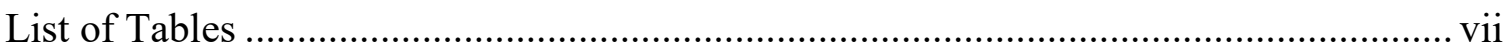

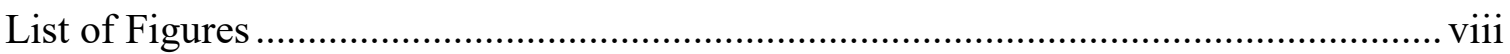

List of Acronyms and Abbreviations .........................................................................

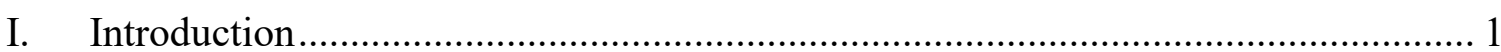

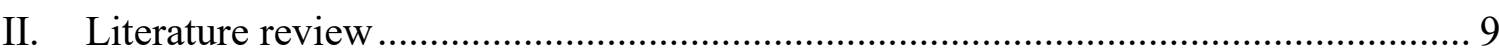

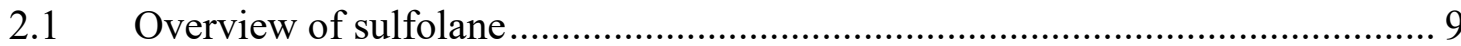

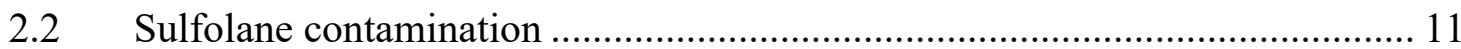

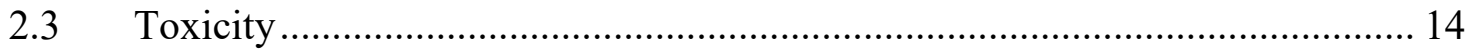

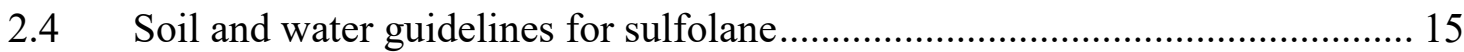

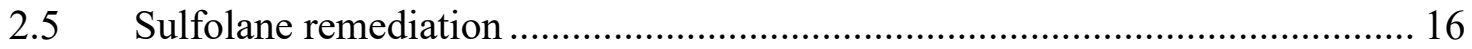

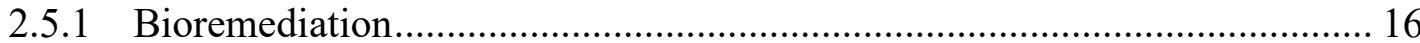

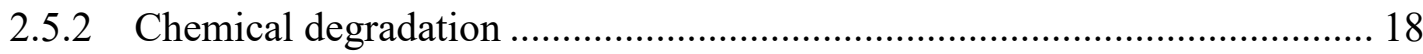

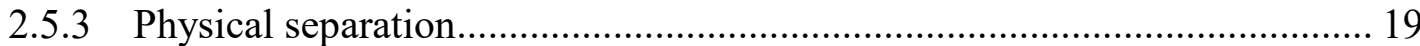

2.6 Analytical methods for the detection and quantification of sulfolane .............. 21

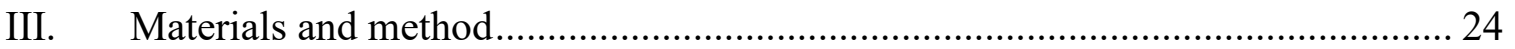

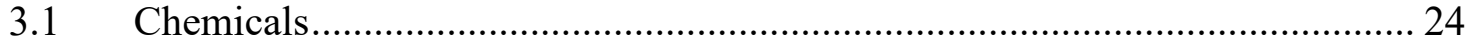

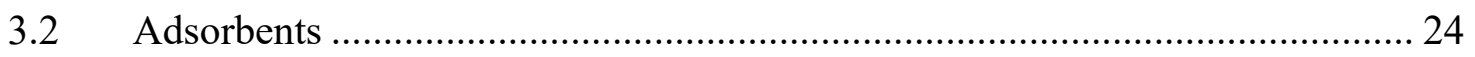

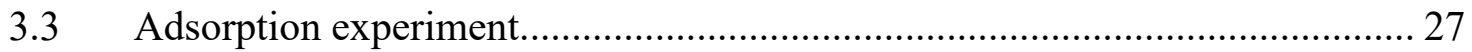

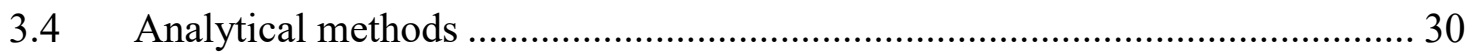




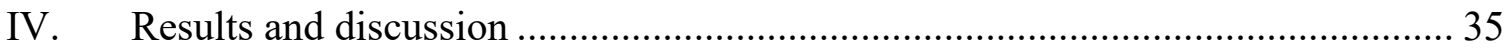

4.1 Development of sulfolane analysis method using GC/MS ............................... 35

4.1.1 Sulfolane retention time and mass spectrum. ......................................... 35

4.1.2 Quantification of sulfolane using $\mathrm{d}_{8}$-sulfolane as an internal standard........... 37

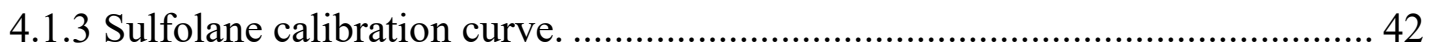

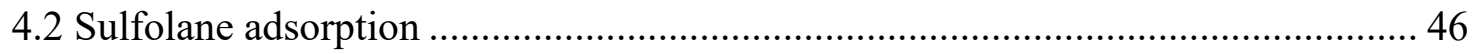

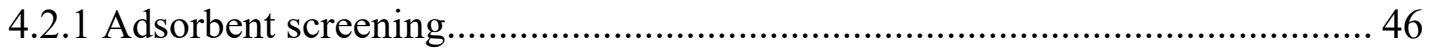

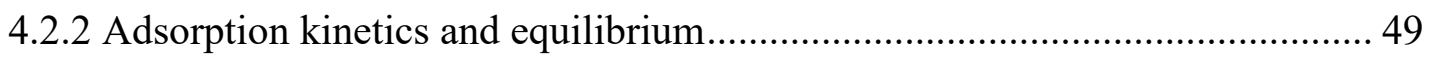

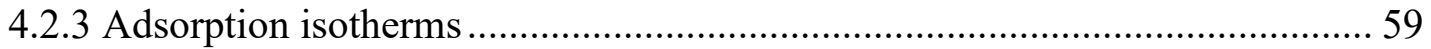

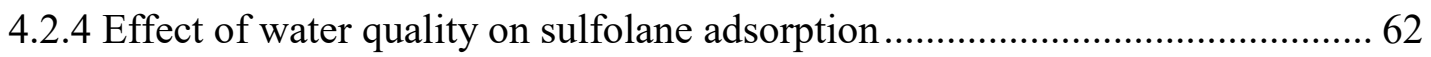

4.2.5 Effect of the co-contaminants DIPA and benzene on sulfolane adsorption .... 65

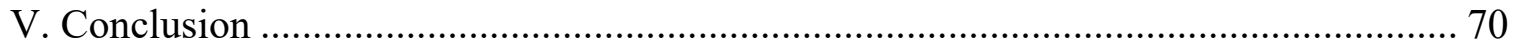

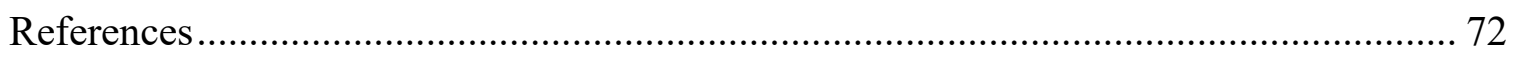




\section{List of Tables}

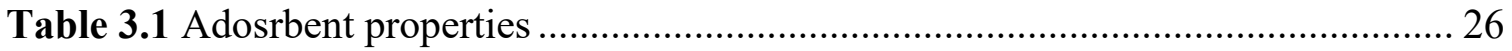

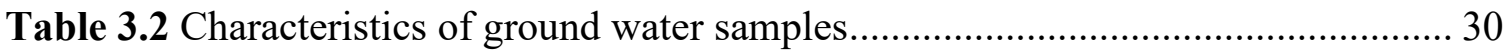

Table 4.1 Area of the sulfolane peak. $100 \mathrm{mg} / \mathrm{L}$ of an aqueous sulfolane was extracted by sulfolane, and $1 \mu \mathrm{L}$ of the toluene fraction was analyzed by GC/MS seven times........38

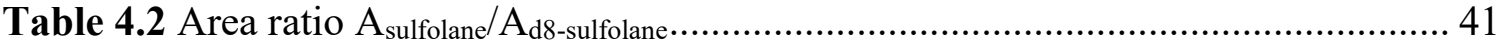

Table 4.3 Area of the sulfolane peak. Seven different $1 \mathrm{mg} / \mathrm{L}$ of an aqueous sulfolane standards were extracted by sulfolane, and $0.5 \mu \mathrm{L}$ of each toluene fraction was analyzed

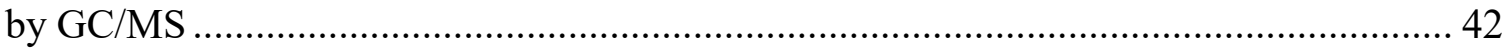

Table 4.4 $\mathrm{A}_{\text {sulfolane }} / \mathrm{A}_{\mathrm{d} 8 \text {-sulfolane }}$ as a function of sulfolane concentration......................... 46

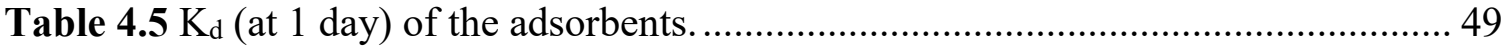

Table 4.6 Pseudo first and second order fitting parameters ....................................... 54

Table 4.7 Langmuir and Freundlich isotherm fitting parameters............................... 61 


\section{List of Figures}

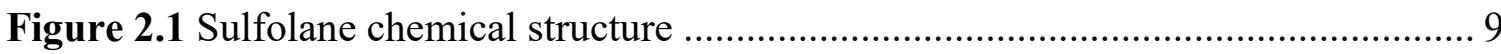

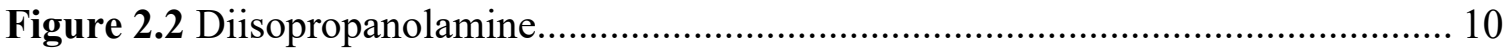

Figure 3.1 Flow chart of liquid-liquid extraction for sulfolane analysis ........................ 32

Figure 3.2 The derivatization reaction of amines and fluorenylmethyloxycarbonyl chloride (Chang \& Yu, 2011).

Figure 4.1 Total Ion Chromatogram of sulfolane. $100 \mathrm{mg} / \mathrm{L}$ of an aqueous sulfolane was extracted by sulfolane, and $1 \mu \mathrm{L}$ of the toluene fraction was analyzed by GC/MS....

Figure 4.2 Mass spectrum of sulfolane. $\mathrm{M} / \mathrm{z}=120$ corresponds to the sulfolane molecular ion, whereas $\mathrm{m} / \mathrm{z}=56.1$ corresponds to the $\mathrm{C}_{4} \mathrm{H}_{8}{ }^{+}$ion, $\mathrm{m} / \mathrm{z}=41.1$ corresponds to $\mathrm{CH}_{3}$ $\mathrm{CH}=\mathrm{CH}^{+}$ion, and $\mathrm{m} / \mathrm{z}=27$ corresponds to $\mathrm{CH}_{2}=\mathrm{CH}^{+}$ion........................

Figure 4.3 Selected ion monitoring $(\mathrm{m} / \mathrm{z}=120) \mathrm{GC} / \mathrm{MS}$ chromatogram of a sulfolane sample. $100 \mathrm{mg} / \mathrm{L}$ of an aqueous sulfolane was extracted by toluene, and $1 \mu \mathrm{L}$ of the

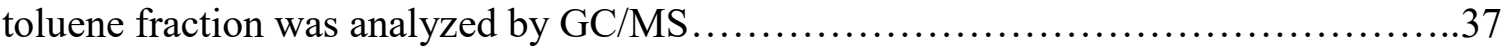

Figure 4.4 Molecular structure of deuterated $\mathrm{d}_{8}$-sulfolane $(\mathrm{MW}=128) \ldots \ldots \ldots \ldots \ldots . \ldots 39$

Figure 4.5 Selected ion monitoring $(\mathrm{m} / \mathrm{z}=120) \mathrm{GC} / \mathrm{MS}$ chromatogram of a $\mathrm{d}_{8}$-sulfolane sample, which was prepared by extracting $0.5 \mathrm{mg} / \mathrm{L}$ of aqueous $\mathrm{d}_{8}$-sulfolane by toluene. 1$\mu \mathrm{L}$ of the toluene fraction was analyzed by GC/MS ................................. 39

Figure 4.6 Selected ion monitoring $(\mathrm{m} / \mathrm{z}=120) \mathrm{GC} / \mathrm{MS}$ chromatogram of a sulfolane sample which was prepared by extracting $0.5 \mathrm{mg} / \mathrm{L}$ aqueous sulfolane by toluene. $1 \mu \mathrm{L}$ of the toluene fraction was analyzed by GC/MS

Figure 4.7 Calibration curve for sulfolane $(0.05-1 \mathrm{mg} / \mathrm{L})$, which was established based

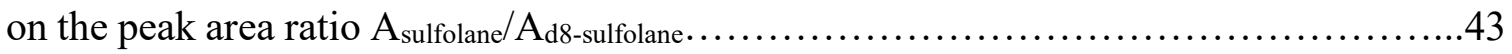


Figure 4.8 Calibration curve for sulfolane $(1-100 \mathrm{mg} / \mathrm{L})$, which was established based on

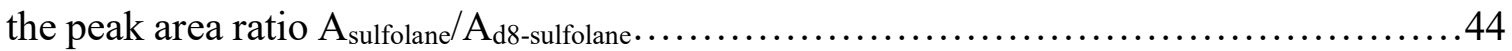

Figure 4.9 Calibration curve for sulfolane $(100-500 \mathrm{mg} / \mathrm{L}) \ldots \ldots \ldots \ldots \ldots \ldots \ldots \ldots \ldots \ldots$

Figure 4.10 Sulfolane peak obtained from analyzing the toluene extract of a $500 \mathrm{mg} / \mathrm{L}$ aqueous sample.

Figure 4.11 Adsorption of sulfolane by various adsorbents. Experimental conditions: contact time $\mathrm{t}=24 \mathrm{~h} ;[\text { sulfolane }]_{0}=10 \mathrm{mg} / \mathrm{L} ;\left[\mathrm{NaHCO}_{3}\right]=1 \mathrm{mM} ; \mathrm{pH}$ initial $=7.5 \pm 0.1 ; \mathrm{pH}$ final $=7.5 \pm 0.5$; The concentration of activated carbons, Ambersorb 560, Amberlite XAD4, Optipore 490, silica gel was $1 \mathrm{~g} / \mathrm{L}$; the concentration of sand, zeolite, $\mathrm{Fe}_{2} \mathrm{O}_{3}$ and $\mathrm{Al}_{2} \mathrm{O}_{3}$ was $100 \mathrm{~g} / \mathrm{L}$

Figure 4.12 Adsorption of sulfolane on AC5, AC7, AC8, AL-XAD4, OP-L-493, and Ambersorb 560. $2 \mathrm{~g} / \mathrm{L}$ adsorbent, $\mathrm{NaHCO}_{3} 1 \mathrm{mM}$, $\mathrm{pH}$ initial $=7.5 \pm 0.1, \mathrm{pH}$ final $=7.5 \pm$ 0.5. Left: $[\text { sulfolane }]_{0}=10 \mathrm{mg} / \mathrm{L} ;$ Right: $[\text { sulfolane }]_{0}=500 \mathrm{mg} / \mathrm{L} \ldots \ldots \ldots \ldots \ldots \ldots \ldots . . . \ldots 1$

Figure 4.13 Pseudo first order kinetic fittings on AC5, AC7, AC8, Optipore L493, and Ambersorb 560. $\left[\mathrm{NaHCO}_{3}\right]=1 \mathrm{mM}, \mathrm{pH}$ initial $=7.5 \pm 0.1, \mathrm{pH}$ final $=7.5 \pm 0.5$, [adsorbent $]=$ $2 \mathrm{~g} / \mathrm{L}$. Top: [Sulfolane $]_{0}=10 \mathrm{mg} / \mathrm{L}$, bottom: [Sulfolane $]_{0}=500 \mathrm{mg} / \mathrm{L} \ldots \ldots \ldots \ldots \ldots \ldots \ldots \ldots$

Figure 4.14 Pseudo second order kinetic fittings on AC5, AC7, AC8, Optipore L493 and Ambersorb 560. $\left[\mathrm{NaHCO}_{3}\right]=1 \mathrm{mM}, \mathrm{pH}$ initial $=7.5 \pm 0.1, \mathrm{pH}$ final $=7.5 \pm 0.5$, [adsorbent $]=$ 2 g/L. Top: [Sulfolane $]_{0}=10 \mathrm{mg} / \mathrm{L}$, bottom: [Sulfolane $]_{0}=500 \mathrm{mg} / \mathrm{L} \ldots \ldots \ldots \ldots \ldots \ldots \ldots . \ldots . \ldots . \ldots . \ldots$

Figure 4.15 Weber-Morris model fitting of sulfolane adsorption on Ambersorb 560. $[\text { Sulfolane }]_{0}=10$ and $500 \mathrm{mg} / \mathrm{L},\left[\mathrm{NaHCO}_{3}\right]=1 \mathrm{mM}, \mathrm{pH}$ initial $=7.5 \pm 0.1, \mathrm{pH}$ final $=7.5 \pm 0.5$, $[A S-560]=2 \mathrm{~g} / \mathrm{L}$. Left: $[\text { Sulfolane }]_{0}=10$ and right $[\text { Sulfolane }]_{0}=500 \ldots \ldots \ldots \ldots \ldots \ldots . .58$ 
Figure 4.16 Adsorption isotherms on AC5, AC7, AC8, Optipore L493, Ambersorb 560. $[\text { Sulfolane }]_{0}=1-500 \mathrm{mg} / \mathrm{L},\left[\mathrm{NaHCO}_{3}\right]=1 \mathrm{mM}, \mathrm{pH}$ initial $=7.5 \pm 0.1, \mathrm{pH}$ final $=7.5 \pm 0.5$ [adsorbent] $=2 \mathrm{~g} / \mathrm{L}$, equilibrium time. Left: Langmuir Isotherm and right: Freundlich Isotherm .60

Figure 4.17 Sulfolane adsorption isotherms on AC5 and Ambersorb 560. [Sulfolane $]_{0}=1$ $500 \mathrm{mg} / \mathrm{L}, \mathrm{pH}$ initial $=8 \pm 0.2, \mathrm{pH}$ final $=8 \pm 0.5$, adsorbent $]=2 \mathrm{~g} / \mathrm{L}$, equilibrium time. The data is presented on both normal scale and log-log scale such that the difference at low and high concentrations can be discerned

Figure 4.18 Sulfolane adsorption isotherms on AC5 and Ambersorb 560. [Sulfolane]0=1$500 \mathrm{mg} / \mathrm{L}$, for ICW $1: \mathrm{pH}$ initial $=6 \pm 0.2, \mathrm{pH}$ final $=7 \pm 0.5$, for ICW2: $\mathrm{pH}$ initial $=7 \pm 0.2$ $\mathrm{pH}$ final $=7.5 \pm 0.5$, [adsorbent $]=2 \mathrm{~g} / \mathrm{L}$, equilibrium time. The data is presented on both normal scale and log-log scale such that the difference at low and high concentrations can be discerned. .64

Figure 4.19 Effect of DIPA on sulfolane adsorption. The data is presented on both normal scale and log-log scale such that the difference at low and high concentrations can be discerned. $[\text { Sulfolane }]_{0}=1-500 \mathrm{mg} / \mathrm{L},[\mathrm{DIPA}]_{0}=50 \mathrm{mg} / \mathrm{L},\left[\mathrm{NaHCO}_{3}\right]=1 \mathrm{mM}$, [adsorbent $]$ $=2, \mathrm{pH}$ initial $=7.5$ and 9.9, $\mathrm{pH}$ final $=7.5 \pm 0.2$ and 9.7 \pm 0.2. Left: $\mathrm{AC} 5$, right: ambersorb 560

Figure 4.20 DIPA removal. [Sulfolane $]_{0}=1-500 \mathrm{mg} / \mathrm{L},[\mathrm{DIPA}]_{0}=50 \mathrm{mg} / \mathrm{L},\left[\mathrm{NaHCO}_{3}\right]=$ $1 \mathrm{mM},[$ adsorbent $]=2 \mathrm{~g} / \mathrm{L}, \mathrm{pH}$ initial $=7.5$ and 9.9, $\mathrm{pH}$ final $=7.5 \pm 0.2$ and $9.7 \pm 0.2 . .68$ Figure 4.21 Effect of Benzene on sulfolane adsorption. The data is presented on both normal scale and log-log scale such that the difference at low and high concentrations can be discerned. [Sulfolane $]_{0}=1-500 \mathrm{mg} / \mathrm{L},[\text { Benzene }]_{0}=78 \mathrm{mg} / \mathrm{L},\left[\mathrm{NaHCO}_{3}\right]=1 \mathrm{mM}$, 
$[$ adsorbent $]=2 \mathrm{~g} / \mathrm{L}, \mathrm{pH}$ initial $=7.5 \pm 0.1, \mathrm{pH}$ final $=7.5 \pm 0.5$. Left: AC5, right: ambersorb

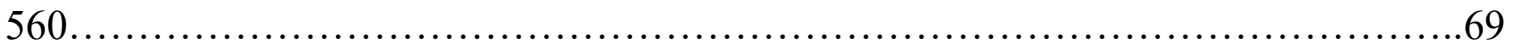




\section{List of Acronyms and Abbreviations}

$\begin{array}{ll}\text { AC } & \text { Activated carbon } \\ \text { AS } & \text { Ambersorb } \\ \text { OP } & \text { Optipore } \\ \text { AL } & \text { Amberlite } \\ \text { DIPA } & \text { Diisopropanolamine } \\ \text { LD } & \text { Lethal dose } \\ \text { MDL } & \text { Method detection limit } \\ \text { MQL } & \text { Method quantification limit } \\ \text { GC } & \text { Gas chromatograph } \\ \text { LC } & \text { Liquid chromatograph } \\ \text { MS } & \text { Mass spectrometry } \\ \text { FID } & \text { Flame ionization detection } \\ \text { eCD } & \text { Electron capture detection } \\ \text { UV } & \text { Ultraviolet } \\ \text { UHPLC } & \text { Ultra-high performance liquid chromatograph } \\ \text { IC } & \text { Ion chromatograph } \\ \text { BTEX } & \text { Benzene, toluene, ethylbenzene and xylene }\end{array}$




\section{Introduction}

Sulfolane (2,3,4,5-tetrahydrothiophene-1,1-dioxide) is a polar organic solvent highly miscible with water and other organic solvents such as toluene, glycerol, acetone, and others (Brown, Ferrigan and Stevenson 1966). It is a versatile solvent used in a variety of industrial applications such as in the oil and gas industry, in the printing of electric and electrical boards, and in the synthesis of many organic substances. The mixture of sulfolane, diisopropanolamine (DIPA) and water is commonly used as a solvent to absorb sour gases (i.e., $\mathrm{H}_{2} \mathrm{~S}, \mathrm{CO}_{2}$ and $\mathrm{COS}$ ) from natural gas streams (CCME 2006). In addition, owing to its high selectivity to aromatic hydrocarbons, sulfolane is a popular solvent used by the petroleum refining and petrochemical industries in the liquid-liquid extraction process that recovers benzene, toluene, xylene and other aromatic compounds from hydrocarbon mixtures (CCME 2005). Sulfolane is also a popular solvent for the production of herbicides, insecticides, polymer, pharmaceuticals, and synthetic fibers. It is also used as an electrolyte solvent in batteries (Stewart and Minnear 2010). The numerous applications of sulfolane makes it become a high demand chemical; up to 36,000 tons of sulfolane are produced worldwide per year (CCME 2005).

Sulfolane has been released into the environment through improper storage and handling of pure sulfolane solvent, as well as through improper disposal of sulfolane-containing wastes. As a result, incidents of sulfolane contamination have been documented in the US, Canada, Australia, Taiwan, and other countries (Stewart and Minnear 2010) (Yang, Liu, et al. 2019). In Canada, the contamination of sulfolane has been reported at Waterton (Alberta), McGregor Lake (Alberta), and at a gas processing plant in British Colombia (CCME 2005), (Stewart and Minnear 2010). The concentration of sulfolane at these sites 
ranged from $300 \mathrm{mg} / \mathrm{L}$ to $700 \mathrm{mg} / \mathrm{L}$, with a maximum concentration being $800 \mathrm{mg} / \mathrm{L}$ which was recorded in an aquifer near a site where sulfolane was used for gas processing applications (Gieg, et al. 1998). Sulfolane is miscible with water, non-volatile, does not adsorb to mineral surfaces to an appreciable extent, and does not biodegrade quickly under conditions where nutrients and oxygen are limited (Luther, Dudas and Fedorak 1998), (Greene, et al. 1998). As such, once released into the subsurface, sulfolane usually travels long distances and creates large contamination plumes that can be difficult to contain and mitigate. For example, the sulfolane plume at Waterton spread over an area of approximately $2.6 \mathrm{~km}^{2}$ (Stewart and Minnear 2010), contaminating not only groundwater but also surface water, soil and plants (CCME 2005). Another example of a widespread contamination of sulfolane was associated with the incident in North Pole (Alaska, US) where the concentration of sulfolane in 317 out of 528 tested private wells located within $6 \mathrm{~km}$ downstream from a refinery plant ranged from 10 to $443 \mu \mathrm{g} / \mathrm{L}$ (DHSS 2012).

Concerns over the presence of sulfolane in the environment have resulted in guidelines for sulfolane in water, soil and biota. The guidelines for water usually vary widely depending on the location and the intended use of the water. For example, the interim guideline for sulfolane in drinking water in Alberta, Canada based on a lifetime exposure was set at 0.04 $\mathrm{mg} / \mathrm{L}$ (Health-Canada 2014), whereas the interim guidelines for fresh water aquatic life and irrigation are $50 \mathrm{mg} / \mathrm{L}$ and $0.5 \mathrm{mg} / \mathrm{L}$, respectively (CCME 2005). In the US, the US Agency for Toxic Substances and Disease Registry developed sulfolane action levels for different age groups, namely $20 \mu \mathrm{g} / \mathrm{L}$ for infants, $32 \mu \mathrm{g} / \mathrm{L}$ for children, and $70 \mu \mathrm{g} / \mathrm{L}$ for adults (DHSS 2012). Meanwhile, the Texas Commission set protective concentration levels to be less than $0.49 \mu \mathrm{g} / \mathrm{L}$ for residential groundwater for ingestion, $1.5 \mu \mathrm{g} / \mathrm{L}$ for 
commercial/industrial groundwater for ingestion, $49 \mu \mathrm{g} / \mathrm{L}$ for residential non-ingestion groundwater, and $150 \mu \mathrm{g} / \mathrm{L}$ for commercial/industrial non-ingestion groundwater (Stewart and Minnear 2010). The guideline values are set on the basis of health concerns, and the range of values across guidelines likely reflects the fact that we lack a thorough understanding of the toxicological effects of sulfolane in human. Most of our current understanding of sulfolane toxicity was developed based on studies investigating the effects of sulfolane on animals including rats, mice, and guinea pigs (Brown, Ferrigan and Stevenson 1966), (M. Andersen, R. Jones, et al. 1997), (Ruppert and Dyer 1985). These studies revealed that sulfolane is a neurotoxin. Once entered in the animal body through injection, ingestion or inhalation, sulfolane can be rapidly absorbed to the blood stream and subsequently transported to the brain area, impacting the nervous and hepatic systems in a short period. More research is needed to improve our understanding of the acute and chronical effects of sulfolane on animal and human health.

As mentioned earlier, DIPA is a co-solvent used together with sulfolane in the extraction of sour gases. Unsurprisingly, DIPA is a common contaminant found along with sulfolane at contaminated sites (Stewart and Minnear 2010), (Greene, Coy and Fedorak 1999), (Luther, Dudas and Fedorak 1998). As with sulfolane, DIPA also has high aqueous solubility and is relatively hydrophilic (CCME 2005). Therefore, DIPA can travel long distances when released into the environment. DIPA contamination has been detected at some sour gas plants in British Columbia and Alberta (CCME 2006). The highest recorded DIPA concentration was $590 \mathrm{mg} / \mathrm{L}$ in a shallow aquifer and $6 \mathrm{mg} / \mathrm{L}$ in a sand aquifer (CCME 2005). In addition to DIPA, benzene and other aromatics hydrocarbons, which are selectively extracted from the hydrocarbon mixtures by sulfolane, are other common co- 
contaminants at sulfolane-contaminated sites. Unlike sulfolane and DIPA, benzene is more hydrophobic and less soluble in water (WHO 1996). As such, benzene is usually present in groundwater at lower concentrations. Benzene with concentrations of up to $16 \mathrm{mg} / \mathrm{L}$ was detected in groundwater near a refinery site in Germany (van Afferden, et al. 2011).

To address sulfolane contaminations, researchers and practitioners had begun investigating the remediation of sulfolane since as early as in the 1980s. Initially, most research efforts focused primarily on the degradation of sulfolane by biological processes (Chou and Swatloski 1982), (Fedorak and Coy 1996), (Greene, et al. 1998), (Greene, Coy and Fedorak 1999). Very recently, researchers also have started investigating the degradation of sulfolane by abiotic processes (Izadifard, Achari and Langford 2017), (Izadifard, Acharia and Langford 2018). These past studies revealed that sulfolane can be biodegraded aerobically, especially in nitrogen- and phosphorous-rich environments. The degradation of sulfolane under anaerobic conditions was reported to be very slow (Greene, et al. 1998), (Kasanke and Leigh 2017), which suggests that the in situ bioremediation of sulfolane will not occur unless additional oxygen is supplemented into the subsurface. It was also observed that the aerobic biodegradation of sulfolane was strongly dependent on temperature, with faster rates of degradation occurring under higher temperatures (Fedorak and Coy 1996), (Greene, et al. 1998). As such, it can be expected that the biodegradation of sulfolane will be slower in cold regions. Regarding the abiotic degradation of sulfolane, recent studies have shown that sulfolane can be destroyed by advanced oxidation-type of processes such as $\mathrm{UV} / \mathrm{O}_{3}, \mathrm{UV} / \mathrm{H}_{2} \mathrm{O}_{2} / \mathrm{O}_{3}, \mathrm{UV} / \mathrm{TiO}_{2}, \mathrm{UV} / \mathrm{S}_{2} \mathrm{O}_{8}{ }^{2-}, \mathrm{CaO}_{2}, \mathrm{CaO} / \mathrm{O}_{3}$ and others (Izadifard, Achari and Langford 2017), (Izadifard, Acharia and Langford 2018). In those studies, the degradation of sulfolane was attributable to reactions involving sulfate and 
hydroxyl radicals $\left(\mathrm{SO}_{4}{ }^{\circ}\right.$ and ${ }^{\circ} \mathrm{OH}$, respectively). However, the ability of $\mathrm{SO}_{4}{ }^{\circ}{ }^{-}$and ${ }^{\circ} \mathrm{OH}$ to destroy sulfolane can be influenced by background solutes (bicarbonate and carbonate, natural organic matter, chloride) and co-contaminants (e.g., DIPA, benzene) present in the groundwater because these solutes can compete with sulfolane for the reactive radical species. The competition for $\mathrm{SO}_{4}{ }^{-}$and ${ }^{\circ} \mathrm{OH}$ between sulfolane and background solutes and co-contaminants can be quantitatively assessed if the reactivity of sulfolane with the radical species were known. However, the information about the second-order reaction rate constants for the reactions between sulfolane and $\mathrm{SO}_{4}{ }^{-}$and ${ }^{\circ} \mathrm{OH}$ does not exist in the literature.

Besides the biotic and abiotic degradations, sulfolane can also be removed from contaminated groundwater by physical separation processes. It appears that extracting groundwater and treating it ex situ by adsorption on granular activated carbon (GAC) is a common remediation approach employed at sulfolane-contaminated sites. Pump-and-treat remediation is a particularly common approach used to prevent the migration of contaminant plumes. However, a careful literature search conducted by the author's of this thesis only returned less than 10 papers that reported the adsorption of sulfolane on various types of surfaces such as clays, aquifer materials, biological activated carbon, and granular carbon (McLeod, et al. 1991), (Ying, et al. 1994), (Kim, Clarke and Lockington 1999), (Diaz 2015), (Luther, Dudas and Fedorak 1998), (Saint-Fort 2006), (Coggeshall and Price 2013). Of the documents that was found, only four documents (two conference proceedings, a patent disclosure and a Master thesis) reported the adsorption of sulfolane on bare (i.e., biomass-free) activated carbon (Coggeshall and Price 2013), (Diaz 2015), (Ying, et al. 1994), (McLeod, et al. 1991). However, in these four documents there was 
very little/no information about adsorption kinetics, isotherms, as well as how the adsorption of sulfolane is affected by solution chemistry and the presence of cocontaminants such as DIPA and benzene. In addition to GAC, other types of adsorbents that are commonly used in water treatment include zeolites, ion exchange resins, synthetic polymeric beads (e.g., Ambersorb 560), and iron and aluminum oxides (Worch 2012), (Blanchard, Maunaye and Martin 1984), (Woodard, Mohr and Nickelsen 2014). However, there has not been any study that evaluated the adsorption of sulfolane on these materials. From the identified knowledge gap in the literature, it is concluded that a systematic assessment of the ability of a wide variety of materials to adsorb sulfolane under conditions relevant to those of contaminated groundwater is critically needed. Such an assessment will provide a valuable knowledge base that will enable practitioners and site owners to select appropriate adsorbents for their contamination scenario, and to design more robust and cost-effective sulfolane adsorption systems. This has the potential to result in tremendous cost savings in remediation.

To this end, the overall objective of this study was to assess the ability of a wide variety of materials at adsorbing sulfolane. The adsorbents tested in this study include 8 different GAC materials (six coconut-based and two coal-based GAC), three polymeric adsorbents (Ambersorb 560, Amberlite XAD4, and Optipore L493), and 4 inorganic adsorbents (iron oxide $\left(\mathrm{Fe}_{2} \mathrm{O}_{3}\right)$, aluminum oxide $\left(\mathrm{Al}_{2} \mathrm{O}_{3}\right)$, sand grains, silica gel, and zeolite). The tested solutions include synthetic solutions consisting of $1 \mathrm{mM} \mathrm{NaHCO}_{3}$ (which served as a $\mathrm{pH}$ buffer and also as an electrolyte) and sulfolane, and two groundwater samples that were collected from an aquifer in the vicinity of a sulfolane-contaminated site. The performance of the adsorbents was assessed through a series of batch experiments that aimed to 
investigate the adsorption kinetics and isotherm, as well as the effects of various water quality parameters such as $\mathrm{pH}$, chloride, sulfate, and others on the adsorption. The effects of the co-contaminants, DIPA and benzene, on the adsorption of sulfolane was investigated employing reaction solutions consisting of bi-solutes, namely sulfolane and DIPA, or sulfolane and benzene.

Another important objective of this study was to develop a simple, robust, and sensitive method for the analysis of sulfolane in aqueous solution. Currently, common sulfolane analysis methods employ Gas Chromatography coupled with a Flame Ionization Detector (GC-FID), Gas Chromatography coupled with a Mass Spectrometry detector (GC-MS), and Liquid Chromatography coupled with a tandem Mass Spectrometry detector (LC-MSMS) (Fedorak and Coy 1996), (Greene, Coy and Fedorak 1999), (Luther, Dudas and Fedorak 1998), (Yang, Liu, et al. 2019), (Headley, Peru and Dickson 1999), (Izadifard, Achari and Langford 2017), (BCELM 2017), (Lu, et al. 2016). GC-FID was used in many studies (Fedorak and Coy 1996), (Greene, Coy and Fedorak 1999), (Luther, Dudas and Fedorak 1998), (Izadifard, Achari and Langford 2017), (Yang, Liu, et al. 2019), but a major disadvantage of this method is that its detection limit (ca. $0.5-1 \mathrm{mg} / \mathrm{L}$ ) is over $10-25$ times higher than the interim guideline for sulfolane in drinking water set by Health Canada. A few studies reported that GC-MS can provide a lower sulfolane detection limit (Headley, Peru and Dickson 1999), (BCELM 2017); however, the analysis often required a complicated sample preparation procedure which involved extracting a large volume of aqueous sample, and concentrating the extractant by evaporation. One of the goals of this study was to develop a simple and fast extraction method that can detect sulfolane levels 
below the guidance value for sulfolane in drinking water set by Health Canada (i.e., below $0.04 \mathrm{mg} / \mathrm{L})$. 


\section{Literature review}

\subsection{Overview of sulfolane}

Sulfolane is an organic compound consisting of a non-polar five membered ring and a highly polar sulfonyl group (Figure 2.1). It is miscible in water and is essentially nonvolatile $\left(\mathrm{P}_{0}=0.01 \mathrm{mmHg}\right.$ at $20^{\circ} \mathrm{C}, \mathrm{K}_{\mathrm{H}}=8.9 \times 10^{-10}$ atm. $\left.\mathrm{m}^{-3} \cdot \mathrm{mol}^{-1}\right)$. Sulfolane is very hydrophilic, evidenced by its low octanol/water partition coefficient $\left(\log \mathrm{K}_{\mathrm{ow}}=-0.77\right)$ and low soil/water partition coefficient $\left(\mathrm{K}_{\mathrm{d}}=0.08 \mathrm{~L}^{\mathrm{kg}}{ }^{-1}\right)(\mathrm{CCME} 2005)$, (Luther, Dudas and Fedorak, Sorption of sulfolane and diisopropanolamine by soils, clays and aquifer materials 1998).

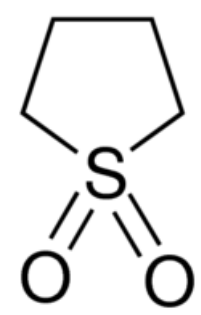

Figure 2.1 Sulfolane chemical structure

Sulfolane was invented by Shell and became commercially available since 1959 . The sulfolane production process involves reacting sulfur dioxide $\left(\mathrm{SO}_{2}\right)$ with butadiene $\left(\mathrm{C}_{4} \mathrm{H}_{6}\right)$ to produce 3-sulfolene, which is then hydrogenated to form sulfolane:

$$
\begin{array}{r}
\mathrm{C}_{4} \mathrm{H}_{6}+\mathrm{SO}_{2} \rightarrow \mathrm{C}_{4} \mathrm{H}_{6} \mathrm{SO}_{2} \\
\mathrm{C}_{4} \mathrm{H}_{6} \mathrm{SO}_{2}+\mathrm{H}_{2} \rightarrow \mathrm{C}_{4} \mathrm{H}_{8} \mathrm{SO}_{2}
\end{array}
$$

Sulfolane is an important solvent in the petrochemical industry because of the two traditional applications, namely waste gas absorption and aromatic hydrocarbon extraction. The term waste gas refers to the sour gases such as $\mathrm{H}_{2} \mathrm{~S}, \mathrm{CO}_{2}, \mathrm{CH}_{3} \mathrm{SH}, \mathrm{COS}, \mathrm{CS}_{2}$, and others that are normally present in natural gas. These gases are responsible for the corrosion of pipelines, drilling equipment and storage tanks. The combustion of fuel containing sulfur 
results in air pollution. In addition, $\mathrm{H}_{2} \mathrm{~S}$ is very poisonous and has the greatest effect on the nervous system. These gases can be removed from natural gas by different processes, but perhaps the most widely used one is the Sulfinol process which was invented by Shell in the late 1950s. The Sulfinol process employs a solvent mixture consisting of sulfolane, diisopropanolamine (DIPA, Figure 2.2), water, and other organic compounds. In this mixture, DIPA serves as a sour gas binding agent. DIPA is a weak base $(\mathrm{pKa}=8.9$ (Kim, Dobrogowska and Hepler 1987)) and is existed in the protonated form under acidic and circumneutral $\mathrm{pH}$ conditions. The positively charged DIPA molecules interacts and binds the sour gases at the middle nitrogen in the DIPA structure. Meanwhile, sulfolane serves as a solvent, promoting the absorption of the sour gases. Sulfolane is the solvent of choice because it is stable at high temperatures, and therefore can be regenerated and recycled by thermal distillation (M. Andersen, R. Jones, et al. 1997).

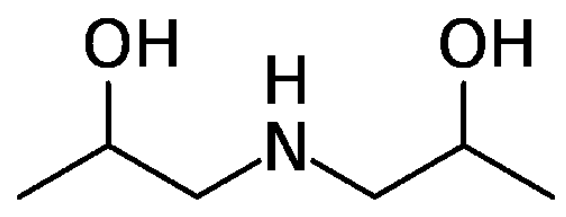

Figure 2.2 Diisopropanolamine

Within the oil and gas industry, sulfolane is also commonly used in the extraction of aromatic hydrocarbons (Stewart and Minnear 2010). In this application, the extraction solvent consists of sulfolane and other hydrocarbon liquids. Sulfolane is the solvent of choice for this process because of its selectivity for aromatic compounds, and also because of its ability to dissolve large quantities of these compounds. After extraction, the aromatic compounds and unwanted substances are separated from each other and from sulfolane by distillation, and the recovered sulfolane is recycled for reuse. 
In addition to the two aforementioned applications, sulfolane is being used in other processes such as in the production of herbicides, insecticides, plastics, synthetic resins and soap (Stewart and Minnear 2010). Sulfolane is also used in the wood delignification to extract lignin from wood chips, as a solvent in extractive distillation process, polymer and drug production, and as a battery's electrolyte. Sulfolane is also being used in the textile industry for the treatment of fiber, dyes and fabric before dying (CCME 2006). The numerous applications of sulfolane make it become a high demand chemical; up to 36,000 tons of sulfolane are produced worldwide per year (CCME 2006). As such, sulfolane appears in the High Production Volume (HPV) chemical list by the Environmental Protection Agency (EPA), which is the list that consists of compounds with production and/or import volume of more than one million pounds per year (Stewart and Minnear 2010).

\subsection{Sulfolane contamination}

Being a popular solvent in many applications, it is unsurprising that sulfolane has been found at sites where it was produced, used, and disposed. In particular, sulfolane can be released into the environment through improper storage and handling of pure sulfolane solvent, as well as through improper disposal of sulfolane-containing wastes. Sulfolanecontaminated sites were found at gas processing plants, pesticide manufacturing plants, and oil refinery plants in North America, Australia, Taiwan and other countries (Stewart and Minnear 2010), (Yang, Liu, et al. 2019). As mentioned earlier, sulfolane is highly soluble in water (essentially miscible with water), non-volatile, and is very hydrophilic.

Sulfolane also does not biodegrade under anaerobic conditions (Greene, et al. 1998), (Kasanke and Leigh 2017). Therefore, once sulfolane is released into the subsurface, it can 
travel long distances and create large contamination plumes that can be difficult to contain and mitigate. Moreover, sulfolane is slightly heavier than water $\left(\mathrm{d}=1.276 \mathrm{~g} / \mathrm{cm}^{3}\right.$ at $15^{\circ} \mathrm{C}$, (CCME 2006)), and as such pure sulfolane solvent can migrate deep into the subsurface when spills occur. This section will highlight some of the prominent sulfolane contamination cases in the history.

According to Stewart and Minnear (Stewart and Minnear, 2010), one of the prominent cases of sulfolane contamination was associated with a site owned by Norco Chemical Plant (Louisiana, US) where sulfolane was produced from 1967 to 1988. In the 1990s, sulfolane was found in soil and groundwater at 4 waste disposal sites. The average sulfolane concentration in the groundwater at these sites ranged from 10 to $100 \mathrm{mg} / \mathrm{L}$, with the maximum concentration being $2,900 \mathrm{mg} / \mathrm{L}$. The concentrations of sulfolane in soil and ditch sediment were $369 \mathrm{mg} / \mathrm{kg}$ and $36.1 \mathrm{mg} / \mathrm{kg}$, respectively, while up to $126 \mathrm{mg} / \mathrm{L}$ of sulfolane was found in the surface water in the ditches. Natural attenuation, phytoremediation and interceptor trenches were applied to remediate the sites, but it is unclear whether these approaches were effective at remediating the site.

Another case of sulfolane contamination occurred at a pesticide plant in California, US. At this site, sulfolane was used as a process solvent, and sulfolane concentrations of up to 3 $\mathrm{mg} / \mathrm{L}$ were measured in the groundwater near the plant. The remediation of the groundwater was performed by extracting the groundwater to the surface, followed by treating the water by a biologically activated carbon process (i.e., pump-and-treat). According to Stewart and Minnear (Stewart and Minnear, 2010), after approximately 6 years of active remediation, the concentration of sulfolane in the groundwater was reported to be below $19 \mu \mathrm{g} / \mathrm{L}$. 
Sulfolane contamination was also documented at a gas processing plant in California where a spill of over 100 gallons of pure sulfolane occurred in 2008 . The incident resulted in the contamination of Las Flores Creek and then Corral Creek, which runs toward the Pacific Ocean. The concentration of sulfolane in a sample collected from this area was reported to be $570 \mathrm{mg} / \mathrm{L}$. According to Stewart and Minear (Stewart and Minnear, 2010), the site owner immediately closed the gas processing system and blocked the gate in the creek.

Another prominent case of sulfolane contamination occurred in 2010 in North Pole, Alaska (US) where sulfolane was found in private drinking water wells in the vicinity of an oil refinery plant. Among 528 private wells located within $6 \mathrm{~km}$ downstream from the plant, 88 wells had sulfolane concentration ranging from 10 to $20 \mu \mathrm{g} / \mathrm{L}, 29$ wells ranging from 20.1 to $32 \mu \mathrm{g} / \mathrm{L}, 38$ wells ranging from 32.1 to $70 \mu \mathrm{g} / \mathrm{L}$, and 92 wells were over $70 \mu \mathrm{g} / \mathrm{L}$. The impacted area has been provided long-term alternative water source for consumption purposes (DHSS 2012).

Other cases of sulfolane contamination that have been documented include the contamination incident that took place at a petroleum refinery company in the Virgin Islands (US) where sulfolane and aromatic hydrocarbons were found in the sewer line, and at several natural gas processing complexes in Alberta (Canada) where both sulfolane and DIPA were found in groundwater. As mentioned earlier, sulfolane is often used with DIPA and other organic solvents. As such, DIPA is one of the co-contaminants that are typically found at sulfolane contaminated sites. Similar to sulfolane, DIPA is hydrophilic and highly soluble in water $\left(\mathrm{K}_{\mathrm{ow}}=-0.82, \mathrm{C}_{\mathrm{w}}^{\mathrm{s}}=0.87 \mathrm{~kg} / \mathrm{L}\right)$. Other co-contaminants that can be found along sulfolane include benzene, toluene, ethylbenzene, xylene (BTEX) and other aromatic hydrocarbons. These compounds are usually present in the spent sulfolane solvent. 


\section{$2.3 \quad$ Toxicity}

Overall, the toxicity of sulfolane is poorly understood. Most of our current understanding of sulfolane toxicity was developed based on studies investigating the effects of sulfolane on animals including rats, mice, and guinea pigs (Brown, Ferrigan, \& Stevenson, 1966), (Andersen et al., 1997), (Ruppert \& Dyer, 1985). These studies revealed that sulfolane is a neurotoxin. Once entered in the animal body through injection, ingestion or inhalation, sulfolane can be rapidly absorbed to the blood stream and subsequently transported to the brain area, impacting the nervous and hepatic systems in a short period. It was found that the lethal dose LD 50 ranged from 0.6 to $3.8 \mathrm{~g} / \mathrm{kg}$ body weight depending on the administration method and type of animal (Brown, Ferrigan and Stevenson 1966), (M. Andersen, R. Jones, et al. 1976). However, the central nervous system of the tested animals was affected even at lower doses, as was evidenced by the convulsion of the animals (Ruppert and Dyer 1985). Sulfolane did not appear to have any effect when it was in direct contact with skin, even in sensitive shaved skin areas of guinea pigs (Brown, Ferrigan and Stevenson 1966). Temporary eye irritation was experienced by rabbits in the direct eye exposure test. The inhalation toxicity was examined by exposing animals to vaporized sulfolane, and convulsions, chronic lung inflammation, vomiting, and death were observed in laboratory animals during 90 days of inhalation tests (M. Andersen, R. Jones, et al. 1997). It can be concluded from animal studies that sulfolane would impact human health at greater doses. However, the studies mentioned above only assessed the toxicological effect for only up to 6 months of contact with sulfolane. Currently, knowledge about the chronical effect of sulfolane on animals as well as humans is lacking. 


\subsection{Soil and water guidelines for sulfolane}

Concerns over the presence of sulfolane in the environment have resulted in guidelines for sulfolane in water, soil and biota. The guidelines for water usually vary widely depending on the location and the intended use of the water. For example, the interim guidelines set by the Canadian Environmental Quality Guidelines are $0.09 \mathrm{mg} / \mathrm{L}$ for groundwater, 0.5 $\mathrm{mg} / \mathrm{L}$ for water used for irrigation, $0.6 \mathrm{mg} / \mathrm{L}$ for livestock watering, and $50 \mathrm{mg} / \mathrm{L}$ for fresh water aquatic life (CCME 2005). In 2014, in response to an incident of sulfolane spill at a gas plant in Alberta, Health Canada was requested to establish a health-based drinking water guidance value for sulfolane (Health-Canada, 2014). The value was set at $0.04 \mathrm{mg} / \mathrm{L}$, i.e., over two times lower than the value set by the Canadian Council of Ministers of the Environment (CCME). However, this value is only considered as a secondary value: it is not a problem of concern if the concentration of sulfolane occasionally exceeds this value in a short period. Meanwhile, in the US, the US Agency for Toxic Substances and Disease Registry developed sulfolane action levels for different age groups, namely $20 \mu \mathrm{g} / \mathrm{L}$ for infants, $32 \mu \mathrm{g} / \mathrm{L}$ for children, and $70 \mu \mathrm{g} / \mathrm{L}$ for adults (DHSS 2012). The Texas Commission set protective concentration levels to be less than $0.49 \mu \mathrm{g} / \mathrm{L}$ for residential groundwater for ingestion, $1.5 \mu \mathrm{g} / \mathrm{L}$ for commercial/industrial groundwater for ingestion, $49 \mu \mathrm{g} / \mathrm{L}$ for residential class 3 groundwater, and $150 \mu \mathrm{g} / \mathrm{L}$ for commercial/industrial class 3 groundwater (Stewart and Minnear 2010). The guideline values are set on the basis of health concerns, and the range of values across guidelines likely reflects the fact that we lack a thorough understanding of sulfolane toxicity on human. It is worth noting that the values in the guidelines do not mean to indicate whether a concentration level is safe or unsafe. Rather, it is a screening level meant to indicate that a contaminant can potentially 
cause public health concern and therefore should be subjected to further investigation. Action levels are set around 1000 times lower than the animal health effect levels.

\subsection{Sulfolane remediation}

Sulfolane is considered as an emerging contaminant. As such, to date there have been only a handful of studies investigating the remediation of sulfolane. Most of the previous studies focused on the treatment of sulfolane by biological processes (Greene, et al. 1998), (E. A. Greene 1999), (Fedorak and Coy 1996), (McLeod, et al. 1991), (Yang, Liu, et al. 2019), while a few recent studies also have looked at the treatment of sulfolane by chemical oxidation (Izadifard, Achari and Langford 2017), (Izadifard, Acharia and Langford 2018).

\subsubsection{Bioremediation}

The biodegradation of sulfolane was investigated in as early as 1982 by Chou and Swatloski who studied the use of an activated sludge system to treat a refinery wastewater stream that contained $80 \mathrm{mg} / \mathrm{L}$ of sulfolane (Chou and Swatloski 1982). It was observed in this study that $98 \%$ of the sulfolane was degraded by an activated sludge system with a hydraulic retention time of 2 day. This result suggested that sulfolane can be biodegraded under aerobic conditions. In the same study, high sulfolane levels were spiked into the activated sludge reactor to examine the system performance under shock loadings. When $300 \mathrm{mg} / \mathrm{L}$ of sulfolane was spiked into the system, the concentration of sulfolane in the effluent initially surged to $210 \mathrm{mg} / \mathrm{L}$ and remained at this level for the first 72 hours. Subsequently, the effluent concentration reduced to $40 \mathrm{mg} / \mathrm{L}$ after 96 hours, and to $10 \mathrm{mg} / \mathrm{L}$ after 120 hours. These observations suggested that if given adequate acclimation time the bacterial community in the treatment system could handle high concentrations of sulfolane. The researchers also reported that the $\mathrm{pH}$ of the solution dropped as sulfolane was removed, 
presumably due to the formation of sulfuric acid; as such, $\mathrm{pH}$ adjustment was required during the treatment.

The ability of sulfolane to undergo aerobic degradation was confirmed in several other studies. For example, McLeod et al (McLeod, et al. 1991) investigated the treatment of tap water spiked with $1 \mathrm{mg} / \mathrm{L}$ of sulfolane by biological activated carbon columns that were purged with air. It was observed that compared with the activated carbon columns that did not contain any biomass, the ones that contained biomass showed better sulfolane removal and longer time to breakthrough. In another study (Greene, et al. 1998), sulfolane was observed to be aerobically degraded in microcosms that were constructed from the aquifer materials collected from sulfolane-contaminated sites. The reaction solution in each microcosm contained $200 \mathrm{mg} / \mathrm{L}$ sulfolane, and was supplemented with $\mathrm{N}$ and $\mathrm{P}$. It was observed that the concentration of sulfolane decreased to below $0.5 \mathrm{mg} / \mathrm{L}$ after 200 hours of incubation at $8^{\circ} \mathrm{C}$. In the same study, the degradation of sulfolane was also investigated under anoxic conditions (i.e., under conditions in which $\mathrm{NO}_{3}{ }^{-}$and $\mathrm{Mn}(\mathrm{IV})$ served as the terminal electron acceptors). The degradation of sulfolane also occurred under these conditions, although at much slower rates. This result suggests that the degradation of sulfolane in the absence of oxygen would not occur to an appreciable extent. The results reported by Greene et al (Greene, et al. 1998) were corroborated by the results from other studies which observed that the degradation of sulfolane only took place in the presence of oxygen (Fedorak and Coy 1996) (Yang, Liu, et al. 2019) (Kasanke and Leigh 2017). It was also observed that supplementing $\mathrm{N}$ and $\mathrm{P}$ into the reaction solution significantly accelerated the sulfolane degradation. Collectively, these past studies suggest that sulfolane-contaminated sites can be remediated by in situ bioremediation if dissolved 
oxygen can be supplemented into the subsurface. In situ bioremediation can be used to remediate sulfolane source zone. For the remediation of sulfolane plumes, however, supplementing oxygen to a wide area will be challenging and expensive.

\subsubsection{Chemical degradation}

If there is little information in the published literature about the biological degradation of sulfolane, there exists even less information about the abiotic degradation of sulfolane. However, the abiotic natural transformation of sulfolane via mechanisms such as hydrolysis or substitution is unlikely given that sulfone does not have functional groups and/or reactive sites susceptible to such transformation reactions. This was confirmed by Kasanke and Leigh who run sterile microcosms in the dark for over 100 days (Kasanke and Leigh 2017). The study showed that under either aerobic or anaerobic conditions, no sulfolane abiotic degradation occurred. In terms of engineered abiotic degradation of sulfolane, three very recent studies investigated the oxidation of sulfolane by advanced oxidation-type of processes, namely $\mathrm{UV} / \mathrm{O}_{3}, \mathrm{UV} / \mathrm{O}_{3} / \mathrm{H}_{2} \mathrm{O}_{2}, \mathrm{UV} / \mathrm{TiO}_{2}, \mathrm{UV} / \mathrm{S}_{2} \mathrm{O}_{8}{ }^{2-}$, and $\mathrm{UV} / \mathrm{S}_{2} \mathrm{O}_{8}{ }^{2-} /$ ozone. It was reported that sulfolane degradation took place relatively rapidly in these processes (half-life of a few hours), presumably via reactions with sulfate ( $\mathrm{SO}_{4}{ }^{\circ}$ ) and hydroxyl ( $\left.{ }^{\circ} \mathrm{OH}\right)$ radicals. These results suggest that in situ chemical oxidation (ISCO) methods that involve injecting solutions of $\mathrm{H}_{2} \mathrm{O}_{2}$ or persulfate $\left(\mathrm{S}_{2} \mathrm{O}_{8}{ }^{2-}\right)$ into the subsurface have the potential to be an effective means of remediating sulfolane-contaminated sites. In these ISCO methods, $\mathrm{H}_{2} \mathrm{O}_{2}$ can be activated into ${ }^{\circ} \mathrm{OH}$ by naturally-occurring iron minerals or by a dissolved iron solution that is co-injected with $\mathrm{H}_{2} \mathrm{O}_{2}$, while $\mathrm{S}_{2} \mathrm{O}_{8}{ }^{2-}$ can be activated into $\mathrm{SO}_{4}{ }^{*}$ and ${ }^{\circ} \mathrm{OH}$ by naturally-occurring minerals, heat, dissolved iron, or by a base. These results also suggest that an ex situ (i.e. pump-and-treat) advanced oxidation 
processes could be employed for the remediation of sulfolane-contaminated groundwater. However, the ability of $\mathrm{SO}_{4}{ }^{-}$and ${ }^{\circ} \mathrm{OH}$ to destroy sulfolane can be influenced by background solutes (bicarbonate and carbonate, natural organic matter, chloride) and co-contaminants (e.g., DIPA) present in the groundwater because these solutes can compete with sulfolane for the reactive radical species. In fact, it was reported that sulfolane was degraded at a slower rate in the presence of bicarbonate, amines, and humic substances (Izadifard, Achari and Langford 2017). The competition for $\mathrm{SO}_{4}{ }^{\circ}$ and ${ }^{\circ} \mathrm{OH}$ between sulfolane and background solutes and co-contaminants can be quantitatively assessed if the reactivity of sulfolane with the radical species were known. However, to the best of the author's knowledge, the information about the second-order reaction rate constants for the reactions between sulfolane and $\mathrm{SO}_{4}{ }^{-}$and ${ }^{\circ} \mathrm{OH}$ does not exist in the literature.

\subsubsection{Physical separation}

The physical separation technologies commonly used in water and groundwater treatment include air stripping (which is also known as air sparging), membrane separation, and adsorption. The first technology can be used both ex situ and in situ, while the latter two technologies can only be used for ex situ treatment. Air stripping is a common method for removing volatile compounds such as chlorinated solvents (e.g., trichloroethylene, perchloroethylene, 1,1,1 trichloroethane) from groundwater (EPA 1991), (Russell, Matthews and Sewell 1992), but it has been proven to be ineffective at removing nonvolatile compounds such as 1,4 dioxane (Woodard, Mohr and Nickelsen 2014). Given that sulfolane is a non-volatile compound $\left(\mathrm{K}_{\mathrm{H}}\right.$ of sulfolane $=8.9 \times 10^{-10} \mathrm{~atm} \cdot \mathrm{m}^{3} / \mathrm{mol}(\mathrm{CCME}$ 2006), which is lower than that of 1,4 dioxane, $\mathrm{K}_{\mathrm{H}}=4.80 \times 10^{-6} \mathrm{~atm} \cdot \mathrm{m}^{3} / \mathrm{mol}$ (EPA 2017)), it is predicted that sulfolane will not be removed at any appreciable extent from 
groundwater by air stripping. Regarding membrane separation, ultrafiltration, nanofiltration, and reverse osmosis processes have been shown to be capable of separating organic compounds such as pharmaceutically active compounds, endocrine disrupting chemicals, pesticides, and others (Bellonaa, et al. 2004). The separation mechanism on ultrafiltration membranes was attributable to hydrophobic adsorption, whereas the mechanism on nanofiltration and reverse osmosis membranes was thought to be size exclusion. Based on these evidences from the literature, it is likely that sulfolane can be separated, at least in part, by nanofiltration and reverse osmosis. However, it also has been shown that low-molecular weight, neutrally charged compounds such as 1,4 dioxane can pass through reverse osmosis membranes. Therefore, further research is needed to evaluate the ability of membrane separation to remove sulfolane from drinking water and contaminated groundwater.

Contaminant separation by adsorption involves the use of a solid adsorbent that can adsorb contaminant and remove it from the solution. The most commonly used adsorbents in water treatment processes are granular activated carbons (GAC), although other materials such as zeolite, ion-exchange resins, polymeric resins (e.g., Ambersorb 560), iron oxides, and aluminum oxides are also being used (Worch 2012), (Blanchard, Maunaye and Martin 1984), (Woodard, Mohr and Nickelsen 2014). It appears that removing sulfolane from groundwater by ex situ treatment using GAC adsorption is a relatively common practice, especially for containing sulfolane plumes. However, the author's extensive literature search returned only less than ten documents that discussed the adsorption of sulfolane, including three papers that discussed the sulfolane adsorption on clays and aquifer materials (Luther, Dudas and Fedorak 1998), (Kim, Clarke and Lockington 1999), (Saint- 
Fort 2006), two papers and conference proceedings investigated the sulfolane adsorption on biological activated carbon (McLeod, et al. 1991), (Ying, et al. 1994), a patent disclosure (Coggeshall and Price 2013) and a Master thesis that reported the adsorption of sulfolane on bare (i.e., bio-mass free) GACs (Diaz 2015). The papers on biological activated carbon and the patent on bare granular activated carbon contained little/no information regarding the kinetics of sulfolane adsorption, adsorption isotherm, and how factors such as water chemistry conditions and co-contaminants (e.g., DIPA, benzene) can influence sulfolane adsorption. Zeolites, ion exchange resins, synthetic polymeric beads (e.g., Ambersorb 560), and iron and aluminum oxides have been used in water treatment (Worch 2012), (Blanchard, Maunaye and Martin 1984), (Woodard, Mohr and Nickelsen 2014). However, there has not been any study that evaluated the adsorption of sulfolane on these materials. From the identified knowledge gap in the literature, it has been concluded that a systematic assessment of the ability of a wide variety of materials to adsorb sulfolane under conditions relevant of contaminated groundwater is critically needed. Such an assessment will provide a valuable knowledge base that will enable practitioners and site owners to design more robust and cost-effective sulfolane adsorption systems, which has the potential to result in tremendous cost savings in remediation.

\subsection{Analytical methods for the detection and quantification of sulfolane}

Currently, a standard method for the analysis of sulfolane does not exist. Across the published literature, the methods used to measure sulfolane in water, soil, and biota samples varied greatly in terms of how samples were prepared, the analytical instrumentation that was employed, and the method's detection limit (MDL). Headley et al (Headley, Fedorak and Dickson 2002) composed a relatively comprehensive review of 
the methods of sulfolane analysis that were used in the studies that were published before 2002. However, given that most guidelines for sulfolane were introduced after 2002, it is appropriate to revisit the issue of sulfolane analysis to identify analytical methods that can potentially achieve an MDL that is lower than sulfolane guideline levels. To this end, this section will provide a critical review of the sulfolane analytical methods used prior but also after 2002, focusing specifically on the analysis of sulfolane in aqueous samples (e.g., groundwater, drinking water).

The analysis of organic contaminants in environmental samples often involves separating the contaminant using either a gas chromatograph (GC) or a liquid chromatograph (LC), and detecting and quantifying the contaminant by a detector (e.g., flame ionization detector (FID), electron capture detector (eCD), conductivity detector, UV-visible light absorption detector, mass spectrometer). Compared with the analysis of contaminants such as chlorinated solvents and pesticides, polycyclic aromatic hydrocarbons, BTEX, phenols, the analysis of sulfolane is challenging because 1) sulfolane is highly hydrophilic and therefore will not interact with non-polar separation columns (e.g., DB5 GC columns, $\mathrm{C}_{18}$ reversephase LC columns) to an appreciable extent, 2) sulfolane absorbs light poorly in the UV/visible region and therefore cannot be quantified by light absorption, and 3) sulfolane is neutrally charged and therefore cannot be detected by a conductivity detector. For these reasons, it is not surprising that the most commonly used method for the analysis of sulfolane in the literature was GC-FID, even though the MDL of GC-FID is often in the range of mg/L (Fedorak and Coy 1996), (Greene, Coy and Fedorak 1999) (Luther and Fedorak 1998), (Izadifard, Achari and Langford 2017), (Yang, Liu, et al. 2019). In the studies that used GC-FID, aqueous samples were often extracted by liquid-liquid extraction 
to transfer sulfolane from the aqueous phase into an organic phase (e.g., dichloromethane), and the extractant was injected into the GC that was equipped with a non-polar DB5 column. However, direct injection of aqueous samples (i.e., without liquid-liquid extraction sample preparation step) was used in a few studies (E. A. Greene 1999). Regardless of the sample preparation method, the sulfolane MDL by GC-FID was often above $0.5-2 \mathrm{mg} / \mathrm{L}$ (i.e., 10 to 50 times greater than Health Canada's guidance value of $0.04 \mathrm{mg} / \mathrm{L}$ ). Another drawback of the analysis of sulfolane by GC-FID was poor reproducibility, even when an internal standard was used (Fedorak and Coy 1996).

Sulfolane can also be analyzed by GC coupled with a Mass Spectrometry detector (GCMS). The GC-MS method developed by Headley et al (Headley, Peru and Dickson 1999) aimed at measuring sulfolane in plant tissues. This method involved sample extraction by toluene, analyte separation by a non-polar column, and detection of sulfolane by a mass selective detector operated in the selected ion monitoring mode. A linear calibration curve was established for the sulfolane concentration range of $0.15-4 \mathrm{mg} / \mathrm{L}$. It is worth noting that the calibration standards were prepared by dissolving pure sulfolane in toluene.

Outside the realm of the published literature, MDL for sulfolane reported by commercial laboratories is often in the low part-per-billion levels ( $\mu \mathrm{g} / \mathrm{L})$ (e.g., (BCELM 2017), (CCME 2006). The method used by these laboratories often consisted of extraction of a large volume of aqueous sample by liquid-liquid extraction (quite often multiple extraction is required). Subsequent to extraction, sulfolane is analyzed by GC-MS. However, the detailed information of the analytical method (e.g., sample preparation procedure, GC oven temperatures) is not disclosed. In one method, isotopic-labelled sulfolane (i.e., deuterated $\mathrm{d}_{8}$-sulfolane) was used as an internal standard (BCELM 2017). 


\section{Materials and method}

\subsection{Chemicals}

All chemicals were of reagent grade and were used without further purification. Sulfolane $\left(\mathrm{C}_{4} \mathrm{H}_{8} \mathrm{SO}_{2}, 99 \%\right.$ purity) was purchased from Fisher Scientific. Deuterated sulfolane, $\left(\mathrm{d}_{8}-\right.$

sulfolane, $\mathrm{C}_{4} \mathrm{D}_{8} \mathrm{SO}_{2}, 97 \%$ purity) with an isotopic purity of 98 atom $\% \mathrm{D}$ was purchased from Sigma Aldrich. Other chemicals including fluorenylmethyloxycarbonyl chloride (FMOC-Cl - $\mathrm{C}_{15} \mathrm{H}_{11} \mathrm{ClO}_{2}, 97 \%$ purity), diisopropanol amine $\left(\mathrm{C}_{6} \mathrm{H}_{15} \mathrm{NO}_{2}, \geq 98 \%\right.$ purity), benzene $\left(\mathrm{C}_{6} \mathrm{H}_{6}, \geq 99.9 \%\right)$, sodium borohydride $\left(\mathrm{NaBH}_{4}, \geq 98 \%\right.$ purity), sodium hydroxide $(\mathrm{NaOH})$, sulfuric acid $\left(\mathrm{H}_{2} \mathrm{SO}_{4}, 98\right.$ wt.\%) toluene $\left(\mathrm{C}_{7} \mathrm{H}_{8}\right)$, sodium bicarbonate $\left(\mathrm{NaHCO}_{3}\right)$, boric acid $\left(\mathrm{H}_{3} \mathrm{BO}_{3}\right)$, sodium azide $\left(\mathrm{NaN}_{3}\right)$, and sodium chloride $(\mathrm{NaCl})$ were bought from either Sigma Aldrich or VWR. Reaction solutions were prepared using ultrapure water with resistivity of 18.2 M $\Omega . c m$ from a Direct-Q water purification system.

\subsection{Adsorbents}

The adsorbent tested in this study were 8 different GAC materials (six coconut-based, and two coal-based GAC), three polymeric adsorbents (Ambersorb 560, Amberlite XAD4, and Optipore L493), and 4 inorganic adsorbents (iron oxide $\left(\mathrm{Fe}_{2} \mathrm{O}_{3}\right)$, aluminum oxide $\left(\mathrm{Al}_{2} \mathrm{O}_{3}\right)$, sand grains, silica gel, and zeolite). Granular activated carbon is the most frequently used type of adsorbent in water treatment. The 8 activated carbon materials were denoted as $\mathrm{AC} 1, \mathrm{AC} 2, \mathrm{AC} 3$ etc. $\mathrm{AC} 1$ and $\mathrm{AC} 8$ were obtained from Calgon Carbon (USA); AC2 was from Carbon Activated Corporation (USA); AC3 - 6 were provided by Evoqua (USA). The three coconut-based activated carbons AC3, AC4, and AC6 have the same mesh size and iodine number, but differ in density $(0.46-0.52,0.43-0.46$ and $0.45-0.52 \mathrm{~g} / \mathrm{cc}$, respectively). The polymeric adsorbents and inorganic adsorbents were obtained from 
Sigma Aldrich, except that zeolite was provided by KMI Zeolite Corporation (USA) and sand grains came from the Britannia water treatment plant (Ottawa, Canada). The three hydrophobic polymeric materials tested include Ambersorb 560 (AS-560), Amberlite XAD4 (AL-XAD-4), and Optipore L493 (OP-L-493). These polymeric materials offer an alternative to GAC for the removal of many types of organic compounds. AS-560 has been shown to be effective at adsorbing 1,4-dioxane, which is an organic contaminant that to some extent resembles sulfolane (i.e., both compounds have cyclic structure, are of low molecular weight, and are hydrophilic) (Woodard, Mohr and Nickelsen 2014). AL-XAD4 and OP-L-493 were effective at removing 2-nitrophenol (Lin and Juang 2009), methyl tert-butyl ether and tert-butyl alcohol (Bi, Haderlein and Schmidt 2005). Silica gel was tested because it was shown that it can be used to selectively recover sulfolane solvent from a mixture of organic compounds (Deal and Garnett 1976). The other inorganic adsorbents (i.e., sand, iron oxide, alumina oxide, and zeolite) were tested to assess the extent of sulfolane removal that can be expected to occur in coagulation/flocculation and sand filtration processes of conventional drinking water treatment plants. The physico-chemical properties of these materials are reported in Table 1. The data was collected from the material fact sheets and as such some information was not available. 
Table 3. 1 Adsorbent properties

\begin{tabular}{|c|c|c|c|c|}
\hline Adsorbents & Mesh size & $\begin{array}{l}\text { Iodine number } \\
\qquad(\mathrm{mg} / \mathrm{g})\end{array}$ & $\begin{array}{c}\text { Surface area } \\
\qquad\left(\mathrm{m}^{2} / \mathrm{g}\right)\end{array}$ & $\begin{array}{c}\text { Pore size } \\
(\AA)\end{array}$ \\
\hline $\mathrm{AC} 1$ (coconut based) & $12 \times 40$ & 1050 & & \\
\hline AC2 (coconut based) & $8 \times 30$ & 1093 & 1125 & \\
\hline AC3 (coconut based) & $12 \times 30$ & 1100 & & \\
\hline AC4 (coconut based) & $12 \times 30$ & 1100 & & \\
\hline AC5 (coconut based) & $8 \times 30$ & 1100 & & \\
\hline AC6 (coconut based) & $12 \times 30$ & 1100 & & \\
\hline AC7 (coal based) & $8 \times 30$ & 909 & 917 & \\
\hline AC8 (bituminous based) & - & 1000 & & \\
\hline Ambersorb 560 & & & $450-9999$ & \\
\hline Amberlite XAD4 & $20-60$ & & 725 & 50 \\
\hline Optipore L493 & $20-50$ & & 1100 & 46 \\
\hline Silica gel & $\sim 300$ & & 550 & 60 \\
\hline $\mathrm{Fe}_{2} \mathrm{O}_{3}$ & $<5 \mu \mathrm{m}$ & & 150 & \\
\hline $\mathrm{Al}_{2} \mathrm{O}_{3}$ & 150 & & 155 & 58 \\
\hline Sand & - & - & - & - \\
\hline Zeolite & $14 * 30$ & & 40 & $4-7$ \\
\hline
\end{tabular}




\subsection{Adsorption experiment}

All adsorption experiments were triplicated and conducted at room temperature $\left(21 \pm 2{ }^{\circ} \mathrm{C}\right)$ employing $15 \mathrm{~mL}$ polypropylene test tubes that contained $10 \mathrm{~mL}$ reaction solutions. The reaction solutions consisted of either 10 or $500 \mathrm{mg} / \mathrm{L}(0.083-4.17 \mathrm{mM})$ sulfolane, $1 \mathrm{mM}$ $\mathrm{NaHCO}_{3}$ (which served as a pH buffer and background electrolyte), and $1-100 \mathrm{~g} / \mathrm{L}$ of an adsorbent. The initial solution $\mathrm{pH}$ was around 7.5. The test tubes were sealed carefully and mixed end-over-end on a Thermo Fisher rotator. At predetermined time intervals, a few tubes were taken off from the rotator, and the adsorbent was separated from the liquid phase either by gravity, centrifugation ( $8000 \mathrm{~g}, 5 \mathrm{mins})$ or by filtration through a $0.2-\mu \mathrm{m}$ nylon syringe filter. The supernatant (from settling or centrifugation) and filtrate (from filtration) were subsampled and analyzed for sulfolane and $\mathrm{pH}$. No sulfolane loss was observed in control experiments (i.e., adsorbent-free experiments), suggesting that the losses of sulfolane by adsorption to test tube walls and by volatilization were minimal. Therefore, the amount of sulfolane adsorbed on the adsorbent in each experiment can be calculated based on the following mass balance equation:

$$
q=\frac{\left(C_{0}-C_{w}\right) \times V}{m}
$$

with $q$ being the concentration of sulfolane on the adsorbent $(\mathrm{mg} / \mathrm{g}), C_{0}$ being the initial concentration of sulfolane, $C_{w}$ is the concentration of sulfolane remained in the solution $(\mathrm{mg} / \mathrm{L}), \mathrm{V}$ is the volume of the solution $(\mathrm{L})$ and $m$ is the mass of adsorbent $(\mathrm{g})$.

The adsorption kinetic and isotherms models were fitted in linearized form using SigmaPlot version 14.0. 
The influence of DIPA and $\mathrm{C}_{6} \mathrm{H}_{6}$ (i.e., the co-contaminants) on the adsorption of sulfolane by AC5 and Ambersorb 560 was investigated in a separate set of experiments. (AC 5 and Ambersorb 560 were chosen because these were among the most effective sulfolane adsorbents, as will be seen in the Results and discussion section). In these experiments, in addition to $1-500 \mathrm{mg} / \mathrm{L}$ sulfolane the reaction solution also consisted of either $50 \mathrm{mg} / \mathrm{L}$ $(\sim 0.38 \mathrm{mM})$ DIPA or $78 \mathrm{mg} / \mathrm{L}(1 \mathrm{mM}) \mathrm{C}_{6} \mathrm{H}_{6}$. In the experiment with DIPA, the $\mathrm{pH}$ of the solution was adjusted to either $\mathrm{pH} \sim 7.5$ or 9.9. DIPA has a pKa of 8.9 (Kim, Dobrogowska and Hepler 1987). Therefore, the \% of DIPA molecules that were protonated (i.e., the fraction that carried a positive charge) was $96 \%$ (at $\mathrm{pH} 7.5$ ) and $10 \%$ (at $\mathrm{pH} 9.9$ ). Experiments with $\mathrm{C}_{6} \mathrm{H}_{6}$ were conducted employing borosilicate glass tubes because $\mathrm{C}_{6} \mathrm{H}_{6}$ adsorbed on polypropylene tubes. The test tubes were mounted on the rotator, and was mixed end-over-end. At predetermined time intervals, a few test tubes were sacrificed and the solid were separated by gravitational settling or by filtration. Subsequently, the $\mathrm{pH}$ of the concentration of sulfolane in the solution was analyzed.

Another set of experiment was conducted to examine the effect of dissolved organic carbon (DOC) and major cations and anions (e.g., $\mathrm{Ca}^{2+}, \mathrm{Mg}^{2+}, \mathrm{Cl}^{-}, \mathrm{SO}_{4}{ }^{2-}, \mathrm{NO}_{3}^{-}$) on the adsorption of sulfolane. This experiment employed two types of synthetic water (denoted as ICW1 and ICW2) and two types of groundwater (denoted as GW1 and GW2), which were collected from an aquifer in the vicinity of a sulfolane-impacted area. ICW1 consisted of 3 $\mathrm{mM} \mathrm{CaCl}_{2}$ and $1.5 \mathrm{mM} \mathrm{MgSO}_{4}$, while ICW2 consisted of $1 \mathrm{mM} \mathrm{NaHCO}_{3}, 5 \mathrm{mM} \mathrm{K}_{2} \mathrm{SO}_{4}$ and $3 \mathrm{mM} \mathrm{NaCl}$. The water chemistry of the two groundwater samples are reported in Table 2 in the following page. Prior to each adsorption experiment, the groundwater samples were filtered through a $0.2-\mu \mathrm{m}$ paper filter to remove suspended particles and bacteria. 
Subsequently, sulfolane was added into the groundwater samples such that the initial concentration of sulfolane in each test solution was $1-500 \mathrm{mg} / \mathrm{L}$. In addition, $1 \mathrm{mM}$ of $\mathrm{NaN}_{3}$ was added to inhibit microbial activities. $10 \mathrm{~mL}$ aliquots of the reaction solution then were poured into $15 \mathrm{~mL}$ polypropylene test tubes which contained $0.02 \mathrm{~g}$ of either GAC 5 or Ambersorb 560 (i.e., the concentration of the adsorbent in each test tube was $2 \mathrm{~g} / \mathrm{L}$ ). The adsorption experiment was conducted and the concentration of sulfolane remained in the solution together with the solution $\mathrm{pH}$ at each time point were measured following the procedure described above. 
Table 3. 2 Characteristics of ground water samples

\begin{tabular}{|c|c|c|}
\hline Parameters & GW1 & GW2 \\
\hline $\mathrm{pH}$ & 7.7 & 8.1 \\
\hline TOC (total organic carbon) $(\mathrm{mg} / \mathrm{L})$ & 3.19 & 0.87 \\
\hline TC (total carbon) $(\mathrm{mg} / \mathrm{L})$ & 68.75 & 49.18 \\
\hline IC (inorganic carbon) $(\mathrm{mg} / \mathrm{L})$ & 65.56 & 48.31 \\
\hline Chloride $(\mathrm{mg} / \mathrm{L})$ & 117.61 & 69.08 \\
\hline Nitrate $(\mathrm{mg} / \mathrm{L})$ & 49.00 & 20.36 \\
\hline Sulfate $(\mathrm{mg} / \mathrm{L})$ & 341.65 & 38.77 \\
\hline Bromide $(\mathrm{mg} / \mathrm{L})$ & 0.41 & 0.25 \\
\hline Fluoride $(\mathrm{mg} / \mathrm{L})$ & 1.51 & 1.50 \\
\hline Phosphate $(\mathrm{mg} / \mathrm{L})$ & 2.48 & 2.90 \\
\hline Calcium $(\mathrm{mg} / \mathrm{L})$ & 139.83 & 58.59 \\
\hline Magnesium (mg/L) & 33.08 & 8.21 \\
\hline Potassium $(\mathrm{mg} / \mathrm{L})$ & 13.37 & 11.10 \\
\hline Sodium $(\mathrm{mg} / \mathrm{L})$ & 182.00 & 85.20 \\
\hline
\end{tabular}

\subsection{Analytical methods}

$\mathrm{pH}$ was measured using Orion Star A221 pH meter. Major anions in the groundwater samples reported in Table 2 were analyzed on a Thermo Aquion ion chromatograph (IC), while major cations were measured on a Perkin Elmer Inductively Coupled Plasma Optical Emission Spectrometer (ICP-OES). Total organic carbon (TOC) and inorganic carbon (IC) were analyzed on a Shimadzu organic carbon analyzer. Sulfolane was measured on an 
Agilent 7820A Gas Chromatograph - 5977B Mass Selective Detector (GC/MS) equipped with a DB-5ms column $(30 \mathrm{~m} \times 0.25 \mathrm{~mm}$, film thickness of $0.25 \mu \mathrm{m})$. Sample preparation for GC/MS analysis involved extracting sulfolane from aqueous samples by toluene. In a typical extraction process (Figure 3.1), $10 \mu \mathrm{L}$ of an aqueous solution of $2 \mathrm{mM} \mathrm{d}$-sulfolane (i.e., an internal standard) was added to $990 \mu \mathrm{L}$ of sample, and this $1 \mathrm{~mL}$ aqueous solution was added to a conical glass vial containing $2 \mathrm{~mL}$ of toluene. Subsequently, the extraction vial was mixed vigorously for approximately 1 minute by a vortex mixer, and was kept quiescent for a few minutes to allow toluene to separate from the aqueous solution. The toluene layer which was on the top of the aqueous layer then was subsampled and transferred to a $\mathrm{GC}$ vial using a disposable glass pipette. One microliter of the sample was injected to the GC/MS system by a PAL3 robotic auto sampler. The GC/MS was run in a splitless mode with ultra-high purity 5.0 helium gas (flow rate of $1 \mathrm{~mL} / \mathrm{min}$ ) serving as the carrier gas. The GC/MS initial temperatures were as follows: injection port temperature: $285^{\circ} \mathrm{C}$; GC/MS transfer line temperature: $285^{\circ} \mathrm{C}$, ion source temperature: $285^{\circ} \mathrm{C}$, quadrupole temperature: $150^{\circ} \mathrm{C}$. The $\mathrm{GC}$ oven temperature was programed as follows: initial temperature was $80{ }^{\circ} \mathrm{C}$ which programmed to hold for 2 minutes, then raised from $80{ }^{\circ} \mathrm{C}$ to $140{ }^{\circ} \mathrm{C}$ at $10^{\circ} \mathrm{C} / \mathrm{min}$, and then from $140^{\circ} \mathrm{C}$ to $280^{\circ} \mathrm{C}$ at $40^{\circ} \mathrm{C} / \mathrm{min}$. Subsequently, the temperature was held at $280^{\circ} \mathrm{C}$ for 5 mins (i.e., until the end of analysis). The electron ionization (EI) source was set at $70 \mathrm{eV}$. The MS was operated in the total ion current (TIC) mode to determine sulfolane's mass spectrum, and in the selected ion monitoring (SIM) mode $\left(\mathrm{m} / \mathrm{z}=120\right.$ and 128 for sulfolane and $\mathrm{d}_{8}$-sulfolane, respectively) at a dwell time of 50 ms per ion for the quantitation of sulfolane. Data acquisition and analyses were performed using Agilent's Mass Hunter Qualitative Analysis B.07.00. 


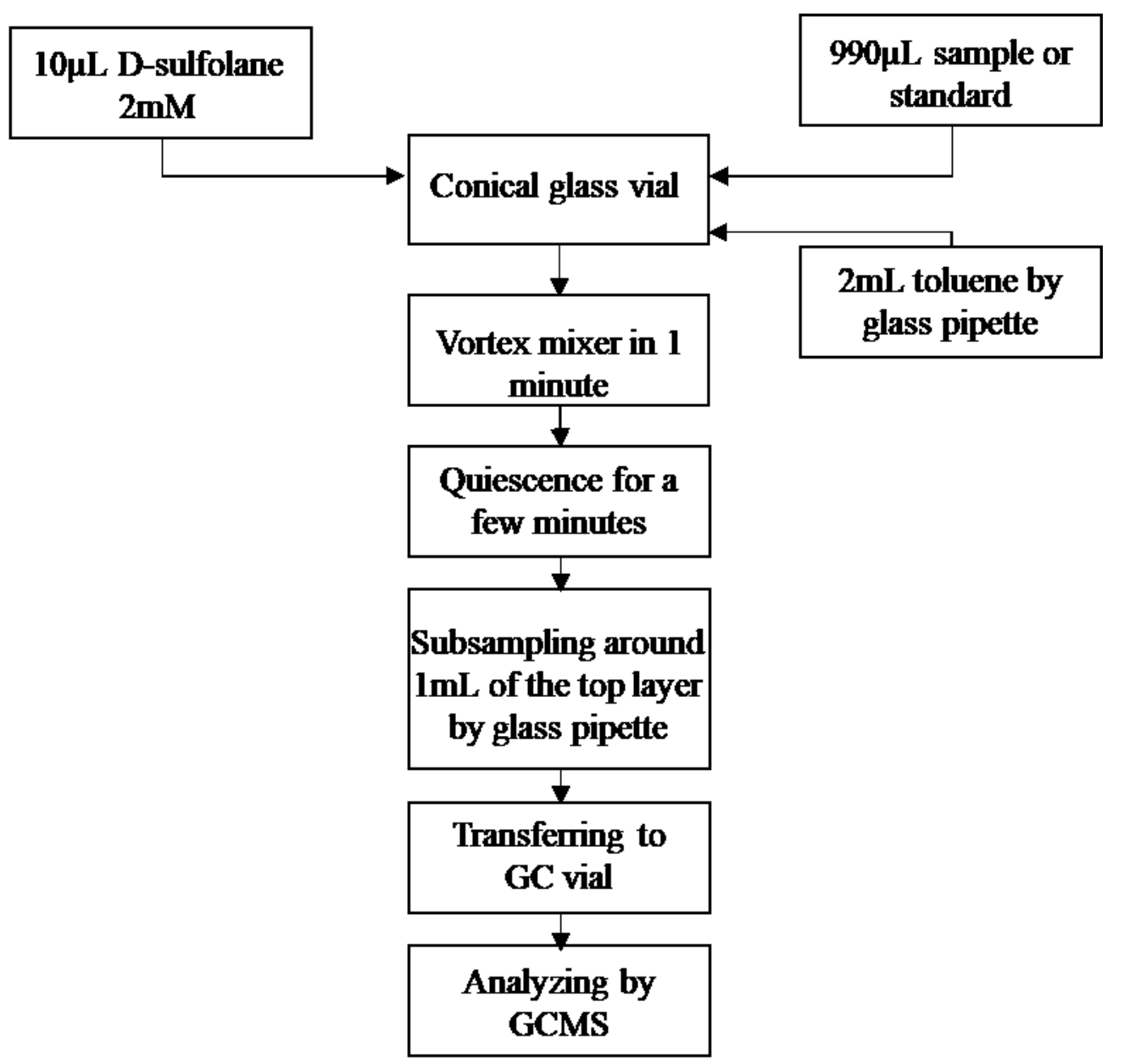

Figure 3.1 Flow chart of liquid-liquid extraction for sulfolane analysis

Sulfolane calibration curve was used to determine unknown sample concentrations. In the low concentration range i.e. $<1 \mathrm{mg} / \mathrm{L}$, six different standard solutions from 50 to 1000 $\mu \mathrm{g} / \mathrm{L}$ were prepared. A concentrated stock solution $1000 \mu \mathrm{g} / \mathrm{L}$ was made from sulfolane $99 \%$ and milli-Q water. The 5 remaining standards were prepared by serial dilutions. For this low concentration range, standard solutions and samples were also extracted by toluene following the extraction procedure described in Figure 3.1, however, $4990 \mu \mathrm{L}$ of sample was added to the conical glass vial instead of $990 \mu \mathrm{L}$. 
DIPA and Benzene were measured by a Thermo Scientific Ultimate 3000 ultra-high performance liquid chromatograph (UHPLC) equipped with a photodiode array UV-visible detector. Benzene sample vials were filled to the top without head space. Ten microliter of benzene sample was injected to UHPLC and it was carried by a mobile phase that consists of $55 \%$ Acetonitrile: $45 \% \mathrm{H}_{2} \mathrm{SO}_{4} 1 \mathrm{mM}$ with a flowrate $1 \mathrm{~mL} / \mathrm{min}$. Benzene was detected at UV $255 \mathrm{~nm}$ after 3.5 mins.

DIPA cannot be measured directly by UV-visible detector because the compound does not absorb light to an appreciable extent. Therefore, DIPA was measured by derivatization with FMOC-Cl, an organic compound with a fluorophore consisting of conjugated $\pi$ bonds (BCELM 2017). The derivatization was performed by adding $25 \mu \mathrm{L}$ borate buffer and 100 $\mu \mathrm{L}$ FMOC-Cl $2.5 \mathrm{mM}$ that prepared in acetonitrile into $0.5 \mathrm{~mL}$ sample. The HPLC vial was vortexed and incubated for about 30 mins under low heat condition. After incubation, 10 $\mu \mathrm{L}$ of $\mathrm{HCl} 30 \%$ was added to the vial before mixing again with a vortex. The reaction between a secondary amine and FMOC-Cl is presented in Figure 3.2. The derivatized product is a fluorophore that contains aromatic rings with several conjugated $\pi$ bonds that have strong UV absorption. The product DIPA-FMOC was injected to UHPLC with the injection volume of $10 \mu \mathrm{L}$. The eluent was set up at $40 \%$ acetonitrile: $60 \% 1 \mathrm{mM} \mathrm{H}_{2} \mathrm{SO}_{4}$ with a flow rate of $1 \mathrm{~mL} / \mathrm{min}$. Derivatized DIPA has a retention time of $6.7 \mathrm{~min}$, and was detected at UV $265 \mathrm{~nm}$. 


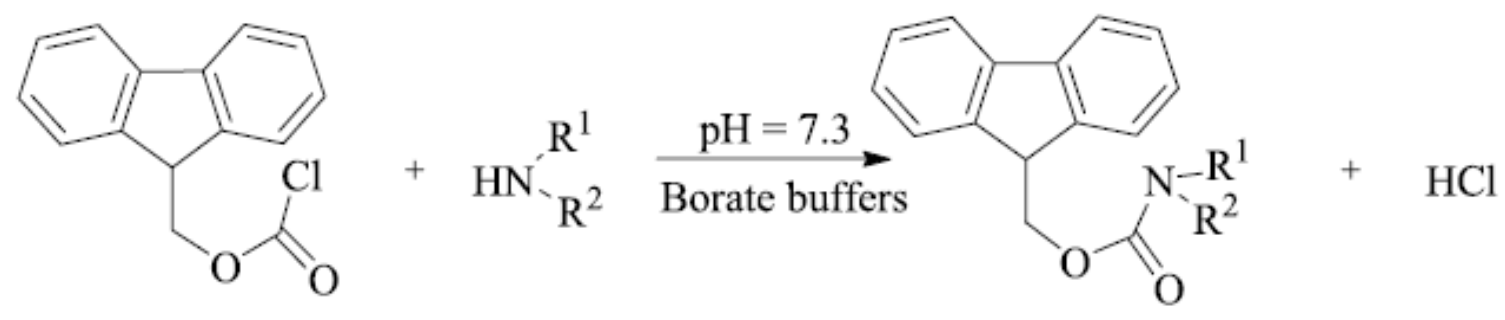

Figure 3.2 The derivatization reaction of amines and fluorenylmethyloxycarbonyl chloride (Chang \& Yu, 2011). 


\section{Results and discussion}

\subsection{Development of sulfolane analysis method using GC/MS}

\subsubsection{Sulfolane retention time and mass spectrum}

A method for the quantification of sulfolane by GC/MS was developed by first investigating the elution time of sulfolane from the GC column. To this end, a $100 \mathrm{mg} / \mathrm{L}$ of an aqueous sulfolane sample, prepared by adding sulfolane to deionized water, was extracted with toluene, and the toluene fraction was injected into the GC/MS. The MS detector was set to monitor for mass to charge $(\mathrm{m} / \mathrm{z})$ values ranging from 25 to 140 , and the total ion chromatogram of this analysis is presented in Figure 4.1.

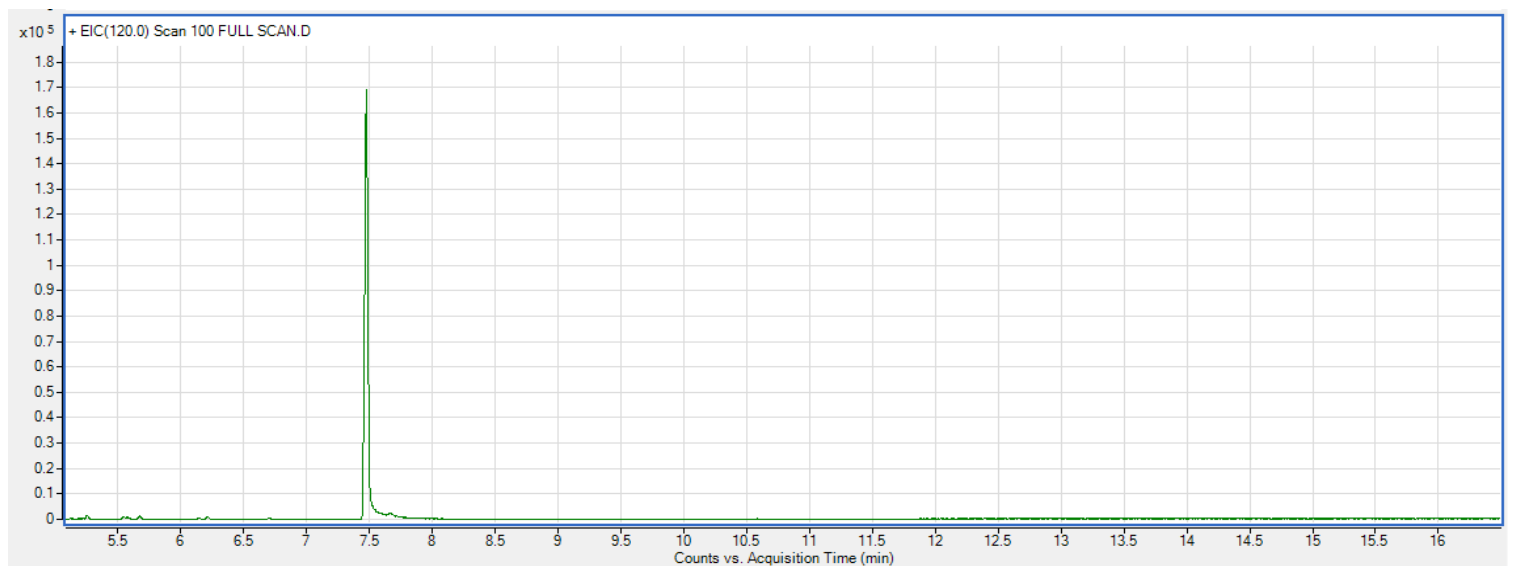

Figure 4.1 Total Ion Chromatogram of sulfolane. $100 \mathrm{mg} / \mathrm{L}$ of an aqueous sulfolane was extracted by sulfolane, and $1 \mu L$ of the toluene fraction was analyzed by GC/MS.

From this figure, it can be seen that a sharp peak eluted at approximately $t=7.5 \mathrm{~min}$. The mass spectrum of this peak, presented in Figure 4.2, consists of m/z values 41, 56, and 120 . The $\mathrm{m} / \mathrm{z}$ value of 120 can be assigned to the molecular ion peak of sulfolane (MW $=120)$, while $\mathrm{m} / \mathrm{z}=41$ and $\mathrm{m} / \mathrm{z}=56$ can be assigned to the $\mathrm{CH}_{3}-\mathrm{CH}=\mathrm{CH}^{+}$and $\mathrm{C}_{4} \mathrm{H}_{8}{ }^{+}$fragments, respectively. There are two more $\mathrm{m} / \mathrm{z}$ values with high relative abundance, namely 28 and 
32. These $\mathrm{m} / \mathrm{z}$ values are present due to $\mathrm{N}_{2}$ and $\mathrm{O}_{2}$, suggesting that there was a small air leak in the GC/MS system. $\mathrm{M} / \mathrm{z}=27$ ion can be assigned to the $\mathrm{CH}_{2}=\mathrm{CH}^{+}$fragment. Overall, the mass spectrum of the peak eluted at $t=7.5$ min suggests that this peak is sulfolane.

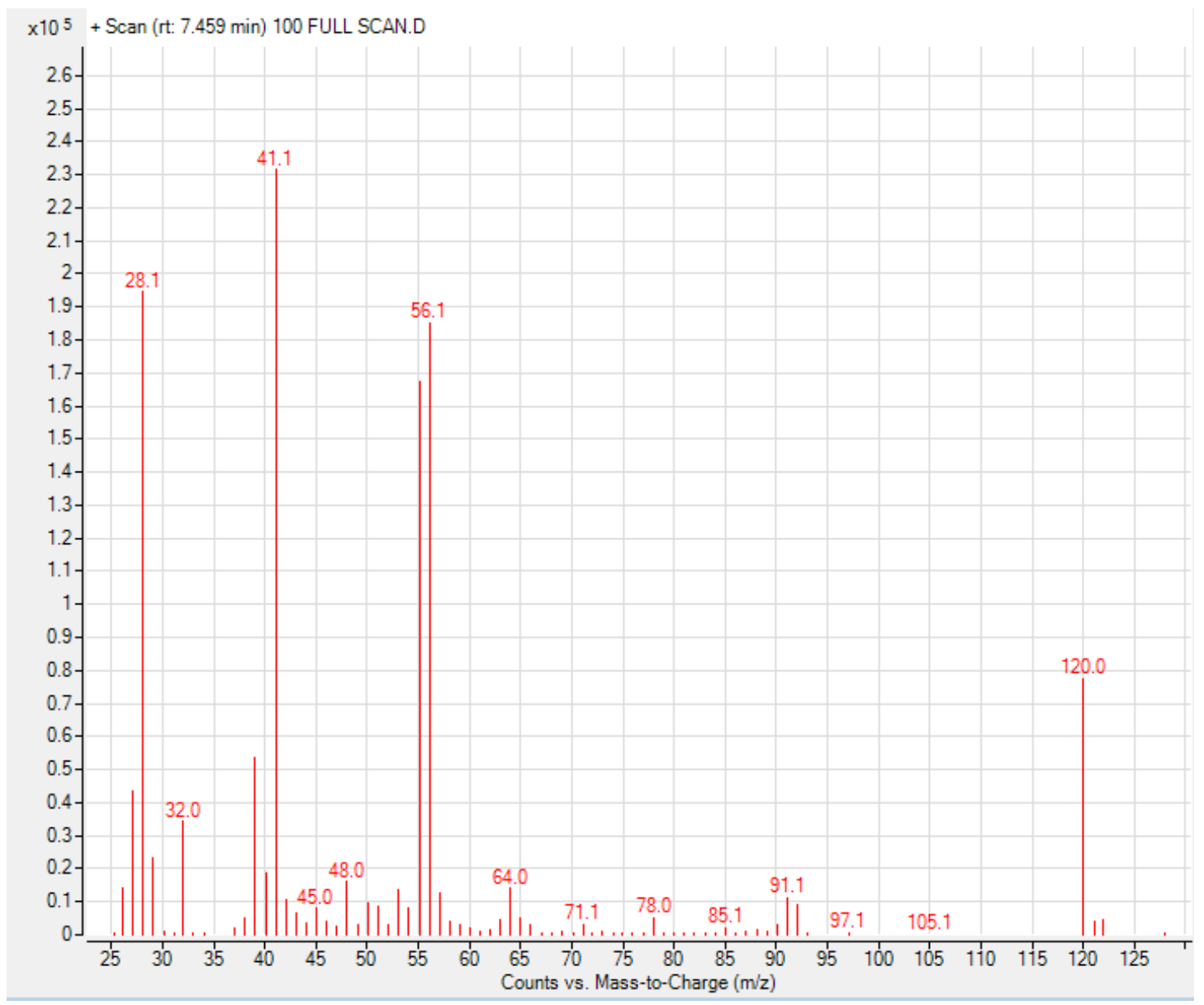

Figure 4.2 Mass spectrum of sulfolane. M/z=120 corresponds to the sulfolane molecular ion, whereas $\mathrm{m} / \mathrm{z}=56.1$ corresponds to the $\mathrm{C}_{4} \mathrm{H}_{8}{ }^{+}$ion, $\mathrm{m} / \mathrm{z}=41.1$ corresponds to $\mathrm{CH}_{3-}$ $\mathrm{CH}=\mathrm{CH}^{+}$ion, and $\mathrm{m} / \mathrm{z}=27$ corresponds to $\mathrm{CH}_{2}=\mathrm{CH}^{+}$ion . 


\subsubsection{Quantification of sulfolane using d8-sulfolane as an internal standard.}

For the quantification of sulfolane, the MS detector was set to run in the selected ion monitoring (SIM) mode to monitor for $\mathrm{m} / \mathrm{z}=120$. While this was not the most abundant ion, its abundance was the most reproducible among all the ions. Figure 4.3 presents the GC-MS-SIM chromatogram of the same sulfolane sample presented in Figure 4.1.

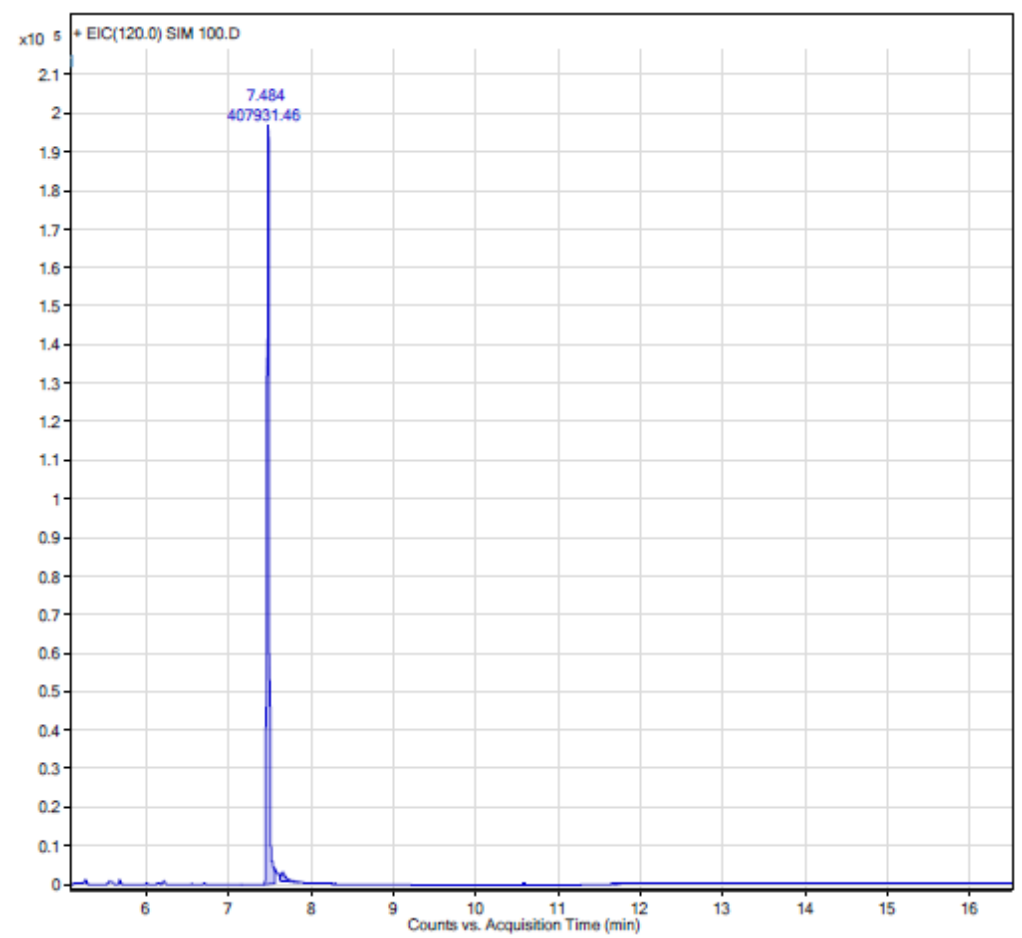

Figure 4.3 Selected ion monitoring $(\mathrm{m} / \mathrm{z}=120) \mathrm{GC} / \mathrm{MS}$ chromatogram of a sulfolane sample. $100 \mathrm{mg} / \mathrm{L}$ of an aqueous sulfolane was extracted by toluene, and $1 \mu \mathrm{L}$ of the toluene fraction was analyzed by GC/MS.

The area of the peak in Figure 4.3 should be proportional to the concentration of sulfolane in the sample. However, it was found that the area varied from injection to injection (Table 4.1 - the relative standard deviation (RSD\%) for $100 \mathrm{mg} / \mathrm{L}$ aqueous sulfolane sample was 
13.1\%). This variation is typical in GC analysis, which is often attributable to the fluctuation in the flow rate of the carrier gas. For GC/MS analysis, the variation in peak area can also be the result of fluctuation in ionization efficiency. It was also found that the peak area varied from sample to sample, even when the aqueous samples subjected to toluene extraction of similar concentration. This was because the efficiency of sulfolane extraction by toluene varied from extraction to extraction, even though all samples were extracted following a consistent procedure (i.e., $1 \mathrm{~mL}$ aqueous sample is extracted by $2 \mathrm{~mL}$ toluene by vigorously mixing the mixture for $1 \mathrm{~min}$ ). For these reasons, the area of the peak of the GC-MS-SIM chromatogram cannot be used to establish a calibration curve.

\begin{tabular}{|c|c|}
\hline Injection & Sulfolane area \\
\hline$\# 1$ & 3237342 \\
\hline$\# 2$ & 4766115 \\
\hline$\# 3$ & 3864354 \\
\hline$\# 4$ & 4519625 \\
\hline$\# 5$ & 4319014 \\
\hline$\# 6$ & 4701020 \\
\hline$\# 7$ & 4681234 \\
\hline
\end{tabular}

Table 4.1 Area of the sulfolane peak. $100 \mathrm{mg} / \mathrm{L}$ of an aqueous sulfolane was extracted by sulfolane, and $1 \mu \mathrm{L}$ of the toluene fraction was analyzed by GC/MS seven times.

To overcome the challenges associated with peak area variation, a common practice in GC analysis is to employ an internal standard (IS) compound. In this study, deuterated sulfolane ( $\mathrm{d}_{8}$-sulfolane, Figure 4.4$)$ is chosen as the IS. $\mathrm{D}_{8}$-sulfolane is essentially similar to the normal sulfolane, except that all the hydrogen atoms in sulfolane are replaced by deuterium atoms, resulting in a compound that has similar physical/chemical properties. The mass of $\mathrm{d}_{8}$-sulfolane, however, is greater than that of the normal sulfolane by 8 Dalton. This difference enables the differentiation of these two compounds by the MS detector. 


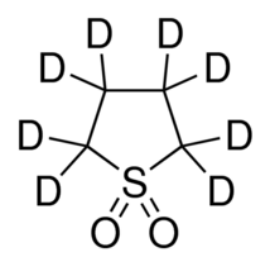

Figure 4.4 Molecular structure of deuterated $d_{8}$-sulfolane $(M W=128)$.

The GC-MS-SIM chromatogram $(\mathrm{m} / \mathrm{z}=128)$ of a $\mathrm{d}_{8}$-sulfolane sample is presented in Figure 4.5. This sample was prepared by extracting an aqueous sample consisting of 0.5 $\mathrm{mg} / \mathrm{L} \mathrm{d}_{8}$-sulfolane with toluene. Compared with the normal sulfolane, $\mathrm{d}_{8}$-sulfolane eluted out of the GC column at a slightly earlier time $(t=7.4 \mathrm{~min})$.

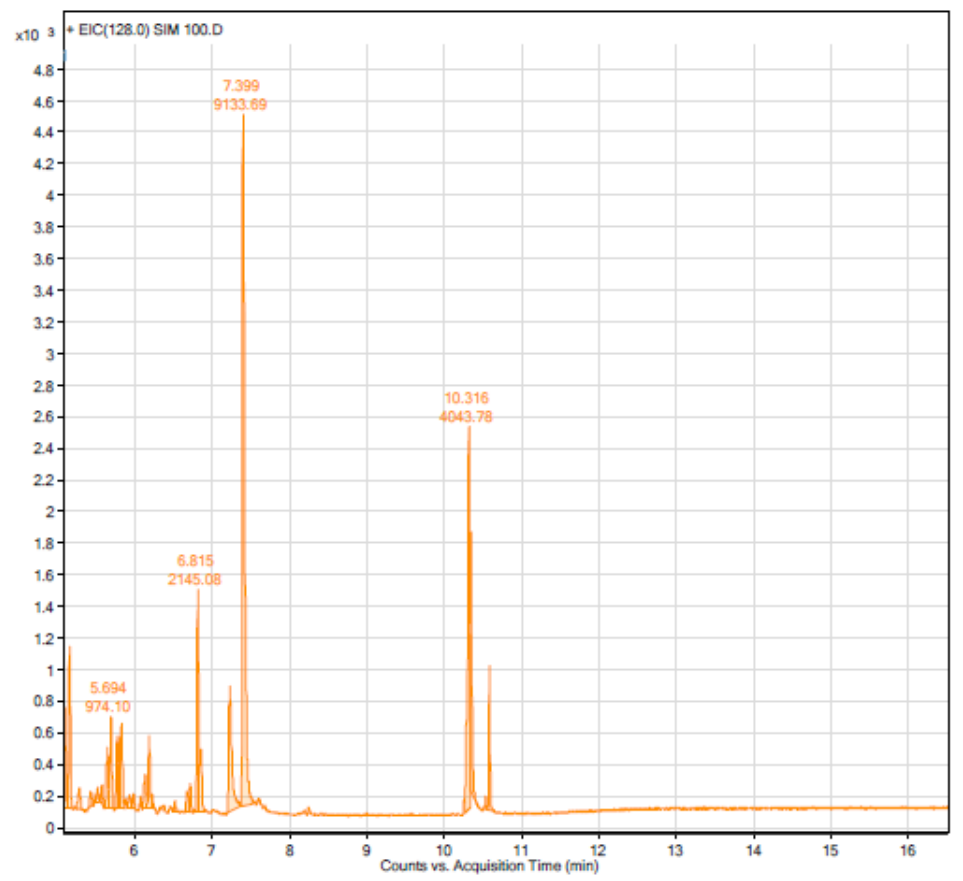

Figure 4.5 Selected ion monitoring $(\mathrm{m} / \mathrm{z}=120) \mathrm{GC} / \mathrm{MS}$ chromatogram of a d8-sulfolane sample, which was prepared by extracting $0.5 \mathrm{mg} / \mathrm{L}$ of aqueous $d_{8}$-sulfolane by toluene. 1 $\mu L$ of the toluene fraction was analyzed by $G C / M S$.

It can be seen in this chromatogram that there are peaks that eluted at different times. The presence of these peaks was most likely due to the bleeding of the GC column, that is the 
thermal breakdown of the stationary phase introduced background contamination into the system. To confirm this hypothesis, an aqueous sample of $0.5 \mathrm{mg} / \mathrm{L}$ of the normal sulfolane was extracted with toluene and analyzed by GC/MS in the SIM mode. The GC-MS-SIM chromatogram $(\mathrm{m} / \mathrm{z}=120)$ of this sample (Figure 4.6) also consists of many peaks in addition to the one corresponding to sulfolane (i.e., the peak that eluted at $t=7.5 \mathrm{~min}$ ). It is worth noting that these peaks were also present in the chromatogram presented in Figure 4.3. However, since the concentration of the aqueous sample in Figure 4.3 was 200 times greater $(100 \mathrm{mg} / \mathrm{L}$ vs. $0.5 \mathrm{mg} / \mathrm{L})$, the sulfolane peak is significantly higher than the other peaks.

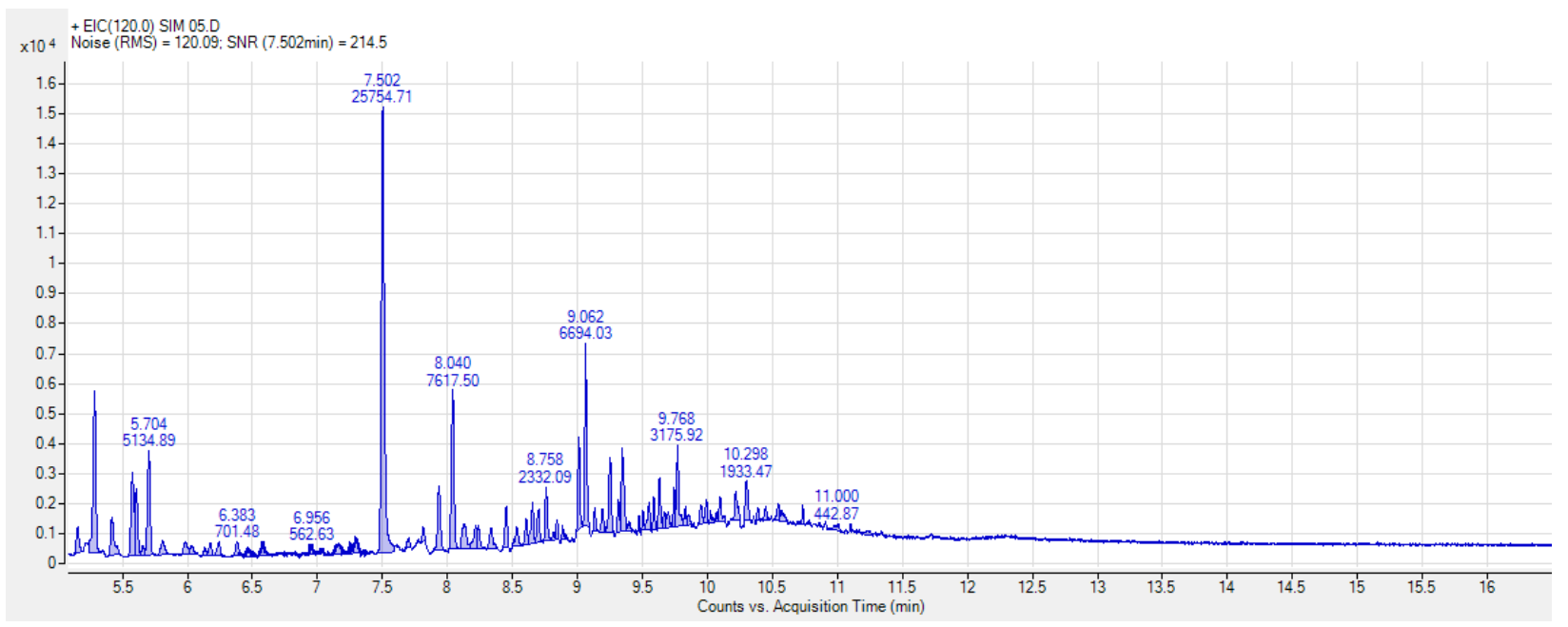

Figure 4.6 Selected ion monitoring $(\mathrm{m} / \mathrm{z}=120) \mathrm{GC} / \mathrm{MS}$ chromatogram of a sulfolane sample which was prepared by extracting $0.5 \mathrm{mg} / \mathrm{L}$ aqueous sulfolane by toluene. $1 \mu \mathrm{L}$ of the toluene fraction was analyzed by $G C / M S$.

Since $\mathrm{d}_{8}$-sulfolane and the normal sulfolane are eluted at the same time, and given that both compounds have similar physical/chemical properties, both compound will be ionized by the electrospray ionization source with the same efficiency. Therefore, while the area of 
the $\mathrm{d}_{8}$-sulfolane and the normal sulfolane peaks may vary from injection to injection, the peak area ratio $\mathrm{A}_{\text {sulfolane }} / \mathrm{A}_{\mathrm{d} 8-\text { sulfolane }}$ is expected to be consistent from injection to injection. In agreement with this hypothesis, the RSD\% based on peak area ratio for the same analysis presented in Table 4.1 is $2.2 \%$ (Table 4.2 ).

\begin{tabular}{|c|c|}
\hline Injection & Asulfolane/Ad8-sulfolane \\
\hline$\# 1$ & 44.6 \\
\hline$\# 2$ & 47.8 \\
\hline$\# 3$ & 45.0 \\
\hline$\# 4$ & 45.6 \\
\hline$\# 5$ & 45.4 \\
\hline$\# 6$ & 45.6 \\
\hline$\# 7$ & 46.1 \\
\hline
\end{tabular}

Table 4.2 Area ratio $A_{\text {sulfolane }} / A_{d 8-\text { sulfolane }}$

In addition to providing a consistent way of quantifying sulfolane by the GC/MS, the internal standard $\mathrm{d}_{8}$-sulfolane can also be used to correct for the varying extraction efficiency when sulfolane in aqueous samples is extracted with toluene. This is illustrated by the results present in Table 4.3. The RSD\% of based on the sulfolane peak area for 7 different extraction was $6.7 \%$, whereas RSD $\%$ based on $\mathrm{A}_{\text {sulfolane }} / \mathrm{A}_{\mathrm{d} 8 \text {-sulfolane }}$ was $2.7 \%$. The results above collectively suggest that a calibration curve can be constructed based on the peak area ratio. 


\begin{tabular}{|c|c|c|}
\hline Extraction & $\begin{array}{c}\text { Sulfolane } \\
\text { area }\end{array}$ & Asulfolane/Ad8-sulfolane \\
\hline$\# 1$ & 40064 & 0.44 \\
\hline$\# 2$ & 37584 & 0.46 \\
\hline$\# 3$ & 34037 & 0.47 \\
\hline$\# 4$ & 38165 & 0.45 \\
\hline$\# 5$ & 33867 & 0.44 \\
\hline$\# 6$ & 34695 & 0.45 \\
\hline$\# 7$ & 38355 & 0.45 \\
\hline
\end{tabular}

Table 4.3 Area of the sulfolane peak. Seven different $1 \mathrm{mg} / \mathrm{L}$ of an aqueous sulfolane standards were extracted by sulfolane, and $0.5 \mu \mathrm{L}$ of each toluene fraction was analyzed by $G C / M S$.

\subsubsection{Sulfolane calibration curve}

A calibration curve for sulfolane is presented in Figure 7. The standards for this calibration curve were prepared by spiking $0.5 \mathrm{mg} / \mathrm{L} \mathrm{d}_{8}$ sulfolane to each of the 6 aqueous standards consisting of $0.05,0.07,0.1,0.5,0.7$, and $1 \mathrm{mg} / \mathrm{L}$ of sulfolane, and subsequently extracting these standards with toluene. The areas of the sulfolane and $\mathrm{d}_{8}$-sulfolane peaks were

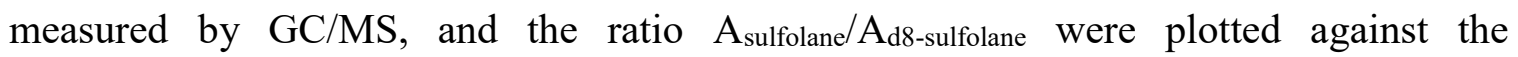
concentration of sulfolane in the initial 6 aqueous standards (i.e., $0.05-1 \mathrm{mg} / \mathrm{L}$ ). As can be seen from Figure 4.7, the $\mathrm{R}^{2}$ value of the linear regression is 0.9998 , suggesting that this calibration curve can be used to measure the concentration of sulfolane in the $0.05-1$ $\mathrm{mg} / \mathrm{L}$ range.

The instrument detection limit (IDL) based on the chromatogram signal to noise ratio $\mathrm{S} / \mathrm{N}$ $=3$ is determined to be $0.01 \mathrm{mg} / \mathrm{L}$, while the instrument quantitation limit (IQL) based on $\mathrm{S} / \mathrm{N}=10$ is determined to be $0.03 \mathrm{mg} / \mathrm{L}$. The whole method of detection limit (MDL) and quantitation limit (MQL) (i.e., including variation due to liquid-liquid extraction) were determined to be $0.02 \mathrm{mg} / \mathrm{L}$ and $0.07 \mathrm{mg} / \mathrm{L}$, respectively. The calibration range of our 
study extends to concentration values significantly lower than those reported by Headley et al $(0.15-4 \mathrm{mg} / \mathrm{L})($ Headley et al, 1999). Note that Headley et al prepared calibration standards by dissolving sulfolane directly into toluene (i.e., no extraction of aqueous solution samples was involved). Also, IS was not employed in their study.

As the concentration of sulfolane in drinking water wells impacted by sulfolane plume often falls in the $0.03-1 \mathrm{mg} / \mathrm{L}$ range (DHSS 2012), the analytical method developed herein can be used to analyze sulfolane in contaminated drinking water wells. This method is simple, does not require large sample volume (only $1-4 \mathrm{~mL}$ is required), and does not require multiple extraction round (only one extraction was involved).

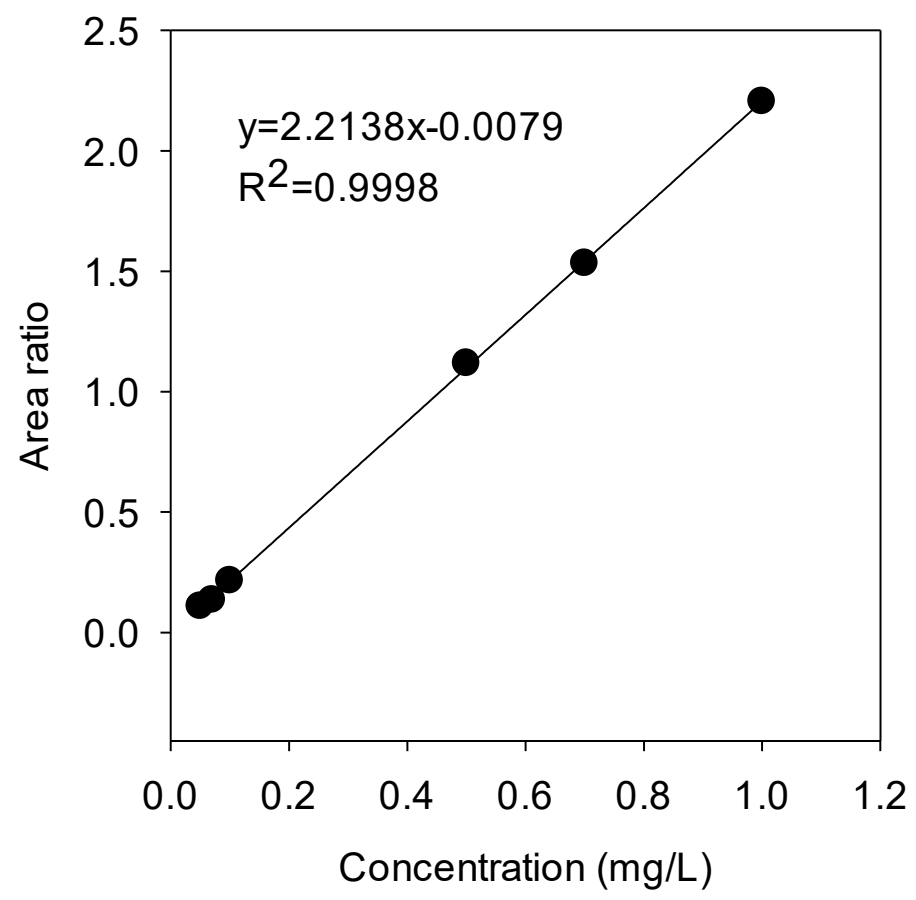

Figure 4.7 Calibration curve for sulfolane $(0.05-1 \mathrm{mg} / \mathrm{L})$, which was established based on the peak area ratio $A_{\text {sulfolane }} / A_{d 8 \text {-sulfolane. }}$ 
The concentration of sulfolane at contaminated sites can range from a few $\mathrm{mg} / \mathrm{L}$ to up to a few hundred mg/L. To explore if the developed method can be used to measure high concentration samples, a calibration curve was established for aqueous standards containing $1-100 \mathrm{mg} / \mathrm{L}$ following the procedure described above, with one exception that to each standard $2.56 \mathrm{mg} / \mathrm{L} \mathrm{d}$-sulfolane was added instead of $0.5 \mathrm{mg} / \mathrm{L}$. As with the calibration curve for the $0.03-1 \mathrm{mg} / \mathrm{L}$ range, the calibration curve for the $1-100 \mathrm{mg} / \mathrm{L}$ is linear $\left(\mathrm{R}^{2}\right.$ of the regression line is 0.9992 - Figure 4.8), suggesting that the developed method can also be used without any modification to measure samples containing up to $100 \mathrm{mg} / \mathrm{L}$.

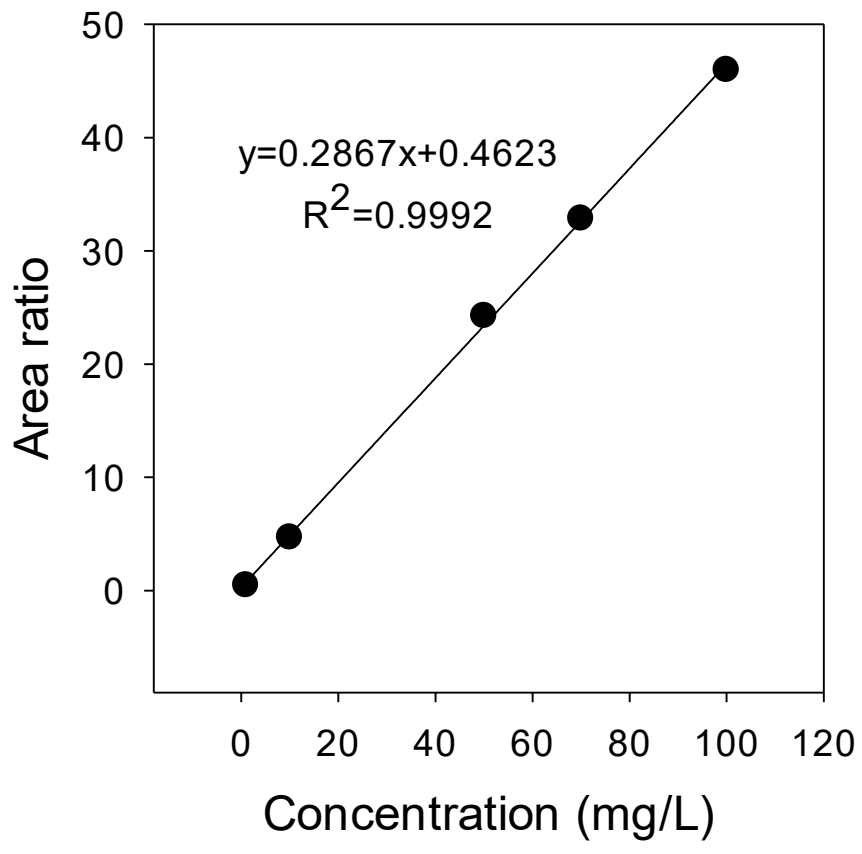

Figure 4.8 Calibration curve for sulfolane $(1-100 \mathrm{mg} / \mathrm{L})$, which was established based on the peak area ratio $A_{\text {sulfolane }} / A_{d 8 \text {-sulfolane. }}$

To further explore the working concentration range of the developed method, another calibration curve was established for aqueous standards consisting of $100-500 \mathrm{mg} / \mathrm{L}$. At a first glance, it appears that the calibration curve in this concentration range is also linear 
$\left(\mathrm{R}^{2}\right.$ value of the linear regression line was 0.9929 - Figure 4.9). However, a closer inspection of the peak area ratio values (Table 4.4) reveals that the MS detector may have been saturated. For example, while the area ratio of the 100, 200 and $300 \mathrm{mg} / \mathrm{L}$ samples proportionally increased as the concentration increased, the area ratio for the 400, 450 and $500 \mathrm{mg} / \mathrm{L}$ samples did not. If the linear response of the detector were to hold, the peak area ratio for the $400 \mathrm{mg} / \mathrm{L}$ would have been 204 (the actual value was 186). Inspection of the peak shape (Figure 10) of the $500 \mathrm{mg} / \mathrm{L}$ sample reveals that the peak is asymmetric, with more sulfolane coming out in the front end (i.e., peak fronting). Peak fronting usually occurs when too much analyte was injected. Based on this result, it is suggested that samples containing more than $100 \mathrm{mg} / \mathrm{L}$ sulfolane should be diluted prior to analysis. Another approach would be to run the GC analysis in the split mode.

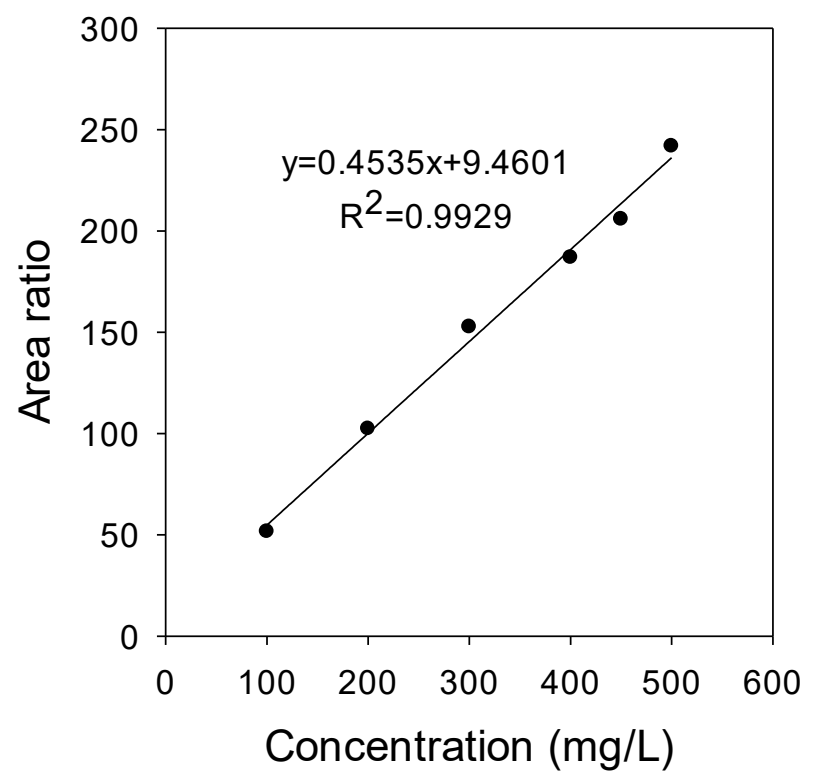

Figure 4.9 Calibration curve for sulfolane $(100-500 \mathrm{mg} / \mathrm{L})$. 


\begin{tabular}{|c|c|}
\hline $\begin{array}{c}\text { Concentration sulfolane } \\
(\mathrm{mg} / \mathrm{L})\end{array}$ & $\mathrm{A}_{\text {sulfolane/ }} \mathrm{A}_{\mathrm{d} 8 \text {-sulfolane }}$ \\
\hline 500 & 241 \\
\hline 450 & 205 \\
\hline 400 & 186 \\
\hline 300 & 152 \\
\hline 200 & 102 \\
\hline 100 & 51 \\
\hline
\end{tabular}

Table 4.4 Asulfolane/Ad8-sulfolane as a function of sulfolane concentration.

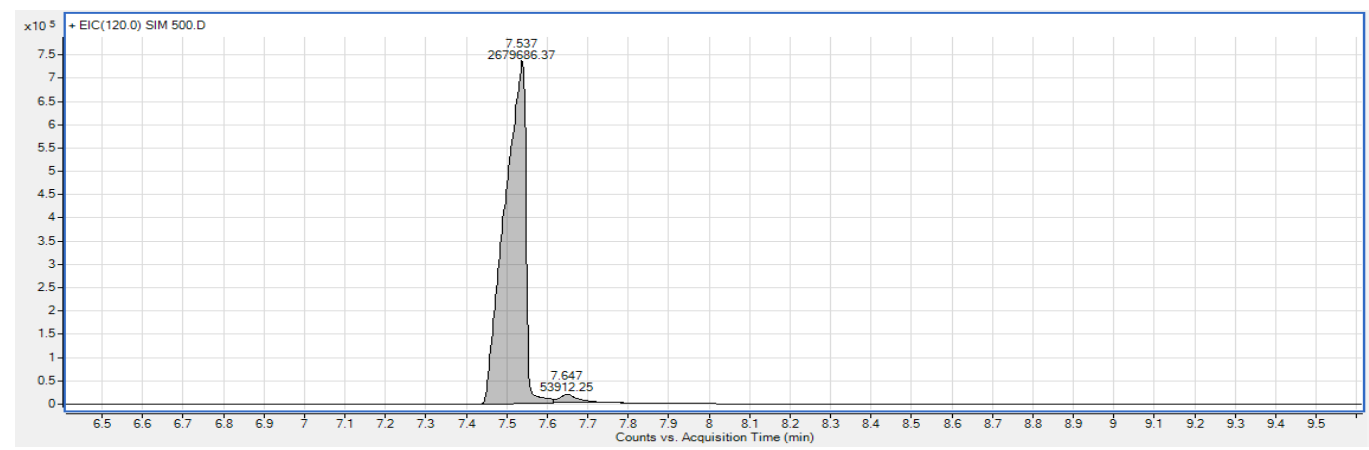

Figure 4.10 Sulfolane peak obtained from analyzing the toluene extract of a $500 \mathrm{mg} / \mathrm{L}$ aqueous sample.

\subsection{Sulfolane adsorption}

\subsubsection{Adsorbent screening}

To quickly gauge the ability of various materials at adsorbing sulfolane, a screening experiment was conducted in which each adsorbent was in contact with an aqueous solution of $10 \mathrm{mg} / \mathrm{L}$ sulfolane for 24 hours. As can be seen from Figure 4.11, sand, zeolite, $\mathrm{Fe}_{2} \mathrm{O}_{3}$, and $\mathrm{Al}_{2} \mathrm{O}_{3}$, were not effective at adsorbing sulfolane even when the concentration of these materials was as high as $100 \mathrm{~g} / \mathrm{L}$. The distribution coefficient values, $\mathrm{K}_{\mathrm{d}}$, were $1.4 \mathrm{~L} / \mathrm{kg}$ for zeolite, $0.3 \mathrm{~L} / \mathrm{kg}$ for sand, $0.1 \mathrm{~L} / \mathrm{kg}$ for $\mathrm{Al}_{2} \mathrm{O}_{3}$, and $0.3 \mathrm{~L} / \mathrm{kg}$ for $\mathrm{Fe}_{2} \mathrm{O}_{3}$. These values are 
comparable to those reported by researchers who investigated the adsorption of sulfolane on clays and soils (Luther, Dudas and Fedorak 1998), (Saint-Fort 2006). The poor sulfolane adsorption capacity of these materials suggests that sulfolane will not be removed to any appreciable extent by coagulation or sand filtration units in conventional drinking water treatment plants.

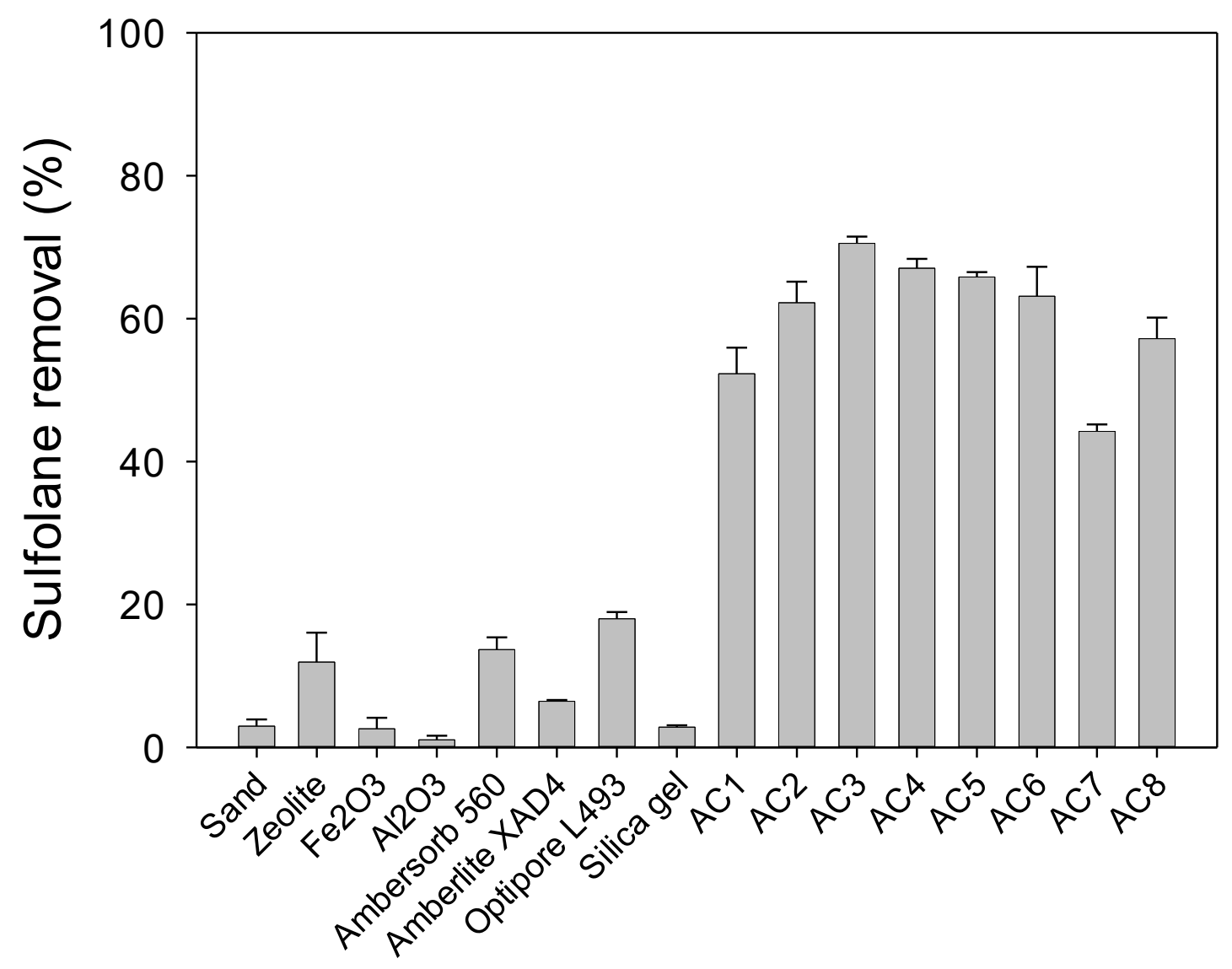

Figure 4.11 Adsorption of sulfolane by various adsorbents. Experimental conditions: contact time $t=24 \mathrm{~h} ;[\text { sulfolane }]_{0}=10 \mathrm{mg} / \mathrm{L} ;\left[\mathrm{NaHCO}_{3}\right]=1 \mathrm{mM} ; \mathrm{pH}$ initial $=7.5 \pm 0.1$; $p H$ final $=7.5 \pm 0.5$; The concentration of activated carbons, Ambersorb 560, Amberlite XAD4, Optipore 490, silica gel was $1 \mathrm{~g} / \mathrm{L}$; the concentration of sand, zeolite, $\mathrm{Fe}_{2} \mathrm{O}_{3}$ and $\mathrm{Al}_{2} \mathrm{O}_{3}$ was $100 \mathrm{~g} / \mathrm{L}$. 
Activated carbons were the best adsorbents of the tested materials. The $\mathrm{K}_{\mathrm{d}}$ of 8 activated carbon materials ranged from 835 to $2475 \mathrm{~L} / \mathrm{kg}$. The adsorption of sulfolane on AC is most likely driven by non-specific interactions (i.e., hydrophobic interaction driven by Van Der Waals forces) because sulfolane is a neutral compound, and also because the sulfone functional group is unlikely to participate in specific interactions with the surface of activated carbon. For the adsorption processes that are driven by non-specific interactions, the adsorption capacity of a material is proportional to its surface area and pore volumes, specifically the volumes of the micropores (Worch 2012), and AC materials with lowest micropore volumes are expected to have the lowest adsorption capacity. Consistent with this hypothesis, $\mathrm{AC} 1, \mathrm{AC} 7$ and $\mathrm{AC} 8$ have the lowest sulfolane adsorption capacity among the tested AC, with $\mathrm{K}_{\mathrm{d}}$ values of $1095 \mathrm{~L} / \mathrm{kg}, 835 \mathrm{~L} / \mathrm{kg}$ and $1337 \mathrm{~L} / \mathrm{kg}$, for A1, AC7 and AC8, respectively (Table 4.5). AC7 and AC8 were made from coal and have the lowest iodine number (Table 3.1). Iodine number is quantified based on the amount of iodine adsorbed (mg) per every gram of activated carbon, and is a measure of the activated carbon's microporosity (Sontheimer, Crittenden and Summers 1988). Iodine number is also often correlated with AC's surface area (Worch 2012). It is worth noting that the iodine number of $\mathrm{AC} 1$ is higher than that of $\mathrm{AC} 8$ (1050 vs. 1000), yet its $\mathrm{K}_{\mathrm{d}}$ value is smaller than that of AC8 $(1095 \mathrm{~L} / \mathrm{kg}$ vs $1337 \mathrm{~L} / \mathrm{kg})$. This suggests that other physical/chemical parameters of activated carbon may control the adsorption of sulfolane. Sulfolane partition coefficient $\mathrm{K}_{\mathrm{d}}$ of $\mathrm{AC} 2, \mathrm{AC} 3, \mathrm{AC} 4, \mathrm{AC} 5$ and $\mathrm{AC} 6$ are relatively comparable, ranging from $1712 \mathrm{~L} / \mathrm{kg}$ to $2475 \mathrm{~L} / \mathrm{kg}$. These materials are made from coconut, and have similar iodine number (Table 3.1). 
Silica gel was previously reported to be capable of selectively recovering sulfolane solvent from a mixture of organic compounds (Deal and Garnett 1976). In the current study, $\mathrm{K}_{\mathrm{d}}$ of silica gel was $28.8 \mathrm{~L} / \mathrm{kg}$, which is approximately 100 times greater than that of sand. However, $\mathrm{K}_{\mathrm{d}}$ of silica gel is 30 to 80 times smaller than those of AC. This result suggests that silica gel may not be an appropriate adsorbent for the removal of sulfolane from water, especially considering the fact that silica gel is significantly more expensive than activated carbon.

The sulfolane adsorption capacity of the polymeric adsorbents AS-560, AL-XAD-4 and OP-L-493 were higher than those of the inorganic adsorbents, but lower than those of AC. The $\mathrm{K}_{\mathrm{d}}$ values of AS-560 was $158 \mathrm{~L} / \mathrm{kg}$, of AL-XAD-4 was $69 \mathrm{~L} / \mathrm{kg}$, and of OP-L-493 was $219.1 \mathrm{~L} / \mathrm{kg}$.

\begin{tabular}{|l|l|l|l|}
\hline \multicolumn{1}{|c|}{ Adsorbents } & $\mathrm{Kd}(\mathrm{L} / \mathrm{kg})$ & \multicolumn{1}{c|}{ Adsorbents } & $\mathrm{Kd}(\mathrm{L} / \mathrm{kg})$ \\
\hline AC1 (coconut based) & 1095 & Ambersorb 560 & 158 \\
\hline AC2 (coconut based) & 1712 & Amberlite XAD4 & 69 \\
\hline AC3 (coconut based) & 2475 & Optipore L493 & 219 \\
\hline AC4 (coconut based) & 2106 & Silica gel & 28.8 \\
\hline AC5 (coconut based) & 1998 & $\mathrm{Fe}_{2} \mathrm{O}_{3}$ & 0.3 \\
\hline AC6 (coconut based) & 1781 & $\mathrm{Al}_{2} \mathrm{O}_{3}$ & 0.1 \\
\hline AC7 (coal based) & 835 & Sand & 0.3 \\
\hline AC8 (coal based) & 1337 & Zeolite & 1.4 \\
\hline
\end{tabular}

Table $4.5 K_{d}$ (at 1 day) of the adsorbents.

\subsubsection{Adsorption kinetics and equilibrium}

While the screening test presented above can be used to quickly compare different adsorbents, this test does not provide a full picture of the adsorbent's adsorption capacity. This is because adsorption equilibrium may not have been attained within the time frame of the test (24 hours). Therefore, a subset of the adsorbents was further tested in a kinetic experiment in which the concentration of sulfolane in the solution in contact with an 
adsorbent was measured over time. The tested materials included AC5 (a coconut-based AC), AC7 and AC8 (coal-based AC), AS-560, AL-XAD4 and OP-L-493. The initial concentration of sulfolane was either $10 \mathrm{mg} / \mathrm{L}$ or $500 \mathrm{mg} / \mathrm{L}$, which represented the high and low contamination scenarios, respectively.

In all the experiments with $\mathrm{AC}$, the concentration of sulfolane in the solution decreased quickly within the first few hours (data for the first hour was not shown in Figures 4.12). The concentration of sulfolane did not change appreciably beyond one day, suggesting that adsorption equilibrium had been attained. Adsorption equilibrium was established within the first 24 hours with AL-XAD4, and within 48h with OP-L-493. In contrast, the concentration of sulfolane in the experiment with AS-560 gradually decreased over several days, with adsorption equilibrium not being established until after 10 days. The slow adsorption of sulfolane on AS-560 is somewhat unexpected given that AS-560 has greater volume of mesopores and macropores than AC (Woodard, Mohr and Nickelsen 2014). In fact, one of the key advantages of AS-560 over AC mentioned in the literature was the adsorption of contaminants on AS-560 is expected to be faster due to the greater volume of mesopores and macropores, as well as the uniform shape of the pores (Woodard, Mohr and Nickelsen 2014). 

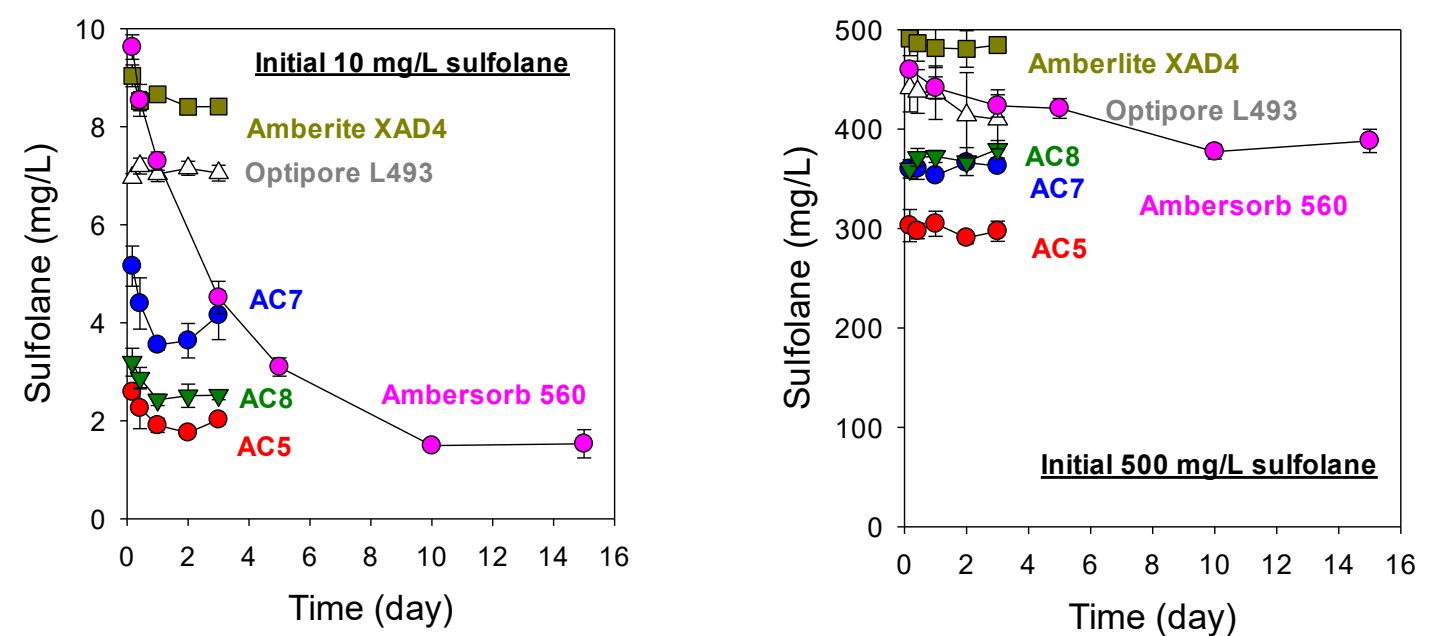

Figure 4.12 Adsorption of sulfolane on AC5, AC7, AC8, AL-XAD4, OP-L-493, and Ambersorb 560. $2 \mathrm{~g} / \mathrm{L}$ adsorbent, $\mathrm{NaHCO}_{3} 1 \mathrm{mM}$, $\mathrm{pH}$ initial $=7.5 \pm 0.1, \mathrm{pH}$ final $=7.5 \pm$ 0.5. Left: [sulfolane $]_{0}=10 \mathrm{mg} / \mathrm{L} ;$ Right: [sulfolane $]_{0}=500 \mathrm{mg} / \mathrm{L}$.

The adsorption of contaminants in aqueous solutions is thought to be consisted of three major steps, starting with the diffusion of the adsorbate from the bulk solution to the surface of the adsorbent, followed by the diffusion of the adsorbate within the adsorbent's pores that are filled with water (i.e., intra-particle diffusion), which is then followed by the surface reaction between the adsorbate and adsorbent (Faust and Aly 1987). The surface reaction can be either physisorption or chemisorption, depending on the nature of the adsorbent and the interaction between the adsorbate and the surface. Of the three steps, the diffusion of the adsorbate in the solution is usually a fast process (Tan and Hameed 2017). Therefore, either the intra-particle diffusion or the adsorption process is the rate-limiting step. Since sulfolane is a low molecular weight compound with a cyclic structure, it is hypothesized that sulfolane can diffuse easily into micropores of the adsorbents. If this is the case, intra-particle diffusion is unlikely the rate-limiting step. The slow adsorption of 
sulfolane on AS-560, therefore, could be attributable to the slow surface reaction between sulfolane and the surface of AS-560.

The mechanism of adsorption can be investigated by modelling adsorption kinetic data using either adsorption reaction models (if surface reaction is the limiting step) or adsorption diffusion models (if intra-particle diffusion is the limiting step). There are many adsorption reaction models, including the Elovich model, the Avrami model, the Thomas model, the Crank model, the pseudo-first order model, and the pseudo-second order model (Largitte and Pasquier 2016), (Wu, Tseng and Juang 2009), (Tan and Hameed 2017), (Qiu, et al. 2009), (Lima, Adebayo and Machado 2015). Of these models, the most popular ones are the pseudo-first and pseudo-second models (Simonin 2016), (Liu and Shen 2018), (Azizian 2004). The pseudo-first order and pseudo-second adsorption models assume that the rate of adsorption is proportional to the number of available sites on the surface. The pseudo-second model also assumes that the surface reaction is chemisorption and not physisorption (Ho and McKay 1999). The pseudo-first and pseudo second models are described via the following equations:

Pseudo-first order model:

$$
\ln \left(q_{e}-q_{t}\right)=\ln q_{e}-k_{1} t
$$

Pseudo-second order model:

$$
\frac{t}{q_{t}}=\frac{t}{q_{e}}+\frac{1}{k_{2} q_{e}^{2}}
$$

In these equations, $q_{t}$ is the amount of solute adsorbed per mass of adsorbent at time $t, q_{e}$ is the amount of solute adsorbed per mass of adsorbent when equilibrium is established, $k_{1}$ is the pseudo-first order rate constant, and $k_{2}$ is the pseudo-second order rate constant. The pseudo-first order model has been successfully used to describe the adsorption of dyestuffs 
(acid brilliant blue, acid violet, Acid Red 91, Basic Blue 9 and Acid Blue 29) and metal ions $\left(\mathrm{Fe}^{3+}, \mathrm{Pb}^{2+}, \mathrm{Zn}^{2+}, \mathrm{Cr}^{6+}, \mathrm{As}^{3+}\right)$ on activated carbon, coir pith carbon, agricultural byproducts, cow dung, inorganic adsorbents (fly ash, $\mathrm{Fe}(\mathrm{III}) / \mathrm{Cr}(\mathrm{III})$ hydroxide, kaolinite) (Onganer and Temur 1998), (Kadirvelu and Namasivayam 2000), (Dai 1994), (Yamuna and Namasivayam 1993), (Kandah 2001), (Manju, Raji and Anirudhan 1998), (Atun 1996), (Tutem, Apak and Ünal 1998), (Y.-S. Ho 2004). The pseudo-second order model has been successfully used to describe the adsorption of organic substances, dyes, metal ions, oils, herbicides on activated carbon, activated clay, agriculture by-products, peat and other inorganic adsorbents (Manohar, Krishnan and Anirudhan 2002), (Aksu and Kabasakal 2004), (Krishnan and Anirudhan 2003), (Malik 2004), (Y.-S. Ho 2006). The pseudo-second order kinetic model was put forward two decades ago (i.e., almost 100 years after the proposal of the pseudo-first order model), and was used to fit the experiment data that previously informed as first order kinetics (Y.-S. Ho 2006). Ho concluded that pseudo second order kinetic showed better correlation to the experiment data. Since then, the equation has become very popular with more than 10000 citations. However, reexamination of the two models indicated that the pseudo second kinetic was unfairly promoted (Simonin, 2016). It was also suggested that even when the experimental data can be fitted with the pseudo-second order model, whether the adsorption is controlled by intraparticle diffusion or surface reaction cannot be unambiguously determined (Tan and Hameed 2017).

The data obtained from the experiment containing $10 \mathrm{mg} / \mathrm{L}$ and $500 \mathrm{mg} / \mathrm{L}$ sulfolane was fitted with both the pseudo-first order and pseudo-second order models (Figure 4.13 and 
4.14 respectively), and the fitting parameters are presented in Table 4.6. The kinetic data of AL-XAD4 was not fitted because this material had low sulfolane adsorption.

\begin{tabular}{|c|c|c|c|c|c|c|c|}
\hline & \multirow[t]{2}{*}{ Adsorbent } & \multicolumn{3}{|c|}{ Pseudo first order } & \multicolumn{3}{|c|}{ Pseudo second order } \\
\hline & & $\mathrm{k}_{1}$ & $\mathrm{q}_{\mathrm{e}}$ & $\mathrm{R}^{2}$ & $\mathrm{k}_{2}$ & $\mathrm{q}_{\mathrm{e}}$ & $\mathrm{R}^{2}$ \\
\hline \multirow{5}{*}{ 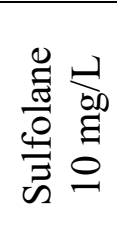 } & AC5 & 6.49 & 1.98 & 0.856 & 18.53 & 4.17 & 0.999 \\
\hline & AC7 & 3.95 & 1.97 & 0.915 & 29.72 & 3.15 & 0.997 \\
\hline & AC8 & 5.93 & 2.01 & 0.859 & 14.35 & 3.89 & 0.999 \\
\hline & OP-L-493 & 20.28 & 1.26 & 0.871 & 45.07 & 1.60 & 0.996 \\
\hline & AS-560 & 0.25 & 4.27 & 0.996 & 0.05 & 5.70 & 0.988 \\
\hline \multirow{5}{*}{ 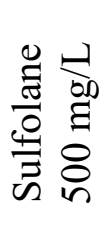 } & AC5 & 2.22 & 31.88 & 0.452 & 0.4 & 112.36 & 0.999 \\
\hline & AC7 & 7.72 & 50.88 & 0.724 & 0.54 & 78.74 & 0.999 \\
\hline & AC8 & 32.46 & 47.13 & 0.990 & na & 71.43 & 0.999 \\
\hline & OP-L-493 & 2.514 & 18.54 & 0.884 & 0.08 & 66.23 & 0.987 \\
\hline & AS-560 & 0.13 & 38.42 & 0.880 & 0.01 & 70.92 & 0.981 \\
\hline
\end{tabular}

Table 4.6 Pseudo first and second order fitting parameters 

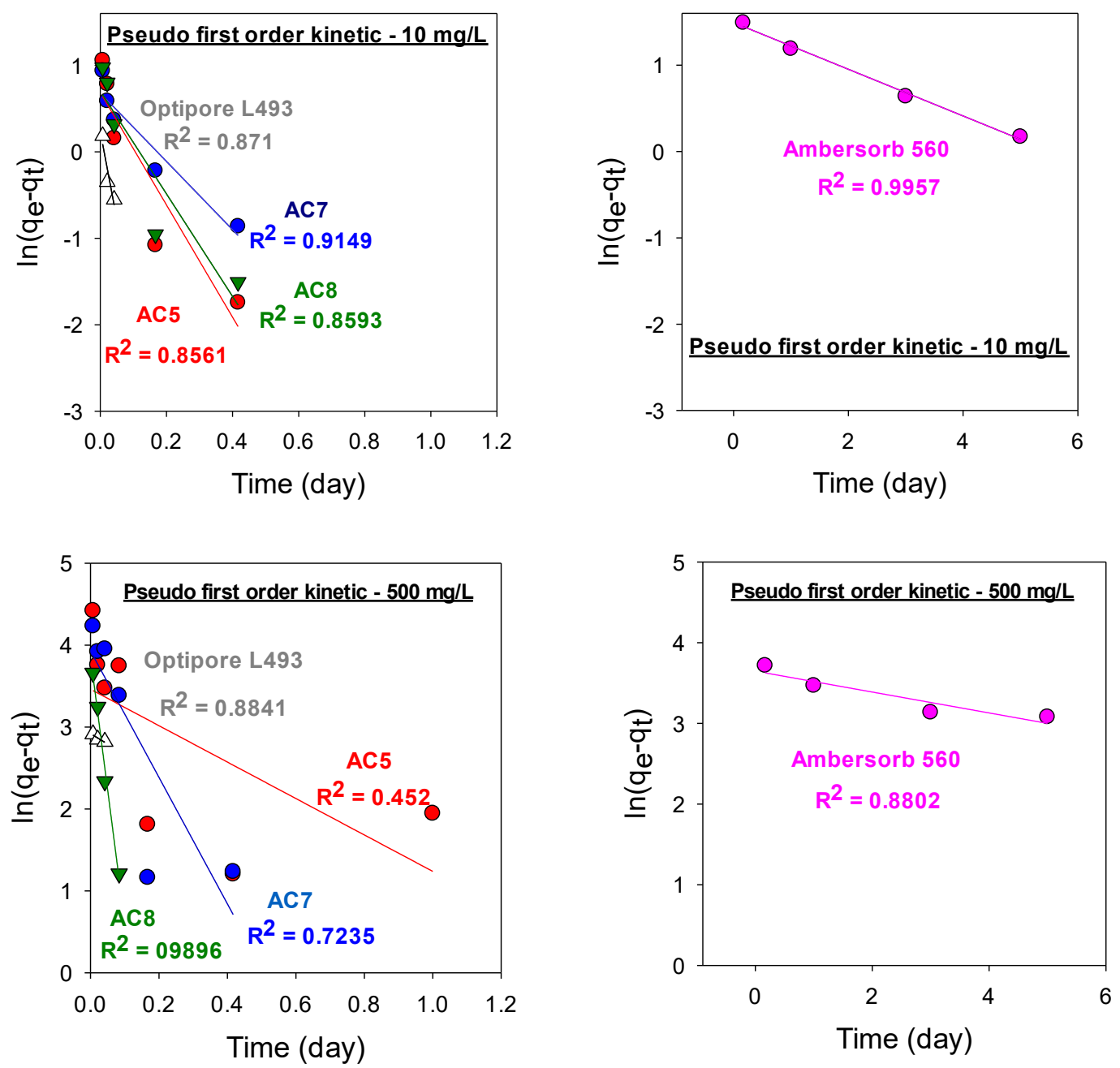

Figure 4.13 Pseudo first order kinetic fittings on AC5, AC7, AC8, Optipore L493, and Ambersorb 560. $\left[\mathrm{NaHCO}_{3}\right]=1 \mathrm{mM}, \mathrm{pH}$ initial $=7.5 \pm 0.1, p H$ final $=7.5 \pm 0.5$, [adsorbent $]=2 \mathrm{~g} / \mathrm{L}$. Top: $[\text { Sulfolane }]_{0}=10 \mathrm{mg} / \mathrm{L}$, bottom: $[\text { Sulfolane }]_{0}=500 \mathrm{mg} / \mathrm{L}$. 

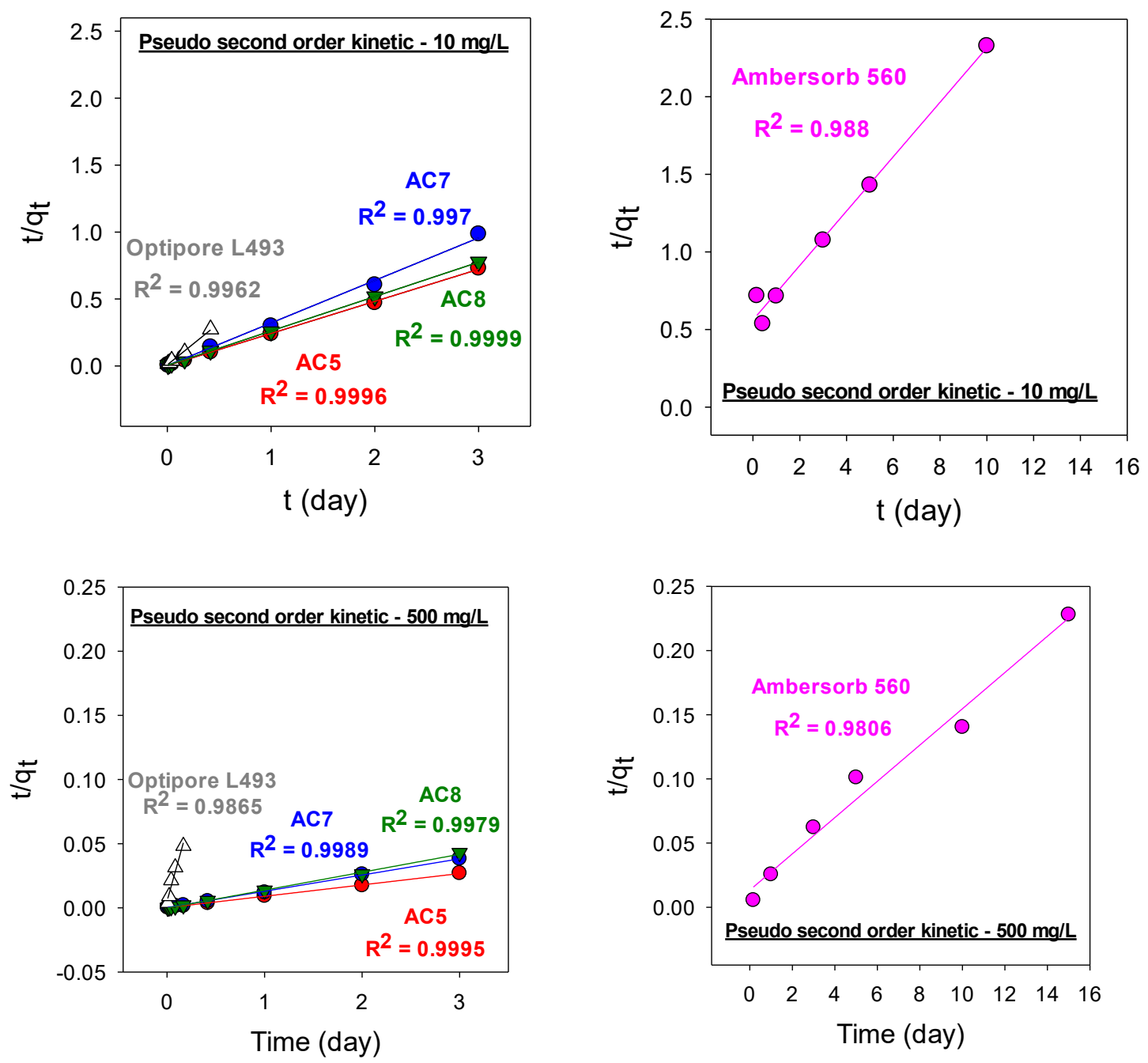

Figure 4.14 Pseudo second order kinetic fittings on AC5, AC7, AC8, Optipore L493 and Ambersorb 560. $\left[\mathrm{NaHCO}_{3}\right]=1 \mathrm{mM}, \mathrm{pH}$ initial $=7.5 \pm 0.1, \mathrm{pH}$ final $=7.5 \pm 0.5$, [adsorbent $]=2 \mathrm{~g} / \mathrm{L}$. Top: $[\text { Sulfolane }]_{0}=10 \mathrm{mg} / \mathrm{L}$, bottom: $[\text { Sulfolane }]_{0}=500 \mathrm{mg} / \mathrm{L}$.

The $\mathrm{R}^{2}$ values of the fittings indicate that the adsorption of sulfolane on all tested materials can be better described the pseudo-second order model except for AS-560 in $10 \mathrm{mg} / \mathrm{L}$ sulfolane solution. At a first glance, therefore, the slow rate of sulfolane adsorption on AS560 could be ascribed to the slow reaction between sulfolane and the surface. As mentioned 
earlier, however, whether the adsorption of sulfolane is diffusion-limited or reactionlimited cannot be conclusively determined based on the pseudo-second order fitting.

To explore if the adsorption of sulfolane can be controlled by intra-particle diffusion, the kinetic data was fitted using the Weber-Morris Intra-particle diffusion model, which is described by the following equation:

$$
q=k_{i d} \sqrt{t}+\mathrm{B}
$$

In this equation, $\mathrm{k}_{\mathrm{id}}$ is the intra particle diffusion rate constant and $\mathrm{B}$ is the initial adsorption $(\mathrm{mg} / \mathrm{g})$. As can be seen from Figure 4.15, the Weber-Morris Intra-particle diffusion model did not provide a perfect fitting $\left(\mathrm{R}^{2}=0.95\right)$. More complex models, such as the homogeneous solid diffusion model or the double-exponent model, should be explored in the future to gain further insights into the mechanism of sulfolane adsorption on AS-560. 

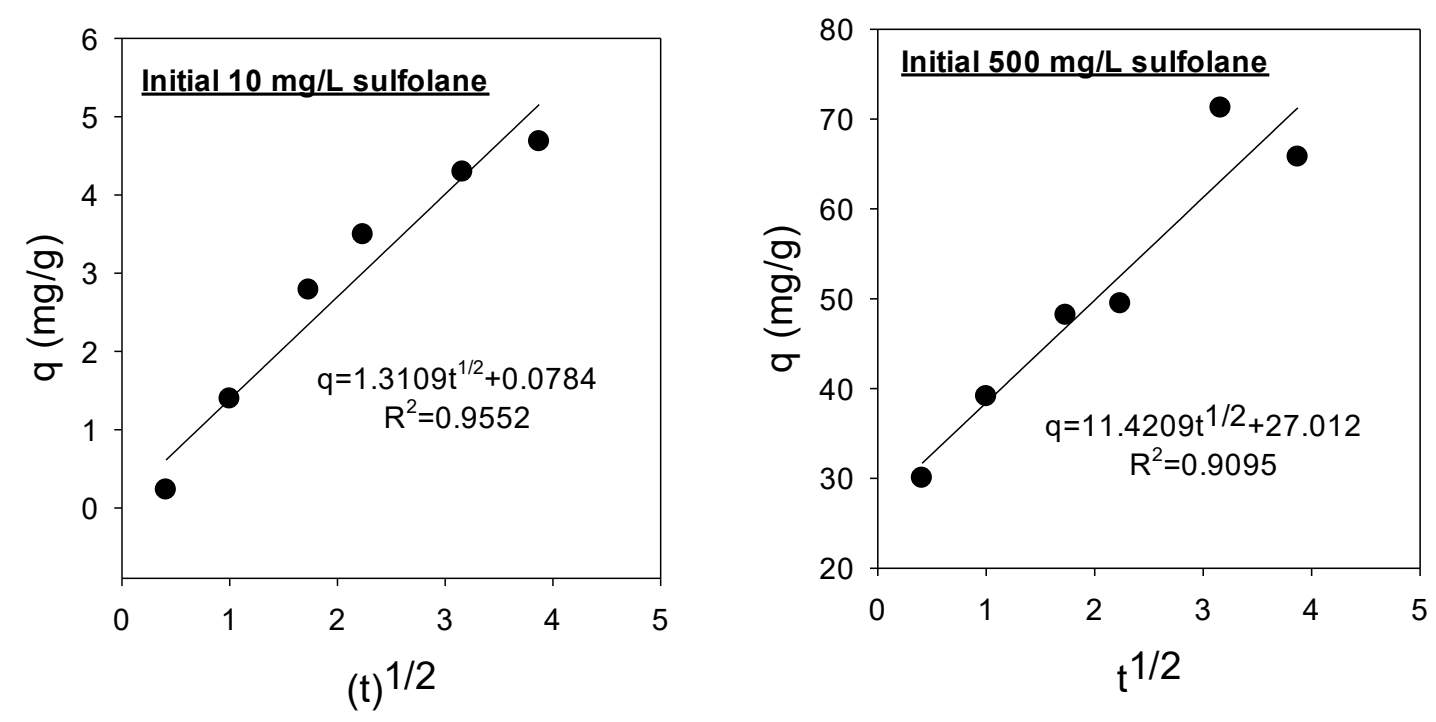

Figure 4.15 Weber-Morris model fitting of sulfolane adsorption on Ambersorb 560. $[\text { Sulfolane }]_{0}=10$ and $500 \mathrm{mg} / \mathrm{L},\left[\mathrm{NaHCO}_{3}\right]=1 \mathrm{mM}, \mathrm{pH}$ initial $=7.5 \pm 0.1, \mathrm{pH}$ final $=7.5 \pm 0.5$, $[A S-560]=2 \mathrm{~g} /$ L. Left: $[\text { Sulfolane }]_{0}=10$ and right $\left[\right.$ Sulfolane ${ }_{0}=500$

The adsorbent screening test reveals that AC materials outperformed AS-560. However, the kinetic experiment suggested that after equilibrium had been established the adsorption capacity of AS-560 was comparable to those of AC. In the experiment with higher initial sulfolane concentration (i.e., $500 \mathrm{mg} / \mathrm{L}$ ), $\mathrm{K}_{\mathrm{d}}$ of AS-560 was $190 \mathrm{~L} / \mathrm{kg}$, compared with $\mathrm{K}_{\mathrm{d}}=$ 390, 240, $210 \mathrm{~L} / \mathrm{kg}$ for AC5, AC7 and AC8 respectively. As such, for the high contamination scenario, AC outperformed AS-560. In contrast, in the solution with an initial sulfolane of $10 \mathrm{mg} / \mathrm{L}, \mathrm{K}_{\mathrm{d}}$ of AS-560 was $2564 \mathrm{~L} / \mathrm{kg}$, compared with $\mathrm{K}_{\mathrm{d}}=2192,940$, $1610 \mathrm{~L} / \mathrm{kg}$ for $\mathrm{AC} 5, \mathrm{AC} 7$ and $\mathrm{AC} 8$ respectively. This suggests that for the low contamination scenario, the adsorption capacity of AS-560 was higher than that of AC5, namely one of the best performed materials. Note that the slow rate of adsorption on AS560 needs to be considered in the design of a AS-560-based treatment system. 


\subsubsection{Adsorption isotherms}

The results presented in the previous section suggest that the initial concentration of sulfolane has an influence on the relative performance of each material. To further evaluate the performance of $\mathrm{AC5}, \mathrm{AC} 7, \mathrm{AC} 8, \mathrm{AS}-560$, and OP-L-493, adsorption isotherm experiments were conducted in which the initial concentration of sulfolane spanned from $1 \mathrm{mg} / \mathrm{L}$ to $500 \mathrm{mg} / \mathrm{L}$. The concentration of sulfolane remained in the solution was measured after adsorption equilibrium has been reached (i.e., after 24 hours in the experiments with AC, 2 days in the experiments with OP-L-493, and after 10 days in the experiments with AS-560). As can be seen from Figure 4.16 - Right, the adsorption capacity $q_{e}$ of OP-L-493 was $4-10$ times smaller than those of the other materials, while $q_{e}$ of AS-560 is comparable with those of AC5, AC7 and AC8, while $q_{e}$. Woodard et al reported that the capacity of AS560 at adsorbing 1,4 dioxane, namely a molecule of similar size, shape, and hydrophobicity as sulfolane, is greater than that of activated carbon by as much as 10 times (Woodard, Mohr and Nickelsen 2014). The difference between the affinity of sulfolane and 1,4 dioxane to AS-560 could be due to the difference in the molecular structure of the two compounds: 1,4 dioxane with two ether groups residing symmetrically in the molecular structure is a nonpolar compounds, whereas sulfolane is more polar because of the sulfone group resides on one side of the structure. 

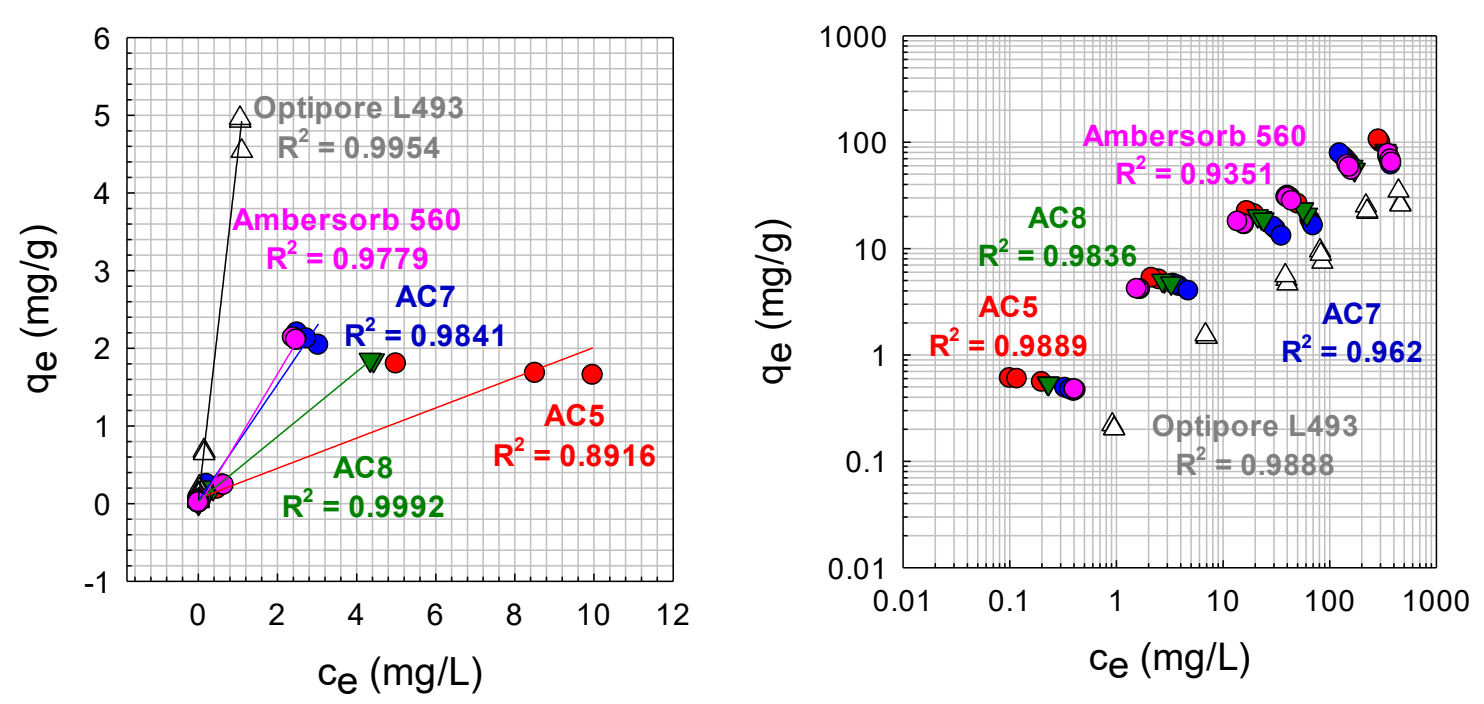

Figure 4.16 Adsorption isotherms on AC5, AC7, AC8, Optipore L493, Ambersorb 560. $[\text { Sulfolane }]_{0}=1-500 \mathrm{mg} / \mathrm{L},\left[\mathrm{NaHCO}_{3}\right]=1 \mathrm{mM}, \mathrm{pH}$ initial $=7.5 \pm 0.1, \mathrm{pH}$ final $=7.5 \pm$ 0.5, [adsorbent] $=2 \mathrm{~g} / \mathrm{L}$, equilibrium time. Left: Langmuir Isotherm; Right: Freundlich Isotherm

Adsorption isotherms can be described by various models, but the most commonly used ones are Langmuir and Freundlich isotherms. Whereas Langmuir isotherm model was developed based on the assumption that all adsorptive sites on the adsorbent are similar, Freundlich isotherm model was developed based on the assumption that the adsorptive sites are not identical. The Langmuir and Freundlich isotherms obey the following formula:

Langmuir isotherm:

$$
q_{e}=\frac{q_{m} K C_{e}}{1+K C_{e}} \quad\left(\text { the linearized form: } \frac{1}{q_{e}}=\frac{1}{q_{m} K} \frac{1}{C_{e}}+\frac{1}{q_{m}}\right)
$$

Freundlich isotherm:

$$
q_{e}=K C_{e}^{1 / n} \quad\left(\text { the linearized form: } \log q_{e}=\log K+\left(\frac{1}{n}\right) \log C_{e}\right)
$$


In the above formulas, $\mathrm{q}_{\mathrm{m}}$ is the maximum adsorption capacity of the adsorbent $(\mathrm{mg} / \mathrm{g})$, and $\mathrm{q}_{\mathrm{e}}$ is the adsorption capacity in equilibrium with the concentration of the adsorbate in the solution $\mathrm{C}_{\mathrm{e}} \mathrm{K}$ in the Langmuir isotherm represents the affinity of adsorbate to the adsorptive site; since all the sites in the Langmuir model are identical, the affinity can be represented by a single $\mathrm{K}$ value. In the Freundlich model, since the sites have different binding energy, the affinity of the adsorbate to the sites is described by the pre-exponent term $\mathrm{K}$ and the exponent term $1 / \mathrm{n}$, which represent the average binding constant value and the distribution of site energy.

\begin{tabular}{|c|c|c|c|c|c|c|}
\hline \multirow{2}{*}{ Adsorbent } & \multicolumn{3}{|c|}{ Langmuir isotherm } & \multicolumn{3}{c|}{ Freundlich isotherm } \\
\cline { 2 - 7 } & $\mathrm{q}_{\mathrm{m}}$ & $\mathrm{K}$ & $\mathrm{R}^{2}$ & $\mathrm{n}$ & $\mathrm{K}$ & $\mathrm{R}^{2}$ \\
\hline AC5 & 14.9 & 0.35 & 0.892 & 1.50 & 2.50 & 0.989 \\
\hline AC7 & 28.49 & 0.05 & 0.984 & 1.38 & 1.18 & 0.962 \\
\hline AC8 & 32.36 & 0.07 & 0.999 & 1.49 & 1.83 & 0.984 \\
\hline OP-L-493 & 22.03 & 0.01 & 0.995 & 1.25 & 0.26 & 0.989 \\
\hline AS-560 & $\mathrm{n} / \mathrm{a}$ & $\mathrm{n} / \mathrm{a}$ & - & 1.43 & 1.74 & 0.935 \\
\hline
\end{tabular}

\section{Table 4.7 Langmuir and Freundlich isotherm fitting parameters}

The isotherms obtained for AC5, AC7, AC8, AS-560, and OP-L-493 suggest that the adsorption of sulfolane on these materials might obey both Langmuir and Freundlich isotherms. The isotherms parameters were presented in Table 4.7. The Freundlich isotherms presented in Figure 4.16 - Right were plotted on a log-log scale; if the isotherms were to obey the Freundlich isotherm model, $\mathrm{C}_{\mathrm{e}}$ would have been linearly proportional to $\mathrm{q}_{\mathrm{e}}$ on this plot. The $\mathrm{R}^{2}$ values of the linear regression of these log-log plots were 0.935109889, which confirm that the adsorption somewhat followed the Freundlich adsorption behavior. The Langmuir isotherm fittings also obtained high $\mathrm{R}^{2}$ from $0.8916-0.9992$, which reveals that the data followed Langmuir isotherm as well. The interpretation for this 
behavior could be in part due to the wide $\mathrm{C}_{\mathrm{e}}$ concentration range, which spanned over three orders of magnitude. Attempts have been made to fit the experimental data with other types of three parameter isotherm, Redlich-Peterson isotherm, Dubinin-Astakhov isotherm, and others. However, none of these isotherms can satisfactorily describe the experimental data.

\subsubsection{Effect of water quality on sulfolane adsorption}

All the adsorption results presented above were obtained from the experiments which employed solutions consisting of only $\mathrm{NaHCO}_{3}$ as the background electrolyte. To examine the effect of the solutes typically present in natural waters (i.e., common cations and anions, dissolved organic carbon) on the adsorption of sulfolane, adsorption experiments were conducted with two types of groundwater GW1 and GW2. Both groundwater samples were collected in the area located in the vicinity of a sulfolane plume. GW1 consists of 5 times more TOC than GW2 (3.2 mg/L vs. $0.9 \mathrm{mg} / \mathrm{L})$, and also contains significantly more hardness and other anions. Sulfolane was spiked into GW1 and GW2 such that the initial concentration ranged from 1 to $500 \mathrm{mg} / \mathrm{L}$. The adsorption isotherms obtained from these experiments reveal that the presence of the background solutes in GW2 did not appreciably affect the adsorption of sulfolane on AC5 and AS-560, while the adsorption was slightly suppressed in GW1. This diminished adsorption of sulfolane in GW1 could be attributable to competitive sorption between sulfolane and the background organic carbon or ions. This result is in contrary to the result reported by Diaz (Diaz 2015), who concluded that the presence of natural organic matter may enhance sulfolane adsorption. However, it is noted that the model organic matter in the study by Diaz was tannic acid, which is not a good representation of the organic matters present in natural waters. 

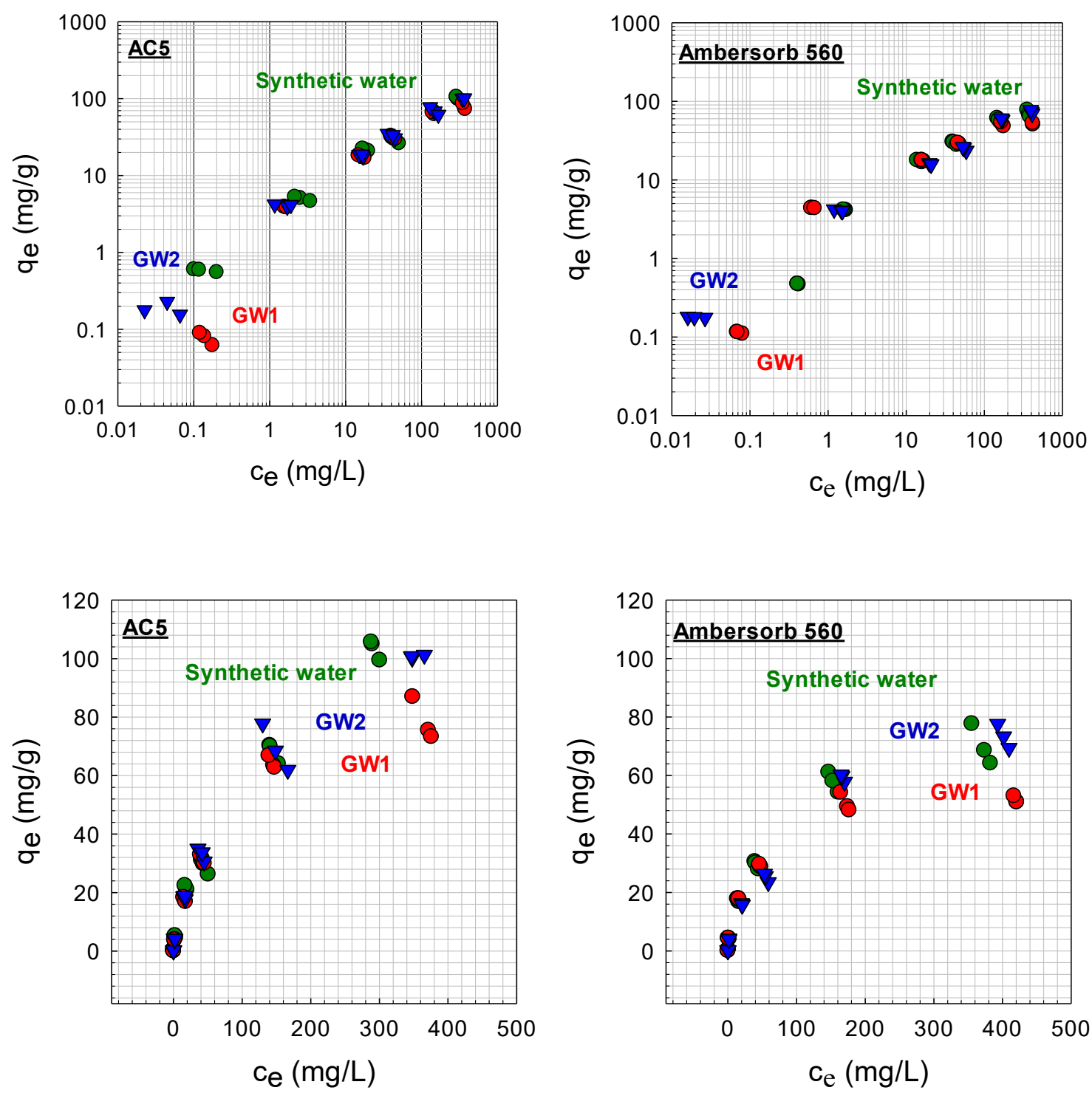

Figure 4.17 Sulfolane adsorption isotherms on AC5 and Ambersorb 560. [Sulfolane] $0=1$ $500 \mathrm{mg} / \mathrm{L}, \mathrm{pH}$ initial $=8 \pm 0.2, \mathrm{pH}$ final $=8 \pm 0.5$, [adsorbent] $=2 \mathrm{~g} / \mathrm{L}$, equilibrium time. The data is presented on both normal scale and log-log scale such that the difference at low and high concentrations can be discerned.

To further investigate whether the inorganic ions or organic carbon plays a dominant role in the reduction of sulfolane adsorption, the isotherm experiments were repeated with 
simulated water samples that contained major ions in GW1. The ion-containing water sample 1 (ICW1) consisted of $3 \mathrm{mM} \mathrm{CaCl}_{2}$ and $1.5 \mathrm{mM} \mathrm{MgSO}_{4}$, while the ions containing water samples 2 (ICW2) carried $1 \mathrm{mM} \mathrm{NaHCO}_{3}, 3 \mathrm{mM} \mathrm{NaCl}$ and $5 \mathrm{mM} \mathrm{K}_{2} \mathrm{SO}_{4}$.
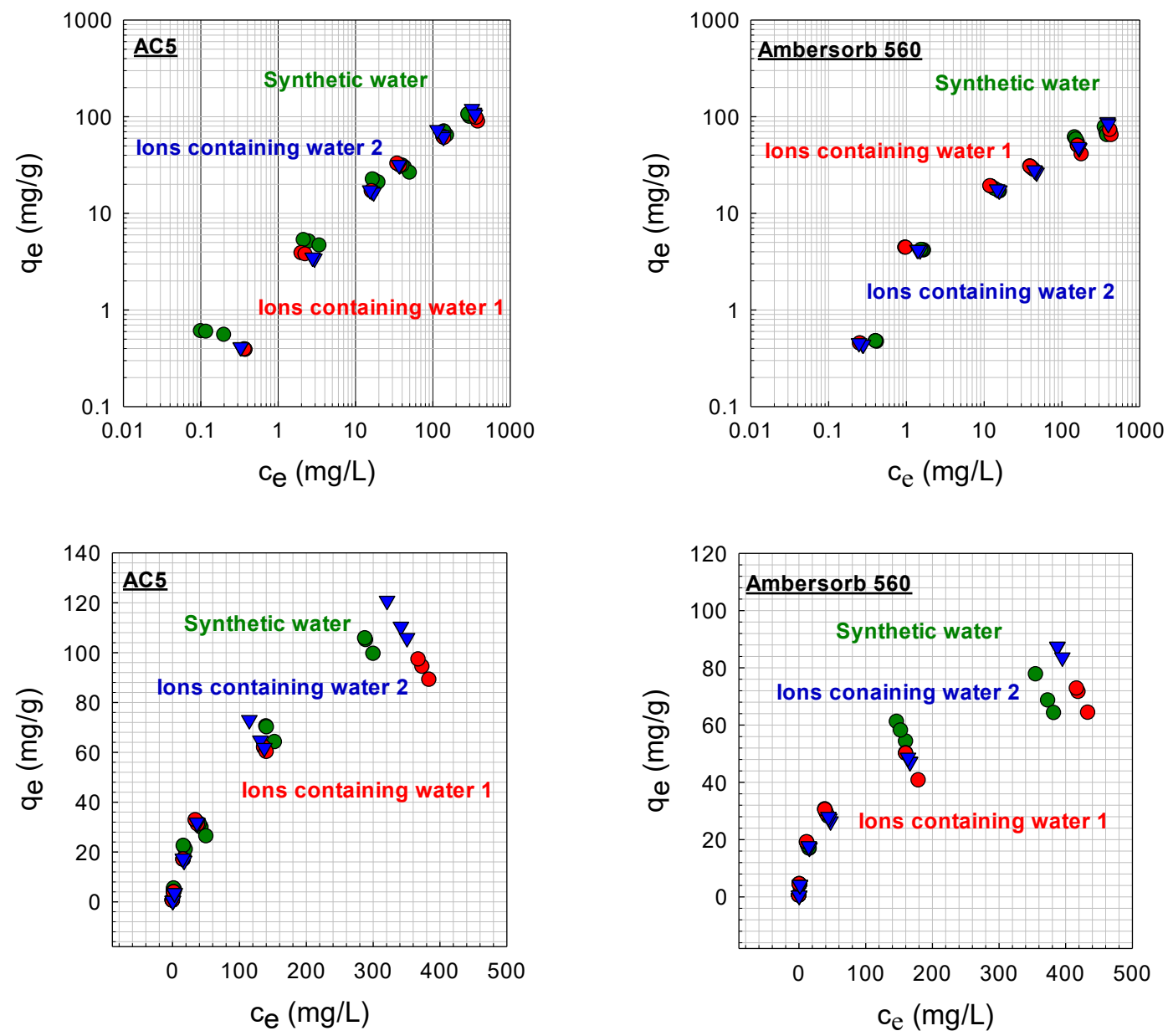

Figure 4.18 Sulfolane adsorption isotherms on AC5 and Ambersorb 560. [Sulfolane] $0=1$ $500 \mathrm{mg} / \mathrm{L}$, for ICW1: $\mathrm{pH}$ initial $=6 \pm 0.2, \mathrm{pH}$ final $=7 \pm 0.5$, for ICW2: $\mathrm{pH}$ initial $=7 \pm$ 0.2 , $p H$ final $=7.5 \pm 0.5$, [adsorbent $]=2 \mathrm{~g} / L$, equilibrium time. The data is presented on both normal scale and log-log scale such that the difference at low and high concentrations can be discerned. 
The above Figure 4.18 showed that sulfolane adsorption capacity was not diminished in ICW2 on both AC5 and AS 560. Sulfolane adsorption slightly decreased in ICW1. This suggested that the presence of the monovalent ions (i.e. $\mathrm{Na}^{+}, \mathrm{K}^{+}, \mathrm{Cl}^{-}$) and divalent anion

(i.e. $\mathrm{SO}_{4}{ }^{2-}$ ) did not affect the adsorption capacity, while the divalent cations (i.e. $\mathrm{Ca}^{2+}$ and $\mathrm{Mg}^{2+}$ ) lowered the adsorption of sulfolane. However, the influence of the divalent cations on the adsorption was not as noticeable as in the authentic GW1. Thus, it is concluded that both organic carbons and divalent cations negatively influenced the sulfolane adsorption.

\subsubsection{Effect of the co-contaminants DIPA and benzene on sulfolane adsorption}

DIPA is one of the major solutes used with sulfolane for the extraction of sour gases from natural gas. DIPA is typically found in the $\mathrm{mg} / \mathrm{L}$ range at sites contaminated with sulfolane. DIPA is an amine with a $\mathrm{pK}_{\mathrm{a}}=8.9$. The acid-base equilibrium of DIPA is represented by the following reaction:

\section{$\mathrm{CH}_{3} \mathrm{CH}(\mathrm{OH}) \mathrm{CH}_{2} \mathrm{NH}_{2}^{+} \mathrm{CH}_{2} \mathrm{CH}(\mathrm{OH}) \mathrm{CH}_{3}<=\mathrm{CH}_{3} \mathrm{CH}(\mathrm{OH}) \mathrm{CH}_{2} \mathrm{NHCH}_{2} \mathrm{CH}(\mathrm{OH}) \mathrm{CH}_{3}+\mathrm{H}^{+}$}

The competitive adsorption between DIPA and sulfolane on AC5 and AS-560 was investigated at $\mathrm{pH}=7.5$ and $\mathrm{pH}=9.9$. At $\mathrm{pH}=7.5,96 \%$ of DIPA molecules in the solution are positively charged, whereas at $\mathrm{pH}=9.9$, only $10 \%$ of DIPA molecules are positively charged. As the adsorption on AC5 and AS-560 is expected to be driven by non-specific interaction forces, charged compounds will have lower affinity than neutral compounds.

The presence of $[\mathrm{DIPA}]_{0}=50 \mathrm{mg} / \mathrm{L}$ diminished the adsorption of sulfolane on both AC5 and AS-560, with the effect of DIPA being more pronounced at higher initial sulfolane concentration (Figures 4.17). This observation can be explained as follows: as [sulfolane $]_{0}$ increased, more DIPA and sulfolane molecules in the solution competed for sorptive sites, resulting in a greater competitive sorption effect and a greater suppression of sulfolane 
adsorption compared with the adsorption in the DIPA-free experiment. In the experiment with $\mathrm{AC5}$, the solution $\mathrm{pH}$ has a minimal effect on the adsorption of sulfolane (Figure 4.19). This is somewhat surprising considering that more DIPA was adsorbed at $\mathrm{pH} 9.9$ than at $\mathrm{pH} 7.5$ (Figure 4.19). In contrast, the effect of competitive sorption between sulfolane and DIPA on AS-560 was more pronounced at $\mathrm{pH} 9.9$ than at $\mathrm{pH} 7.5$, as was evidenced by a greater suppression of sulfolane adsorption at $\mathrm{pH} 9.9$ (Figure 4.19). This is consistent with the fact that more DIPA was adsorbed on AS-560 at $\mathrm{pH} 9.9$ than at $\mathrm{pH}$ 7.5. In both experiments with AC5 and AS-560, the fraction of DIPA adsorbed decreased as the initial concentration of sulfolane increased (Figure 4.19). 

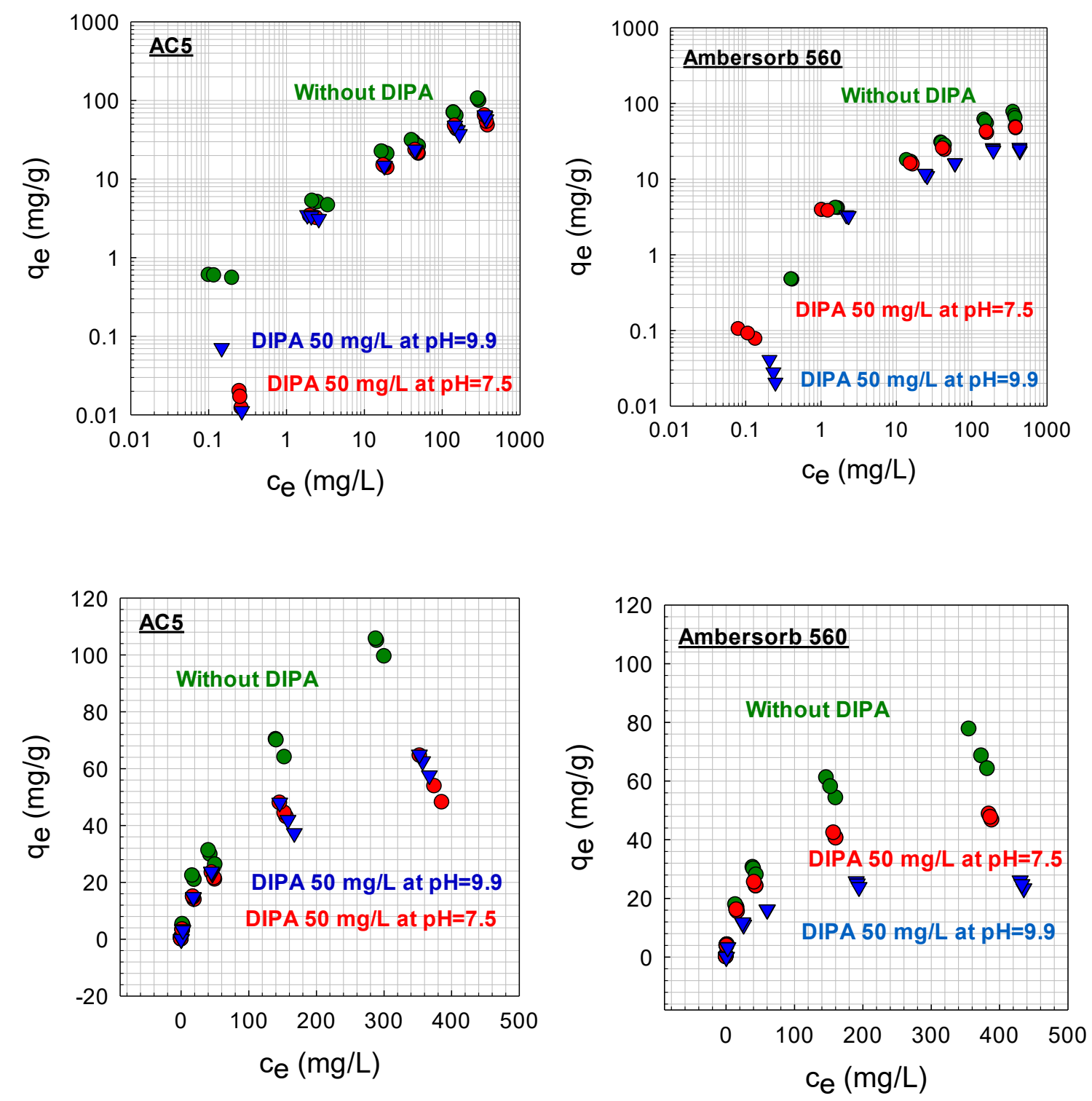

Figure 4.19 Effect of DIPA on sulfolane adsorption. The data is presented on both normal scale and log-log scale such that the difference at low and high concentrations can be discerned. $[\text { Sulfolane }]_{0}=1-500 \mathrm{mg} / \mathrm{L},[D I P A]_{0}=50 \mathrm{mg} / \mathrm{L},\left[\mathrm{NaHCO}_{3}\right]=1 \mathrm{mM}$, [adsorbent] $=2, p H$ initial $=7.5$ and 9.9, $p H$ final $=7.5 \pm 0.2$ and 9.7 \pm 0.2 . Left: $A C 5$, right: ambersorb 560. 


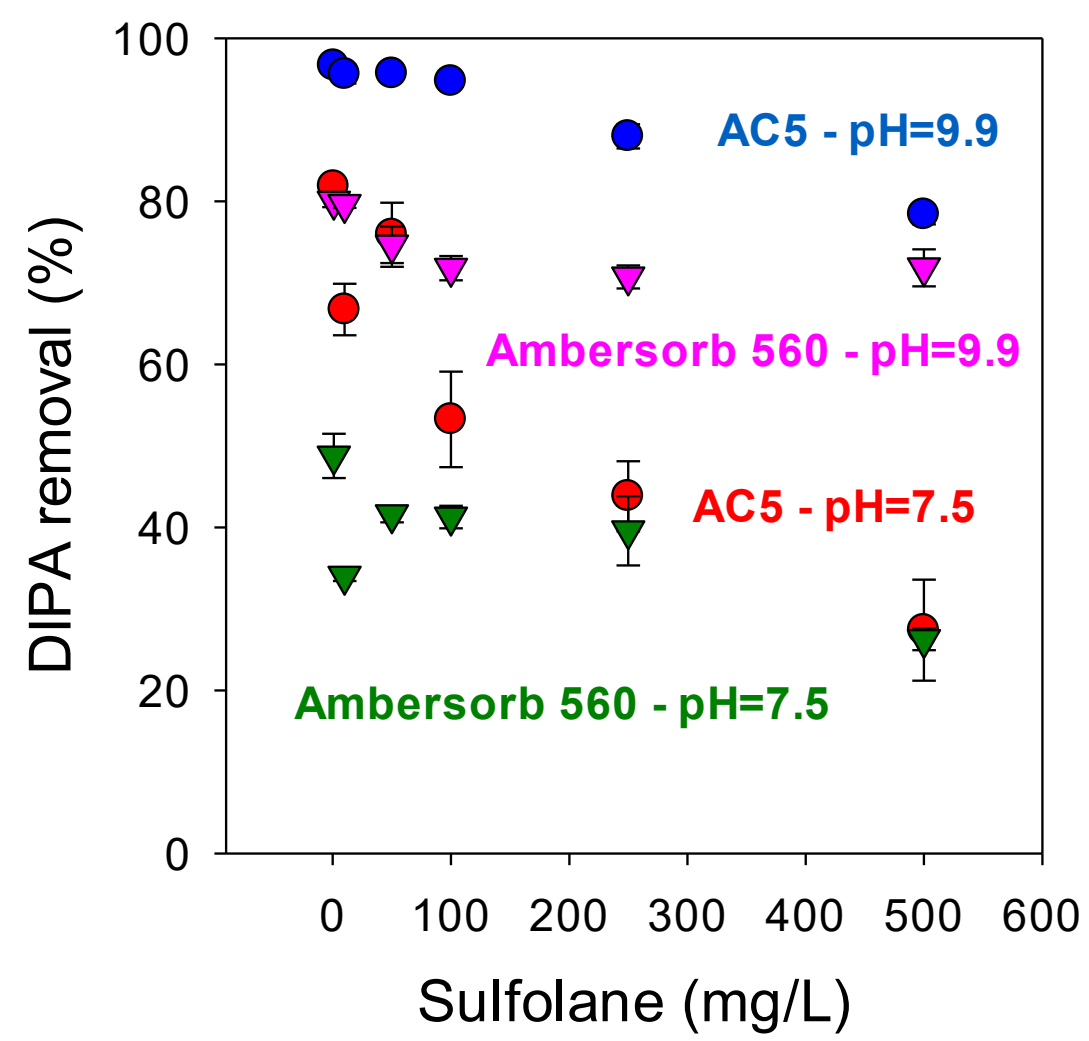

Figure 4. 20 DIPA removal. [Sulfolane $]_{0}=1-500 \mathrm{mg} / \mathrm{L},[D I P A]_{0}=50 \mathrm{mg} / \mathrm{L},\left[\mathrm{NaHCO}_{3}\right]$ $=1 \mathrm{mM}$, [adsorbent $]=2 \mathrm{~g} / \mathrm{L}, \mathrm{pH}$ initial $=7.5$ and 9.9, $\mathrm{pH}$ final $=7.5 \pm 0.2$ and $9.7 \pm 0.2$.

Benzene is another co-contaminant frequently found at sulfolane-contaminated site. The competitive sorption between benzene and sulfolane was investigated employing solutions containing [benzene $]_{0}=78 \mathrm{mg} / \mathrm{L}$ (i.e., $1 \mathrm{mM}$ ). In this experiment, essentially $100 \%$ of benzene was removed from the solution by AC5 and AS-560. The presence of benzene diminished the adsorption of sulfolane on both AC5 and AS-560, although the effect of benzene is less pronounced than DIPA (Figure 4.20). In the competitive sorption experiments described above, the initial concentration of benzene was higher than that of DIPA ( $1 \mathrm{mM}$ benzene vs. $0.37 \mathrm{mM}$ DIPA). The fact that DIPA has a greater influence than benzene on sulfolane adsorption suggests that DIPA and sulfolane might be competing for 
the same adsorptive sites, whereas benzene, an aromatic compound with a greater hydrophobicity $\left(\log K_{\mathrm{ow}}=2.13\right)$, has affinity to sites that are less likely to adsorb sulfolane. The results presented above suggest that less sulfolane adsorption can be expected in the presence of DIPA and benzene. However, the results also suggest DIPA and benzene can also be removed from contaminated water by adsorption.
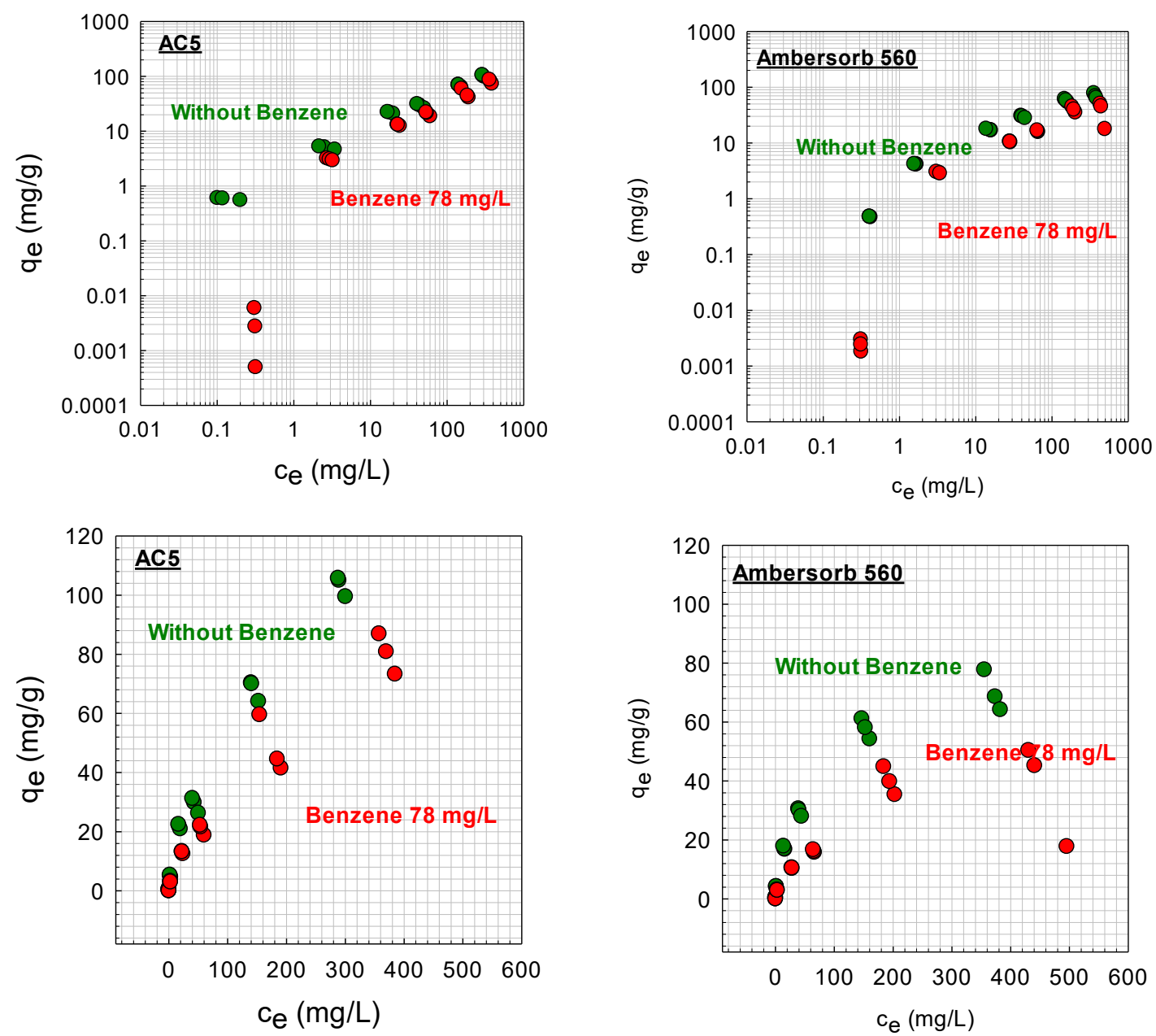

Figure 4.21 Effect of Benzene on sulfolane adsorption. The data is presented on both normal scale and log-log scale such that the difference at low and high concentrations can be discerned. [Sulfolane $]_{0}=1-500 \mathrm{mg} / \mathrm{L},[\text { Benzene }]_{0}=78 \mathrm{mg} / \mathrm{L},\left[\mathrm{NaHCO}_{3}\right]=1 \mathrm{mM}$, [adsorbent $]=2 \mathrm{~g} / \mathrm{L}, \mathrm{pH}$ initial $=7.5 \pm 0.1, \mathrm{pH}$ final $=7.5 \pm 0.5$. Left: AC5, right: Ambersorb 560. 


\section{Conclusion}

This research focused on developing a simple, robust, and sensitive method for the analysis of sulfolane by GC/MS, as well as investigating the adsorption of sulfolane on various adsorbents. Key research tests and their findings are summarized as bellow:

- Sulfolane in aqueous samples was extracted with toluene, and the toluene extract was analyzed for sulfolane by GC/MS. $\mathrm{d}_{8}$-sulfolane was employed as an internal

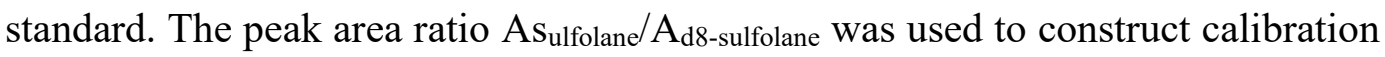
curves. The whole method detection and quantitation limits were 0.03 and 0.07 $\mathrm{mg} / \mathrm{L}$, respectively. The method works for a large range of sulfolane concentration from $\mu \mathrm{g} / \mathrm{L}$ to up to $100 \mathrm{mg} / \mathrm{L}$.

- The screening test suggested that sand, zeolite, $\mathrm{Fe}_{2} \mathrm{O}_{3}$ and $\mathrm{Al}_{2} \mathrm{O}_{3}$ had low sulfolane adsorption capacity. Therefore, the removal of sulfolane in coagulation and filtration units of conventional drinking water treatment plants is not expected to occur appreciably. Future research should examine whether sulfolane can be destroyed by chlorine to assess whether chlorine disinfection can be used to remove sulfolane. The screening test also revealed that the adsorption capacity of polymeric adsorbents was higher than that of the inorganic adsorbents, but were lower than that of activated carbon.

- Adsorption kinetic tests revealed that AS-560 had slow adsorption rate compared to that of ACs and OP L493. However, at low concentration scenario (i.e., 10 $\mathrm{mg} / \mathrm{L}$ ), AS-560 was considered as the best performed adsorbent. Reaction control model (i.e., Pseudo second order kinetic) showed better correlation than diffusion control kinetic model (i.e., Weber-Morris). However, more detailed models should 
be investigated to gain further insights into the sulfolane adsorption mechanism on AS-560.

- Adsorption isotherms with initial concentration spanned $1-500 \mathrm{mg} / \mathrm{L}$ confirmed that adsorption capacity of OP L493 was lower than other materials and AS 560 adsorption capacity was comparable to ACs. The isotherms could be described by either Langmuir or Freundlich model.

- Sulfolane adsorption capacity of AC5 and AS 560 was slightly suppressed in GW1 which contains more ions and dissolved organic carbon..

- The co-contamination DIPA diminished sulfolane adsorption on both AC5 and AS560, at both $\mathrm{pH} 7.5$ and 9.9. The competition effect was more pronounced on AS560 , at higher sulfolane concentration, and at $\mathrm{pH}=9.9$. The other co-contamination benzene also diminished sulfolane adsorption on AC5 and AS-560 but at lower extent than DIPA. 


\section{References}

Aksu, Z., and E. Kabasakal. 2004. "Batch adsorption of 2,4-dichlorophenoxy-acetic acid (2,4-D) from aqueous solution by granular activated carbon." Separation and Purification Technology 223-240.

Andersen, M.E., R.A. Jones, R.G. Mehl, T.A. Hill, L. Kurlansik, and L.J. Jr. Jenkins. 1997. "he inhalation toxicity of sulfolane (tetrahydrothiophene-1,1-dioxide)." Toxicology and Applied Pharmacology 463-472.

Andersen, M.E., RA. Jones, L. Kurlansik, R.G. Mehl, and L.J. Jr. Jenkins. 1976. "Sulfolane-induced convulsions in rodents." Res Commun Chem Pathol Pharmacol $571-580$

Atun, G., Sismanogli, T. 1996. "Adsorption of 4,4'-iso propylidene diphenol and diphenylolpropane 4,4'dioxyaceticacid from aqueous solution on kaolinite." Journal of Environmental Science and Health Part A-Environmental Science and Engineering \& Toxic and Hazardous Substance Control 2055-2069.

Azizian, Saeid. 2004. "Kinetic models of sorption: a theoretical analysis." Journal of Colloid and Interface Science 47-52.

BCELM. 2017. Diisopropanolamine (DIPA) in Water and Soil Samples by HPLC - PBM. British Columbia: Government of British Columbia.

BCELM. 2017. Sulfolane in Water and Soil Samples - PBM. British Columbia: Government of British Columbia.

Bellonaa, Christopher, Jorg E. Drewesa, Pei Xua, and Gary Amy. 2004. "Factors affecting the rejection of organic solutes during NF/RO treatment—a literature review." Water research 2795-2809. 
Bi, Erping, Stefan B. Haderlein, and Torsten C. Schmidt. 2005. "Sorption of methyl tertbutyl ether (MTBE) and tert-butyl alcohol (TBA) to synthetic resins." Water research $4164-4176$.

Blanchard, G., M. Maunaye, and G. Martin. 1984. "Removal of heavy metals from waters by means of natural zeolites." Water research 1501-1507.

Brown, V.K.H., L.W. Ferrigan, and D.E. Stevenson. 1966. "Acute Toxicity and Skin Irritant Properties of Sulfolane." Occupational and Environmental Medicine 302304.

CCME. 2006. Canadian Environmental Quality Guidelines for Diisopropanolamine (DIPA): Water and Soil. Quebec: Canadian Council of Ministers of the Environment.

CCME. 2006. Canadian Environmental Quality Guidelines for Sulfolane:. Quebec: Canadian Council of Ministers of the Environment.

CCME. 2006. Canadian Environmental Quality Guidelines for Sulfolane: Water and Soil. Quebec: Canadian Council of Ministers of the Environment.

CCME. 2005. Canadian Water Quality Guidelines for the Protection of Agricultural Water Uses - DIISOPROPANOLAMINE. Winnipeg: Canadian Council of Ministers of the Environment.

Chou, C.C., and R.A Swatloski. 1982. "Biodegradation of sulfolane in refinery wastewater." Proceedings of the 37th Industrial Waste Conference. Texas: Ann Arbor Science. 559-566.

Coggeshall, Marc, and Shannon Price. 2013. United States Patent US 2013 OO32541A1. 
Dai, M. G. 1994. "The Effect of Zeta Potential of Activated Carbon on the Adsorption of Dyes from Aqueous Solution: I. The Adsorption of Cationic Dyes: Methyl Green and Methyl Violet." Journal of Colloid and Interface Science 223-228.

Deal, Carl H., and Stephen H. Garnett. 1976. United States of America Patent US3953324A.

DHSS. 2012. Sulfolane Plume in Groundwater: Evaluation of Community Concerns about Sulfolane in Private Water Wells. Juneau: State of Alaska.

Diaz, Daniel Alcon. 2015. Evaluating competitive sorption between sulfolane and organic carbon on powdered activated carbon. Ghent: Ghent University.

EPA. 1991. Engineering Bulletin: Air Stripping of Aqueous Solutions. Washington: United States Environmental Protection Agency.

EPA. 2017. Technical Fact Sheet -1,4-Dioxane. United States Environmental Protection Agency.

Faust, Samuel D., and Osman M. Aly. 1987. Adsorption processes for water treatment. Massachusetts: Butterworth.

Fedorak, P. M, and D. L Coy. 1996. "Biodegradation of Sulfolane in Soil and Groundwater Samples from a Sour Gas Plant Site." Environmental Technology 1093-1102.

Gieg, L.M., E.A. Greene, D.L. Coy, and P.M. Fedorak. 1998. "Diisopropanolamine biodegradation potential at sour gas plants." Ground Water Monitoring and Remediation 158-173.

Greene, E. Anne, Debora L. Coy, and Phillip M. Fedorak. 1999. "Laboratory Evaluations of Factors Affecting Biodegradation of Sulfolane and Diisopropanolamine." Bioremediation Journal 299-313. 
Greene, E.Anne, Lisa M. Gieg, Debora L. Coy, and Phillip M. Fedorak. 1998. "Sulfolane biodegradation potential in aquifer sediments at sour natural gas plant sites." Water Research 3680-3688.

Greene, Elizabeth Anne. 1999. Microbial Sulfolane Degradation by Isolated from Contaminated Sour Plant Sediments. Edmonton: University of Alberta.

Headley, J. V., P. M. Fedorak, and L. C. Dickson. 2002. "A review of analytical methods for the determination of sulfolane and alkanolamines in environmental studies." Journal of AOAC International 154-62.

Headley, J.V., K. M. Peru, and L.C. Dickson. 1999. "Gas chromatographic-mass spectrometric determination of sulfolane in wetland vegetation exposed to sour gascontaminated groundwater ." Journal of Chromatography 69-75.

Health-Canada. 2014. Drinking Water Guidance Value for Sulfolane. Alberta: Health Canada.

Ho, Y.S., and G. McKay. 1999. "Pseudo-second order model for sorption processes." Process Biochemistry 451-465.

Ho, Yuh-Shan. 2004. "Citation review of Lagergren kinetic rate equation on adsorption reactions." Scientometrics 171-177.

Ho, Yuh-Shan. 2006. "Review of second-order models for adsorption systems." Journal of Hazardous Materials 681-689.

Izadifard, Maryam, Gopal Achari, and Cooper H Langford. 2017. "Degradation of sulfolane using activated persulfate with UV and UV-Ozone." Water Research 325331. 
Izadifard, Maryam, Gopal Achari, and Cooper H. Langford. 2017. "Degradation of sulfolane using activated persulfate with UV and UV-Ozone." Water Research 325331.

Izadifard, Maryam, Gopal Acharia, and H. Cooper Langford. 2018. "Mineralization of sulfolane in aqueous solutions by $\mathrm{Ozone} / \mathrm{CaO} 2$ and $\mathrm{Ozone} / \mathrm{CaO}$ with potential for field application." Chemosphere 525-540.

Izadifard, Maryam, Gopal Acharia, and H. Cooper Langford. 2018. "Mineralization of sulfolane in aqueous solutions by $\mathrm{Ozone} / \mathrm{CaO} 2$ and $\mathrm{Ozone} / \mathrm{CaO}$ with potential for field application." Chemosphere 525-540.

Kadirvelu, K., and C. Namasivayam. 2000. "Agricultural by-product as metal adsorbent: Sorption of lead(II) from aqueous solution onto coirpith carbon." Environmental Technology 543-549.

Kandah, M. 2001. "Zinc adsorption from aqueous solutions using disposal sheep manure waste (SMW)." Chemical Engineering Journal 543-549.

Kasanke, Christopher P., and Mary Beth Leigh. 2017. "Factors limiting sulfolane biodegradation in." PLoS ONE 1-17. doi:https://doi.org/10.1371/journal.

Kim, Chang Gyun, William P. Clarke, and David Lockington. 1999. "Competitive adsorption of sulfolane and thiolane on clay materials." Korean Journal of Chemical Engineering 215-219.

Kim, Jin-Ho, Celina Dobrogowska, and Loren G. Hepler. 1987. "Thermodynamics of ionization of aqueous alkanolamines." Canadian Journal of Chemistry 1726-1728. 
Krishnan, K.A., and T.S. Anirudhan. 2003. "Removal of cadmium(II) from aqueous solutions by steam-activated sulphurised carbon prepared from sugar-cane bagasse pith: kinetics and equilibrium studies." Water SA 147-156.

Largitte, L., and R. Pasquier. 2016. "A review of the kinetics adsorption models and their application to the adsorption of lead by an activated carbon." Chemical Engineering Research and Design 495-504.

Lima, Éder Cláudio, Matthew Ayorinde Adebayo, and Fernando Machado Machado. 2015. "Kinetic and Equilibrium Models of Adsorption." Carbon Nanomaterials as Adsorbents for Environmental and Biological Applications 33-69.

Lin, Su-Hsia, and Ruey-Shin Juang. 2009. "Adsorption of phenol and its derivatives from water using synthetic resins and low-cost natural adsorbents: A review." Journal of Environmental Management 1336-1349.

Liu, Yu, and Liang Shen. 2018. "From Langmuir Kinetics to First- and Second-Order Rate Equations for Adsorption." Langmuir 11625-11630.

Lu, Yinmei, Rui Zhang, Yuehua Wang, Liyan Ren, Lihua Cui, and Yanxia Liu. 2016. China Patent CN106153776A.

Luther, Sheila, M., Marvin, J. Dudas, and Phillip, M. Fedorak. 1998. "Sorption of sulfolane and diisopropanolamine by soils, clays and aquifer materials." Journal of Contaminant Hydrology 159-176.

Malik, P.K. 2004. "Dye removal from wastewater using activated carbon developed from sawdust: adsorption equilibrium and kinetics." Journal of Hazardous Materials 8188. 
Manju, G. N., C. Raji, and T. S. Anirudhan. 1998. "Evaluation of coconut husk carbon for the removal of arsenic from water." Water Research 3062-3070.

Manohar, D.M., K.A. Krishnan, and T.S. Anirudhan. 2002. "Removal of mercury(II) from aqueous solutions and chlor-alkali industry wastewater using 2mercaptobenzimidazole-clay." Water research 1609-1619.

McLeod, Donald W, Cynthia Y Lin, Wei-Chi Ying, and Michael E Tucker. 1991. "Biological activated carbon process for removing sulfolane from groundwater." Proceedings of the 46th Industrial Waste Conference. New york. 99-112.

Onganer, Y., and Ç. Temur. 1998. "Adsorption dynamics of Fe(III) from aqueous solutions onto activated." Journal of Colloid and Interface Science 241-244.

Qiu, Hui, Lu Lv, Bing-cai Pan, Qing-jian Zhang, Wei-ming Zhang, and Quan-xing Zhang. 2009. "Critical review in adsorption kinetic models." Journal of Zhejiang University-SCIENCE A 716-724.

Ruppert, P.H, and R.S Dyer. 1985. "Acute behavioral toxicity of sulfolane: influence of hypothermia." Toxicology Letters 111-116.

Russell, Hugh H., John E. Matthews, and Guy W. Sewell. 1992. TCE Removal from Contaminated Soil and Ground Water. United States Environmental Protection Agency.

Saint-Fort, R. 2006. "Sulfolane attenuation by surface and subsurface soil matrices." Journal of Environmental Science and Health, Part A: Toxic/Hazardous Substances and Environmental Engineering 1211-31. 
Simonin, Jean-Pierre. 2016. "On the comparison of pseudo-first order and pseudo-second order rate laws in the modeling of adsorption kinetics." Chemical Engineering Journal 254-263.

Sontheimer, H., John C. Crittenden, and R. Scott Summers. 1988. Activated carbon for water treatment. Karlsruhe: Universitat Karlsruhe (TH).

Stewart, Olga, and Lisa Minnear. 2010. SULFOLANE TECHNICAL ASSISTANCE AND EVALUATION REPORT . Alaska: Alaska Department of Environmental Conservation .

Tan, K. L., and B.H. Hameed. 2017. "Insight into the adsorption kinetics models for the removal of contaminants from aqueous solutions." Journal of the Taiwan Institute of Chemical Engineers 25-48.

Tan, K.L., and B.H. Hameed. 2017. "Insight into the adsorption kinetics models for the removal of contaminants from aqueous solutions ." Journal of the Taiwan Institute of Chemical Engineers 1-24.

Tutem, E., R. Apak, and Ç. F. Ünal. 1998. "Adsorptive removal of chlorophenols from water by bituminous shale." Water Research 505-517.

van Afferden, M., K.Z. Rahman, P. Mosig, C. De Biase, M. Thullner, S.E. Oswald, and R.A. Müller. 2011. "Remediation of groundwater contaminated with MTBE and benzene: The potential of vertical-flow soil filter systems." Water research 50635074.

WHO. 1996. Guidelines for drinking-water quality. Geneva: World Health Organization. 
Woodard, Steven, Thomas Mohr, and Michael G. Nickelsen. 2014. "Synthetic Media: A Promising New Treatment Technology for 1,4-Dioxane." Remediation: The Journal of Environmental Cleanup Costs, Technologies, \& Techniques 27-40.

Worch, Eckhard. 2012. Adsorption Technology in Water Treatment: Fundamentals, Processes, and Modeling. Göttingen: Walter de Gruyter GmbH \& Co. KG.

Wu, Feng-Chin, Ru-Ling Tseng, and Ruey-Shin Juang. 2009. "Characteristics of Elovich equation used for the analysis of adsorption kinetics in dye-chitosan systems." Chemical Engineering Journal 366-373.

Yamuna, R. T., and C. Namasivayam. 1993. "Color removal from aqueous solution by biogas residual slurry." Toxicological and Environmental Chemistry 131-143.

Yang, Chu-Fang, Shu-Hui Liu, Yu-Min Sua, Yu-Rong Chena, Chi-Wen Lin, and Keng-Li Lin. 2019. "Bioremediation capability evaluation of benzene and sulfolane contaminated groundwater: Determination of bioremediation parameters." Chemosphere 811-818.

Ying, Wei-Chi, Shennen C. Hannan, Michael E. Tucker, Erik A. Friedrich, and Cynthia Y Lin. 1994. "Successful application of biological activated carbon process for removing sulfolane from groundwater." Proceedings of the 49th Industrial Waste Conference. New York. 149-160. 